University of San Diego

Digital USD

Theses

Theses and Dissertations

Summer 8-31-2017

\title{
Vertical and cross-shore distributions of barnacle larvae in La Jolla, CA nearshore waters: implications for larval transport processes
}

Malloree Lynn Hagerty

University of San Diego

Follow this and additional works at: https://digital.sandiego.edu/theses

Part of the Environmental Sciences Commons, Marine Biology Commons, and the Oceanography Commons

\section{Digital USD Citation}

Hagerty, Malloree Lynn, "Vertical and cross-shore distributions of barnacle larvae in La Jolla, CA nearshore waters: implications for larval transport processes" (2017). Theses. 25.

https://digital.sandiego.edu/theses/25

This Thesis: Open Access is brought to you for free and open access by the Theses and Dissertations at Digital USD. It has been accepted for inclusion in Theses by an authorized administrator of Digital USD. For more information, please contact digital@sandiego.edu. 


\title{
UNIVERSITY OF SAN DIEGO
}

\author{
San Diego
}

\begin{abstract}
Vertical and cross-shore distributions of barnacle larvae in La Jolla, CA nearshore waters: implications for larval transport processes
\end{abstract}

\begin{abstract}
A thesis submitted in partial satisfaction of the requirements for the degree of
\end{abstract}

\author{
Master of Science in Marine Science \\ by \\ Malloree L. Hagerty
}

Thesis Committee

Nathalie B. Reyns, Ph.D., Chair

Jennifer C. Prairie, Ph.D.

Jesús Pineda, Ph.D. 
The thesis of Malloree L. Hagerty is approved by:

Nathalie B. Reyns, Ph.D., Thesis Cbmmittee Chair University of San Diego

\title{
Jenniff. C. Prairie Ph.D., Thesis Committee Member University of San Diego
}

\author{
Jesús Pineda, Ph.D., Thesis Committee Member \\ Woods Hole Oceanographic Institution
}

University of San Diego

San Diego

2017 
Copyright 2017 Malloree Hagerty 


\section{ACKNOWLEDGMENTS}

I'd like to thank my advisor, Dr. Nathalie Reyns, first and foremost for her never-ending guidance and expertise while introducing me to the microscopic world of marine larvae. She never failed to reignite excitement about my research after a meeting, and was always available to answer my many questions. To my thesis committee member, Dr. Jennifer Prairie, thank you for being an incredible professor and providing me with knowledge I needed to carry out this work. Dr. Jesús Pineda, thank you for welcoming me into your lab at WHOI and being an involved and helpful committee member even though we were on opposite sides of the country.

Field collections and sample processing were made possible with assistance from Kate Hargenrader, Anthony Basilio, Diana Fontaine, Marisa Swiderski, Chris Bayne, Colin Gaylord, and Meredith Myers. I'd like to acknowledge all of my colleagues at USD for being excellent classmates and friends, and forming a community that made my time as a master's student fun and rewarding.

To all of my professors and the Environmental and Ocean Sciences faculty as a whole at USD, thank you for helping me grow as a student and scientist, and for the exceedingly engaging environment you've created. As someone who did not have a particularly strong background in marine science before this program, I am indebted to the hands-on and application-based curriculum at USD, without which I would not have had the skills to conduct and complete this work. 
Funding for this research was provided by the National Science Foundation under grants OCE-1357290, OCE-1357327, OCE-1630459, and OCE-1630474. The University of San Diego also provided financial support through generous graduate grants and scholarships.

Last, but certainly not least, I'd like to acknowledge my family. It's difficult to put into words the gratitude I feel for everything they do and everything they are. To my parents, Tammy and Bill, thank you for your constant support and all the visits to the ocean that helped spark my interests and passion while growing up in Ohio. To my siblings, Kailee, Darbee, Avalee, and Croft, thank you for being the best source of inspiration I have. To Ryan, thank you for your positivity and for making each day better. I wouldn't be where I am without all of you, and appreciate how you've always encouraged me to do what I love. 
TABLE OF CONTENTS

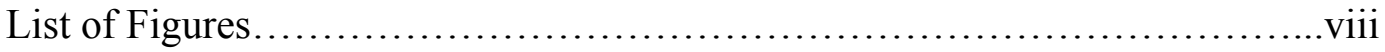

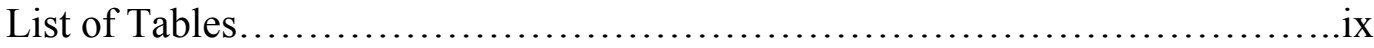

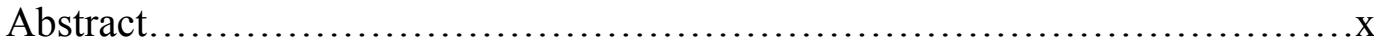

Chapter 1: Introduction

1.1 Larval transport.........................................................

1.2 Study species - barnacles........................................

1.3 Study site - Bird Rock, La Jolla, CA, USA.......................

1.4 Significance and implications....................................... 8

1.5 Research questions addressed..................................

1.6 Literature cited.................................................. 10

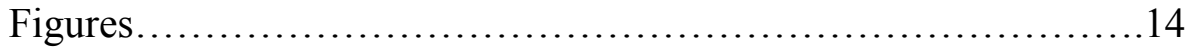

Chapter 2: Constrained nearshore larval distributions driven by thermal stratification

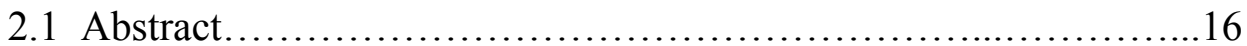

2.2 Introduction................................................... 17

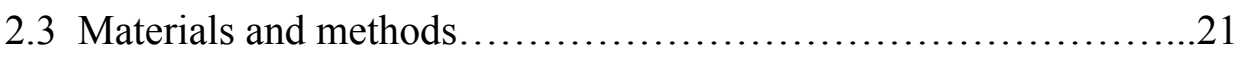

2.3.1 Study site and system.........................................

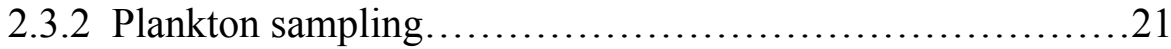

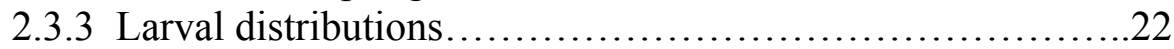

2.3.4 Temperature, currents, and pressure........................25

2.3.5 Relationships between physical variables and larvae..........26

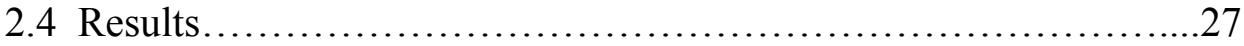

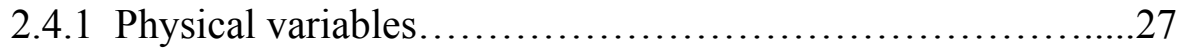

2.4.2 Temporal patterns of larval concentrations...................28

2.4.3 Vertical distributions of larvae.................................29

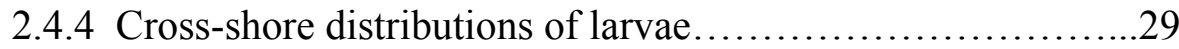

2.4.5 Summary of larval distribution patterns........................30

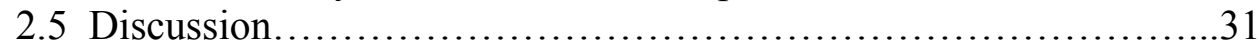

2.6 Literature cited .................................................

Tables and figures............................................. 41

Chapter 3: Conclusion........................................................63

Appendix A: Relationships between larval Mean Depth Distributions (MDDs)

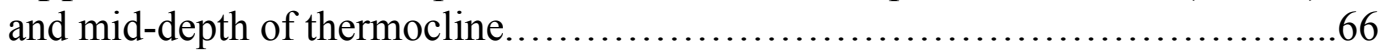

Appendix B: Relationships between larval densities/distributions and thermal

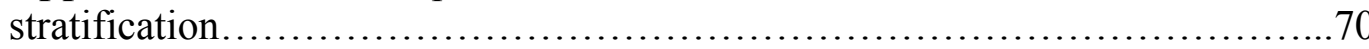


Appendix C: Current measurements, and relationships between larval densities/distributions and currents.

Appendix D: Significant wave height (SWH) measurements, and relationships between larval densities/distributions and SWH.............................92

Appendix E: Larval densities and Mean Depth Distributions (MDDs) at each station during all cruises separated by stage, and by species for cyprids........104

Appendix F: Bubble plots showing concentrations of larvae in each sample

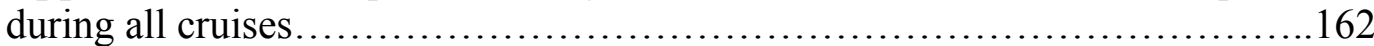

Appendix G: Salinity profiles during each sampling period..................170 


\section{LIST OF FIGURES}

Figure 1.1 Broad map of study area offshore of La Jolla, CA, including outline of South La Jolla State Marine Reserve.....................................14

Figure 2.1 In-depth map of study site including sampling stations, instrument location, and bathymetric data.......................................... 49

Figure 2.2 Average temperature and thermal stratification at each station during

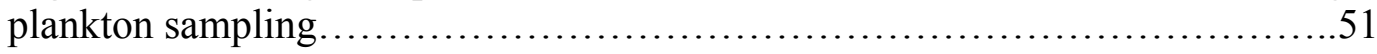

Figure 2.3 Vertical distributions of barnacle larvae..........................53

Figure 2.4 Cross-shelf distributions of barnacle larvae.....................55

Figure 2.5 Mean Distance from Shore (MDS) of barnacle larvae..............57

Figure 2.6 Effect of cross-shore stratification on Mean Distance from Shore (MDS) and Constrained-Distribution Index (CDI) of Chthamalus fissus cyprids.

Figure 2.7 Summary of barnacle larval distributions throughout entire study duration........................................................... 61 


\section{LIST OF TABLES}

Table 2.1 Concentration summary for barnacle nauplii during sampling periods..........................................................4 41

Table 2.2 Concentration summary for barnacle cyprids during sampling periods.............................................................. 43

Table 2.3 Average larval concentrations of nauplii and cyprids in 2014 and

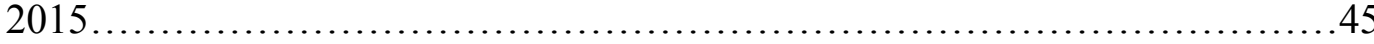

Table 2.4 Results of 2-factor analysis of variance (ANOVA) testing for amongstation and between sampling period differences in larval proportions..........47 


\begin{abstract}
Many marine organisms begin their lives as tiny larvae that are at the mercy of ocean currents. Understanding the transport and subsequent dispersal of larvae is crucial, as it drives population connectivity in the ocean. Larval transport is a complex process involving both physical motions of the water and larval behavior. Vertical positioning is especially important because currents vary throughout the water column, and larvae at different depths will be advected differently. With swimming speeds insufficient to swim against currents, marine larvae can mediate cross-shore transport by controlling their depth distributions. Thus, the overall objective of this study was to characterize the cross-shore and vertical distributions of barnacle larvae in La Jolla, southern California during a two-year period. The sampling design for this research included repeated larval collections in 2-m depth intervals spanning the entire water column at five crossshore stations located in the nearshore between $\sim 200$ to 1000 meters from the rocky intertidal, adult barnacle habitat. Larval distributions were compared to hydrographic factors, including the mid-depth of the thermocline, thermal stratification, current velocities, and wave height, in an attempt to discern biological-physical mechanisms of larval transport. Despite seasonal and annual hydrodynamic variability, vertical and cross-shore distribution patterns of barnacle larvae remained consistent: nauplii were distributed farther from shore and cyprids were constrained nearshore when thermal stratification was high. These results support the inference that behavior is substantial in facilitating transport during pelagic larval stages, and leads to the hypothesis that
\end{abstract}


stratification elicits enhanced behavioral control of barnacle cyprid larvae to remain close to shore and reach their adult habitat. 


\section{CHAPTER 1: Introduction}

\subsection{Larval transport}

Larval transport is the movement of a larva from one point to another (Pineda et al. 2007), and facilitates larval dispersal, which is the spread of larvae from their source to a suitable settlement site at the end of the larval stage (Cowen and Sponaugle 2009). Many marine species have complex life cycles that include a pelagic larval stage (Cowen and Sponaugle 2009), but the mechanism of larval transport in the ocean is multifaceted and complex, and thus poorly understood (Roughgarden et al. 1988, Pineda et al. 2007, Cowen and Sponaugle 2009, Pineda and Reyns 2017). A pivotal unknown includes how far organisms actually disperse, and how to most accurately estimate dispersal distances while taking into account all of the involved biological-physical processes. The movement of larvae away from their spawning site is crucial in limiting competition between adults and offspring (McEdward 1995, Jenkins and Hawkins 2003), but the return of larvae to stable adult populations and required habitats is equally important for their survival. The purpose of this research was to characterize the spatial and temporal distribution of barnacle larvae in nearshore waters of coastal La Jolla, CA over a 2-yr period, and determine physical processes that may influence distribution.

The physical environment drives population dynamics in the ocean, including advection of larvae (Shanks et al. 2003, Cowen et al. 2007, Pineda et al. 2009). Various physical processes can affect larval transport, including internal tidal bores (Shanks 1983, Pineda 1999, Pineda et al. 2009) and wind-driven 
circulation (Tilburg 2003, Tapia et al. 2004, Reyns et al. 2007). These processes, along with Ekman transport (Rivera et al. 2013), lead to variation in current velocity throughout the water column, so larvae occupying different depths will be advected differently (McEdward 1995). Larvae can alter their behavior to move into different depths, thus controlling their cross-shore movements through exposure to varying currents (McEdward 1995, Tapia et al. 2010). However, it remains unclear which physical processes have the greatest effect on larval advection, and what specific cues cause larvae to change their positioning in the water.

The dispersal of intertidal organisms, such as barnacles and numerous other species, is carried out in nearshore habitats. Physical processes in nearshore waters of open coastlines are highly dynamic (Hickey 1979). For marine organisms residing in the rocky intertidal area, the hydrodynamic conditions must be conducive to the shoreward movement of larvae, which also depends on larval behavior to move into water that is being transported towards shore. Many species cannot complete their life cycles unless their larval forms make it to the intertidal zone. However, despite the importance of understanding how physical processes directly adjacent to the coast affect larval dispersal, there have been very few studies involving an in-depth examination of the movement of larvae in those areas. This project characterized nearshore (within $\sim 1 \mathrm{~km}$ from the coast) larval distributions along an open coastline to discern the questions surrounding larval transport processes. Larval distribution patterns were compared to corresponding 
hydrographic and hydrodynamic conditions, thus shedding light on the mechanisms driving larval transport. 


\subsection{Study species - barnacles}

The larvae of barnacles were examined in this study. Barnacles are an ideal model species because their life cycle is similar to that of most invertebrates and fishes (Roughgarden et al. 1988). Because adult barnacles are sessile organisms, we can more easily track barnacle populations by measuring settlement in the intertidal zone. While the dominant barnacles in the intertidal zone near the research site for this study (Chthamalus fissus) are not currently endangered, there are some commercially important barnacle species, such as Pollicipes spp., with protection measures in effect (Jacinto et al. 2009). The findings of my study can apply to larvae of other barnacles such as Pollicipes spp., as well as larvae of countless other marine organisms that are commercially harvested. Barnacle larvae typically spend 2 to 5 weeks in the plankton, and have 7 planktonic stages (Walley and Rees 1969). There are 6 naupliar stages followed by a non-feeding cyprid stage, which has to locate a suitable place to attach and settle before metamorphosis (Walley and Rees 1969).

There is a complex coupling of biological and physical processes surrounding the larval stages of nearshore benthic species such as barnacles (Pineda et al. 2009), and the exact connection between behavioral and environmental processes is not well understood. Marine invertebrate larvae exhibit specific migratory and depth regulation behaviors in response to environmental cues (McEdward 1995). For example, larvae that complete their development nearshore, including barnacles, have been observed to reside below a shallow Ekman layer of seaward-flowing surface waters (Morgan and Fisher 
2010). However, that observation was from a 3-month study, and may not be universally true or applicable to all larval populations and all locations. Barnacle cyprids have a well-developed brain and a greater investment in sensory organs than nauplii, which have more reduced brains (Anil et al. 2010). This can have implications for the exploitation of different currents and response to environmental cues by the different larval stages, two issues that remain unresolved. A previous study carried out at a fixed station $\sim 2 \mathrm{~km}$ from the coast reports evidence of early-stage nauplii remaining near the surface, while latestage cyprids were distributed closer to the ocean floor over a period of $48 \mathrm{hrs}$ (Tapia et al. 2010). My research was designed to help determine if this ontogenetic variation in vertical distribution can be observed continuously yearround in waters closer to shore.

Nauplii are attracted to light to avoid benthic predators, move toward higher concentrations of phytoplankton, and into more rapidly moving surface currents where dispersal is more efficient (McEdward 1995). Barnacle nauplii entering the intertidal zone are at risk of consumption by benthic predators, and the earliest of the 6 stages are usually found close to shore while later stages are found farther from shore (McEdward 1995, Tapia and Pineda 2007). It has also been observed that naupliar swimming rate significantly increases with increasing temperature (Yule 1984), while swimming direction shifts upward in response to increasing pressure, and downward in response to decreasing pressure (McEdward 1995). DiBacco et al. (2011) reported evidence that cyprids altered their swimming behavior to maintain their vertical positions in response to 
downwelling flows. All of these behaviors and characteristics contribute to the potential transport of barnacle larvae, and placement within certain currents could be linked to behaviors that influence positioning. While several different behavioral responses have been observed, many findings are from laboratory studies, and it is uncertain whether or not the same outcomes would be observed in the field. 


\subsection{Study site - Bird Rock, La Jolla, CA, USA}

This study was conducted off the coast of Bird Rock, La Jolla, CA (Figure 1.1). There have been previous studies of larval transport processes a few kilometers north of this area, including barnacle-specific projects (Shanks 1986, Pineda 1994, Tapia and Pineda 2007, Tapia et al. 2010). However, most of these projects focused on barnacle settlement in the intertidal zone instead of larval transport in nearshore waters. The few studies that did investigate larval distributions did so on very short time scales; Tapia and Pineda (2007) was an 8day study while Tapia et al. (2010) was a 48-hr study. My thesis research builds on these existing studies by including horizontal and vertical larval abundances over a 2-yr period, as well as providing new data and introducing novel questions for future research.

The shoreline near Bird Rock provides a good habitat for adult barnacles, and larvae of Chthamalus fissus had been observed in La Jolla nearshore waters (Tapia et al. 2010). The study site also falls within a newly established marine protected area (MPA), the South La Jolla State Marine Reserve (Figure 1.1), so my results help define a possible baseline for larval movement inside of open coastline MPA's. 


\subsection{Significance and implications}

Understanding larval transport is crucial to understanding population connectivity in marine environments, which applies to conservation (Shanks et al. 2003, Borges et al. 2007), genetic diversity (Cowen et al. 2007), and fisheries management (Bradbury and Snelgrove 2001, Reyns et al. 2007, Cowen and Sponaugle 2009). Larval transport and dispersal mechanisms can also be applied to the design and control of marine reserves and MPA's (Shanks et al. 2003). This is increasingly relevant in La Jolla since new marine reserves have recently been established, and their success remains to be determined.

Because barnacles are a good model species, the results of my study can be applied to community interactions of other marine species that have two-phase life cycles. Larval fish have similar challenges as invertebrate larvae during dispersal (McEdward 1995), and while behaviors can change across species, all larvae are susceptible to the same advective processes. The basic mechanism of larval transport is essential knowledge in the pursuit of understanding population dynamics in the ocean. 


\subsection{Research questions addressed}

Population connectivity in the ocean cannot be fully understood without greater knowledge of larval transport. Most marine organisms have a larval stage, and their dispersal is dependent upon both hydrodynamic conditions and behavioral mechanisms. Barnacle larvae respond to changing hydrography in order to exploit different currents (Yule 1984, McEdward 1995, Morgan and Fisher 2010, Tapia et al. 2010, DiBacco et al. 2011). Nearshore waters of open coastlines are subject to dynamic physical processes, which result in different current velocities at different depths, but larval transport is relatively unexplored in these environments. This research addressed the following questions:

1. Is there a pattern in barnacle larval distributions and abundances in $\mathrm{La}$ Jolla nearshore waters over a 2-yr period?

2. How do changes in hydrographic and hydrodynamic conditions (temperature, pressure, currents, depth, distance from shore) in La Jolla nearshore waters impact the spatiotemporal distribution and abundance of barnacle larvae?

3. Does vertical distribution of barnacle larvae depend on ontogenetic stage and changing environmental conditions? 


\subsection{Literature cited}

Anil, A. C., L. Khandeparker, D. V. Desai, L. V. Baragi, and C. A. Gaonkar. 2010. Larval development, sensory mechanisms and physiological adaptations in acorn barnacles with special reference to Balanus amphitrite. Journal of Experimental Marine Biology and Ecology 392:89-98.

Bainbridge, V. 1966. A re-description of the larvae of Lepas fascicularis Ellis and Solander with observations on the distribution of Lepas nauplii in the northeastern Atlantic. Some contemporary studies in marine science:67-81.

Borges, R., R. Ben-Hamadou, M. A. Chícharo, P. Ré, and E. J. Gonçalves. 2007. Horizontal spatial and temporal distribution patterns of nearshore larval fish assemblages at a temperate rocky shore. Estuarine, Coastal and Shelf Science 71:412-428.

Branscomb, E. S., and K. Vedder. 1982. A description of the naupliar stages of the barnacles Balanus glandula Darwin, Balanus cariosus Pallas, and Balanus crenatus Bruguière (Cirripedia, Thoracica). Crustaceana 42:83-95.

Bradbury, I. R., and P. V. Snelgrove. 2001. Contrasting larval transport in demersal fish and benthic invertebrates: the roles of behaviour and advective processes in determining spatial pattern. Canadian Journal of Fisheries and Aquatic Sciences 58:811-823.

Brown, S. K., and J. Roughgarden. 1985. Growth, morphology, and laboratory culture of larvae of Balanus glandula (Cirripedia: Thoracica). Journal of Crustacean Biology 5: 574-590.

Cowen, R., G. Gawarkiewicz, J. Pineda, S. Thorrold, and F. E. Werner. 2007. Population connectivity in marine systems: an overview. Oceanography 20(3):14-21.

Cowen, R. K., and S. Sponaugle. 2009. Larval dispersal and marine population connectivity. Annual review of marine science 1:443-466.

DiBacco, C., H. L. Fuchs, J. Pineda, and K. Helfrich. 2011. Swimming behavior and velocities of barnacle cyprids in a downwelling flume. Marine Ecology Progress Series 433:131-148.

Emlet, R. B., and S. S. Sadro. 2006. Linking stages of life history: how larval quality translates into juvenile performance for an intertidal barnacle (Balanus glandula). Integrative and Comparative Biology 46:334-346.

Hickey, B. M. 1979. The California Current system—-hypotheses and facts. Progress in Oceanography 8:191-279. 
Jacinto, D., T. Cruz, T. Silva, and J. J. Castro. 2009. Stalked barnacle (Pollicipes pollicipes) harvesting in the Berlengas Nature Reserve, Portugal: temporal variation and validation of logbook data. ICES Journal of Marine Science 67:1-7.

Jenkins, S., and S. Hawkins. 2003. Barnacle larval supply to sheltered rocky shores: a limiting factor? Hydrobiologia 503:143-151.

Lewis, C. 1975. Development of the gooseneck barnacle Pollicipes polymerus (Cirripedia: Lepadomorpha): fertilization through settlement. Marine Biology 32:141-153.

McEdward, L. 1995. Ecology of Marine Invertebrate Larvae. CRC Press, Boca Raton.

Miller, K. M., and J. Roughgarden. 1994. Descriptions of the larvae of Tetraclita rubescens and Megabalanus californicus with a comparison of the common barnacle larvae of the central California coast. Journal of Crustacean Biology 14(3):579-600.

Miller, K. M., S. M. Blower, D. Hedgecock, and J. Roughgarden. 1989. Comparison of larval and adult stages of Chthamalus dalli and Chthamalus fissus (Cirripedia: Thoracica). Journal of Crustacean Biology 9: 242-256.

Morgan, S. G., and J. L. Fisher. 2010. Larval behavior regulates nearshore retention and offshore migration in an upwelling shadow and along the open coast. Marine Ecology Progress Series 404:109-126.

Pineda, J. 1994. Spatial and temporal patterns in barnacle settlement rate along a southern California rocky shore. Marine Ecology Progress Series 107:125125.

Pineda, J. 1999. Circulation and larval distribution in internal tidal bore warm fronts. Limnology and Oceanography 44:1400-1414.

Pineda, J., J. A. Hare, and S. Sponaugle. 2007. Larval transport and dispersal in the coastal ocean and consequences for population connectivity. Oceanography 20(3):22-39.

Pineda, J., N. B. Reyns, and V. R. Starczak. 2009. Complexity and simplification in understanding recruitment in benthic populations. Population ecology 51:17-32. 
Pineda J. and N. B. Reyns. 2017. Larval transport in the coastal zone: biological and physical processes. In: Carrier TJ, Reitzel AM, Heyland A (eds) Evolutionary ecology of marine invertebrate larvae. Oxford University Press, p 141-159.

Reyns, N. B., D. B. Eggleston, and R. A. Luettich. 2007. Dispersal dynamics of post-larval blue crabs, Callinectes sapidus, within a wind-driven estuary. Fisheries Oceanography 16:257-272.

Rivera, A., N. Weidberg, A. F. Pardiñas, R. González-Gil, L. García-Flórez, and J. Acuña. 2013. Role of upwelling on larval dispersal and productivity of gooseneck barnacle populations in the Cantabrian sea: management implications. PLoS ONE 8(11): e78482.

Roughgarden, J., S. Gaines, and H. Possingham. 1988. Recruitment dynamics in complex life cycles. Science 241:1460-1466.

Shanks, A. L. 1983. Surface slicks associated with tidally forced internal waves may transport pelagic larvae of benthic invertebrates and fishes shoreward. Marine Ecology Progress Series. Oldendorf 13:311-315.

Shanks, A. L. 1986. Tidal periodicity in the daily settlement of intertidal barnacle larvae and an hypothesized mechanism for the cross-shelf transport of cyprids. The Biological Bulletin 170:429-440.

Shanks, A. L., B. Grantham, and M. H. Carr. 2003. Propagule dispersal distance and the size and spacing of marine reserves. Ecological Applications 13:S159-S169.

Tapia, F. J., J. Pineda, F. J. Ocampo-Torres, H. L. Fuchs, P. E. Parnell, P. Montero, and S. Ramos. 2004. High-frequency observations of wind-forced onshore transport at a coastal site in Baja California. Continental Shelf Research 24:1573-1585.

Tapia, F. J., and J. Pineda. 2007. Stage-specific distribution of barnacle larvae in nearshore waters: potential for limited dispersal and high mortality rates. Marine Ecology Progress Series 342:177-190.

Tapia, F. J., C. DiBacco, J. Jarrett, and J. Pineda. 2010. Vertical distribution of barnacle larvae at a fixed nearshore station in southern California: Stagespecific and diel patterns. Estuarine, Coastal and Shelf Science 86:265-270.

Tilburg, C. E. 2003. Across-shelf transport on a continental shelf: Do acrossshelf winds matter? Journal of Physical Oceanography 33:2675-2688. 
Walley, L. J., and E. Rees. 1969. Studies on the larval structure and metamorphosis of Balanus balanoides (L.). Philosophical Transactions of the Royal Society B: Biological Sciences 256:237-280.

Yule, A. B. 1984. The effect of temperature on the swimming activity of barnacle nauplii. Marine Biology Letters 5:1-11.

Zimmer, R. K., J. T. Fingerut, and C. A. Zimmer. 2009. Dispersal pathways, seed rains, and the dynamics of larval behavior. Ecology 90:1933-1947. 
Figure 1.1 Broad map of study site offshore of Bird Rock, La Jolla, southern California (shown by black rectangle) in the context of California Marine Protected Areas (red shading: South La Jolla State Marine Reserve, blue shading: South La Jolla State Marine Conservation Area).

https://www.wildlife.ca.gov/Conservation/Marine/MPAs/Network/SouthernCalifornia\#27149506-south-la-jolla-state-marine-reserve 


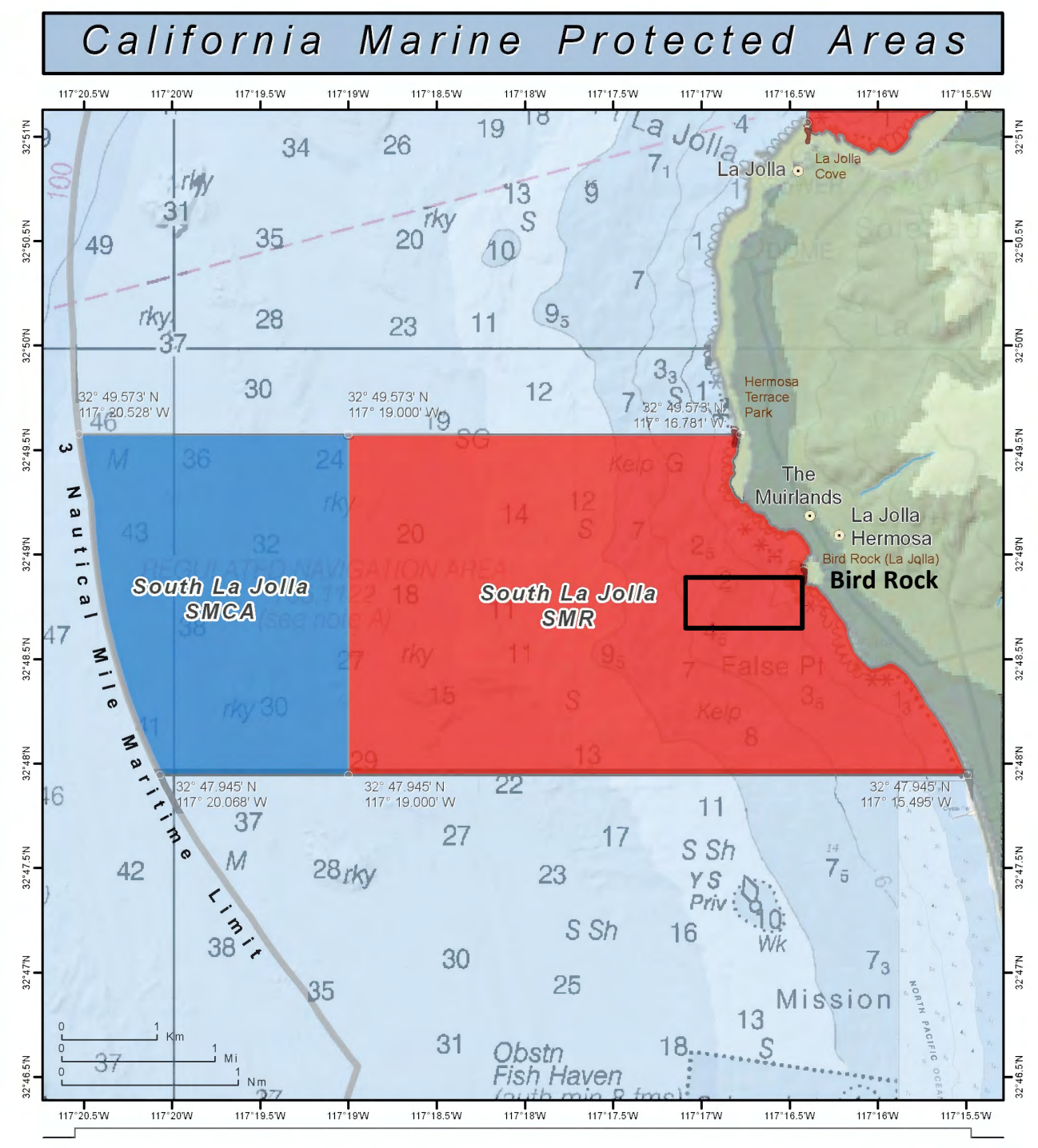




\section{CHAPTER 2: Constrained nearshore larval distributions driven by thermal stratification}

\subsection{Abstract}

Vertical and cross-shore distributions and abundances of shallow water barnacle larvae were characterized in La Jolla in southern California over a 2-yr period. Five stations located within $1 \mathrm{~km}$ of shore and ranging from $4-12 \mathrm{~m}$ water depths were sampled intensively in 2-m depth intervals during 27 cruises throughout spring-summer and fall-winter of 2014 and 2015. Larval abundances significantly decreased from year one to year two, which could be related to the arrival of the warm "Blob" in 2014 and El Niño conditions in 2015. Despite the presence of these large-scale regional disturbances, distinct patterns of vertical and cross-shore larval distributions remained consistent throughout the study duration. Early-stage nauplii and Chthamalus fissus cyprids tracked bottom depth, and cyprids were on average deeper than nauplii. Vertical distributions were not related to the mid-depth of the thermocline or thermal stratification. Early-stage nauplii had a broader cross-shore distribution than cyprids, which were concentrated at inshore stations. Nearshore cyprid accumulation had a positive relationship with stratification, and cyprids moved farther offshore during fallwinter when stratification decreased. These results suggest that thermal stratification elicits enhanced behavioral control of cyprids to remain close to shore and reach the adult habitat. 


\subsection{Introduction}

Larval transport, defined as the movement of a larva from one point to another (Pineda et al. 2007), is crucial to understanding population connectivity in marine environments, with implications for conservation (Shanks et al. 2003, Miller \& Shanks 2004), genetic diversity (Cowen et al. 2007), and fisheries management (Bradbury \& Snelgrove 2001, Reyns et al. 2007, Cowen \& Sponaugle 2009). The biological and physical mechanisms of larval transport in the ocean are multifaceted and complex; they involve physical processes that have the potential to transport larvae, as well as behavioral responses to environmental cues that remain poorly understood (reviewed in: Metaxas 2001, Epifanio \& Cohen 2016, Pineda \& Reyns 2017), particularly in nearshore environments where sampling is challenged by the complexities of shallow bathymetric features. A greater understanding of larval transport processes in nearshore systems has become increasingly essential, as studies reveal that larvae exhibit more constrained distributions than originally assumed (Tapia \& Pineda 2007, Morgan et al. 2009, Shanks \& Shearman 2009, Weidberg et al. 2015, reviewed in Pineda \& Reyns 2017). Larval transport and dispersal mechanisms can inform the designation of marine reserves and marine protected areas (Shanks et al. 2003), and we cannot effectively manage these regions without a more complete grasp on dominant transport mechanisms and larval behavior in waters adjacent to the coast.

The dispersal of intertidal organisms, such as barnacles, is carried out in the nearshore environment where physical processes are highly variable (Morgan 
\& Fisher 2010, Bonicelli et al. 2016). Barnacles transition through six naupliar stages and one cyprid stage, typically during a 2 - 5 week pelagic larval duration (Walley \& Rees 1969). Cyprids are especially interesting because to complete their life cycle they must return to the intertidal zone to find suitable habitats and settle before metamorphosis into adults. Larvae can alter their behavior to move into different depths, thus controlling their cross-shore movements through exposure to varying currents (Metaxas 2001, Tapia et al. 2010, Pineda \& Reyns 2017). Temperature can affect vertical distributions of larvae; gastropods, bivalves, and polychaetes remain below the thermocline and pycnocline, and variation in their abundance is associated with temperature variability (Lloyd et al. 2012). Strong thermoclines can also restrict vertical distributions of larvae, as larval sea scallops were limited to bottom depths when the water column was stratified (Daigle \& Metaxas 2011), becoming more aggregated when thermal stratification was higher (Tremblay \& Sinclair 1990). Changes in Chthamalus fissus barnacle settlement were positively correlated with changes in stratification, and there were significantly more settlers at the more stratified of two sampling locations (Pineda \& López 2002). Stratification is correlated with shear and internal motions, and flows that reverse with depth can occur during highly stratified conditions (Winant \& Bratkovich 1981). Stronger stratification may increase local retention of larvae that exploit more vertically sheared flows (Pineda \& Reyns 2017).

Larvae also employ ontogenetic vertical migrations (Paris \& Cowen 2004, Butler et al. 2011). Older damselfish larvae migrate vertically to remain within 
deeper, on-shore flowing currents and are consequently retained near their natal source (Paris \& Cowen 2004). Early-stage larval spiny lobsters are positively phototactic, but this behavior diminishes with age (Butler et al. 2011). Dispersal simulations based on observed depth distributions revealed that twice as many larvae would successfully recruit to nurseries if they displayed ontogenetic vertical migration when compared with passive dispersers (Butler et al. 2011). Additionally, larvae can respond to and accumulate in convergent flow (Pineda 1999, Shanks \& Shearman 2009, Ryan et al. 2014). Barnacle cyprids respond to downwelling by swimming up in laboratory experiments (DiBacco et al. 2011), and this may be the mechanism in which they became entrained in internal bore warm fronts (Pineda 1999). An autonomous underwater vehicle (AUV) in California sampled higher larval concentrations when frontal gradients were strongest and upwelling anomalies persisted (Ryan et al. 2014). This AUV study also found high abundances of larvae near the seafloor, assumed to result from accumulation in a frontal convergence zone due to swimming behavior and downwelling.

Larval supply to the intertidal can also be related to wave height; a study in Australia reported more barnacle cyprids arriving to shore when wave height was higher (Jeffrey \& Underwood 2000), and a study in California and Oregon observed higher barnacle settlement when waves were larger (Shanks et al. 2010). However, Pfaff et al. (2015) reported that swell height facilitated delivery of mussel larvae, but not barnacle larvae. Onshore transport of barnacles occurred during downwelling, and settlement coincided with low swell, upwelling, and 
spring tides, suggesting that internal tides are associated with transport of larval barnacles to shore (Pfaff et al. 2015). To adequately resolve larval transport and dispersal processes, the vertical distribution of larvae must be further known (discussed in Pineda \& Reyns 2017). Given the recent findings on larval distributions constrained close to shore, studies need to resolve these distributions in the very nearshore.

In this study, we conducted fine-scale, high repetition plankton collections to resolve barnacle larval distributions. Vertical sampling in stratified, 2-m depth intervals throughout the water column was coupled with tight spatial resolution sampling at five cross-shore locations between 280 and $1000 \mathrm{~m}$ from shore, commensurate with measures of physical processes in the nearshore. We hypothesized that larval barnacle abundance and distributions would vary with ontogenetic stage, and changing hydrographic and hydrodynamic conditions. Specifically, we addressed the following questions: What are the fine-scale patterns of vertical and cross-shore barnacle larval distributions in the nearshore? Do nauplii and cyprids display different distribution patterns? Are patterns in larval distribution related to hydrographic and hydrodynamic conditions? 


\subsection{Materials and methods}

\subsubsection{Study site and system}

This study was conducted offshore of Bird Rock, La Jolla, CA and included five sampling stations located at distances of 280, 460, 640, 820 and $1000 \mathrm{~m}$ from shore and at depths of 4, 6, 8, 10, and $12 \mathrm{~m}$, respectively (Fig. 2.1). We selected this study area as the shoreline provides extensive adult barnacle habitat, particularly for the abundant Chthamalus fissus, and larvae of the predominant barnacle species in the region (C. fissus, Balanus glandula, Megabalanus californicus, and Pollicipes polymerus) have been observed in surrounding nearshore waters (Hoffman 1989, Pineda 1991, Pineda 1999, Pineda \& López 2002, Tapia \& Pineda 2007, Tapia et al. 2010). Further, the shelf bathymetry is simple. Sampling occurred during April-July (hereafter springsummer) and September-December (hereafter fall-winter) in 2014 and 2015, and consisted of plankton sampling cruises as well as hydrographic and hydrodynamic measurements obtained from instrument deployments (see below). Sampling periods were chosen to encompass times of barnacle settlement (Hines 1976, Hines 1978, Pineda 1994), and during expected seasonal contrasts in hydrographic conditions: greater spring-summer water column stratification than fall-winter stratification when the onset of cooling and increased storm activity enhances water column mixing (Winant \& Bratkovich 1981, Palacios et al. 2004).

\subsubsection{Plankton sampling}

Plankton sampling was conducted using a $7.6 \mathrm{~m}$ boat with a davit, and included 27 cruises total: 9 in spring-summer and 6 in fall-winter of 2014, 8 in 
spring-summer and 4 in fall-winter of 2015. During each cruise, plankton samples were collected using an Ebara 50DWXU6.4S Dominator submersible semivortex pump to filter $2 \mathrm{~m}^{3}$ of seawater in discrete 2-m depth bins that extended from the surface to the bottom at each of the 5 stations ( 20 samples per cruise with a few exceptions where sea state conditions or equipment failure interrupted sampling). Seawater was filtered through a $118-\mu \mathrm{m}$ mesh net to capture barnacle larval stages (C. fissus larvae range in size: stage I nauplii $\sim 124 \mu \mathrm{m}$ long x $206 \mu \mathrm{m}$ wide through cyprid stage $\sim 493 \mu \mathrm{m}$ long x $246 \mu \mathrm{m}$ wide; Miller et al. 1989) and samples were immediately preserved in $100 \%$ ethanol.

Plankton samples were sorted using a dissecting microscope, and barnacle larvae were enumerated. Nauplii were staged as early- (II-III) or late- (IV-VI) stage, and cyprids were classified to species based on published morphological descriptions (e.g., Lewis 1975, Branscomb \& Vedder 1982, Brown \& Roughgarden 1985, Miller et al. 1989, Miller \& Roughgarden 1994, Shanks 2001). Early-stage nauplii could not be identified to species due to morphological degradation, but late-stage nauplii were classified as C. fissus or 'other' due to their distinct size and shape. C. fissus is the most abundant barnacle in the region, and most early nauplii collected likely belong to this species. Stage I nauplii were not present in our samples, presumably due to the rapid transition to stage II after hatching (Brown \& Roughgarden 1985, Miller et al. 1989).

\subsubsection{Larval distributions}

We described the vertical and horizontal larval distribution patterns of the most abundant barnacle species in our samples; thus, detailed analyses were 
conducted for early-stage barnacle nauplii ( $>98 \%$ of the total nauplii collected; Table 2.1) and C. fissus cyprids, which comprised $>60 \%$ of the barnacle cyprids (Table 2.2). To characterize vertical distribution of larval stages, Mean Depth Distributions (MDDs; Tapia et al. 2010) were calculated for each station according to the following equation:

$$
\begin{aligned}
& \mathrm{MDD}=\Sigma\left(\text { no. } \mathrm{m}^{-3} \text { in sample interval } \times \text { mean depth of sample interval }\right) / \Sigma(\text { no. } \\
& \left.\qquad \mathrm{m}^{-3} \text { at station }\right)
\end{aligned}
$$

We used a 3-factor analysis of variance (ANOVA) to test for differences in MDD between larval stage (early-stage nauplii or C. fissus cyprids), sampling period (spring-summer or fall-winter), and year (2014 or 2015). ANOVA assumptions of normality, homoscedasticity, and absence of collinearity were met. A paired t-test was also used to compare MDDs of early-stage nauplii to C. fissus cyprids.

To account for the vertical dilution of larvae when comparing larval concentrations at stations of varying depths, total larval concentration (no. $\mathrm{m}^{-3}$ ) at each station was multiplied by station depth to standardize samples to larval density (no. $\mathrm{m}^{-2}$ ). To determine if larval abundances varied across stations, we calculated the proportion of total early-stage nauplii and C. fissus cyprids at each station on a given cruise date, and used a 2-factor ANOVA to test for differences in larval proportions between stations and sampling periods. Additionally, we calculated the Mean Distance from Shore (MDS; referred to as 'average distance offshore' in Shanks \& Shearman 2009) of the larval stages for each cruise: 
$\mathrm{MDS}=\Sigma\left(\right.$ no. $\mathrm{m}^{-2}$ at a given station $\times$ distance from shore of station $) / \Sigma\left(\right.$ no. $\mathrm{m}^{-2}$ at all stations)

A Student's t-test was used to compare MDS measurements of early-stage nauplii and C. fissus cyprids. Data were log-transformed to meet the assumption of equal variances. Finally, we developed a Constrained-Distribution Index (CDI) that considered both the influence of larval proportion and distance from shore to further investigate cyprid patterns. The CDI was only calculated for cruise dates where all 5 stations were sampled. First, larval proportion anomalies were calculated for C. fissus cyprids at each station as (the proportion of C. fissus cyprids at each station on a given cruise date) - (the average proportion of $C$. fissus cyprids at each station for all cruises). Then, for each cruise date, the CDI was calculated as:

$\mathrm{CDI}=\Sigma$ (larval proportion anomalies at 4 and $6 \mathrm{~m}$ stations on a given date) $-\Sigma$ (larval proportion anomalies at 8, 10 and $12 \mathrm{~m}$ stations on a given date)

Thus, the resulting index value is positive when cyprid densities are higher than average at the two inshore stations, and negative if cyprid densities are lower than average at the two inshore stations. We chose the two inshore stations as the basis for the index because cyprid MDS (overall mean $=531.19 \mathrm{~m}$, median $=521.34 \mathrm{~m}$ ) was located between the 6 and $8 \mathrm{~m}$ stations, which are 460 and $640 \mathrm{~m}$ from shore. 


\subsubsection{Temperature, currents, and pressure}

A CastAway-CTD (SonTek) was used to obtain temperature and depth measurements before and after plankton pumping at each station. Salinity was not considered in this study because stratification at our study site is due to vertical differences in temperature rather than salinity (Appendix G). Average temperature, mid-depth of the thermocline, and thermal stratification were calculated for each station. Stratification was defined as change in temperature $/ \mathrm{m}$ $\left(\Delta \mathrm{T}{ }^{\circ} \mathrm{C} / \mathrm{m}\right):$

Thermal stratification $=($ temperature at surface - temperature at bottom $) /($ depth of bottom temperature - depth of surface temperature)

Additionally, cross-shore stratification within our study site was calculated by averaging the stratification at the 8,10 , and $12 \mathrm{~m}$ stations for each cruise. These stations were selected to represent the cross-shore stratification as they most frequently exhibited the highest stratification at our site.

A 1200kHz RDI acoustic Doppler current profiler (ADCP) was deployed between the 8 and $10 \mathrm{~m}$ plankton sampling stations (Fig. 2.1) to record current velocities every two seconds throughout the water column in 0.4-m depth bins. Currents were rotated to align the predominant alongshore flow with the coastline, decomposed into alongshore (positive southward) and cross-shore (positive onshore) components, and depth-averaged. Currents associated with each cruise were calculated as the average of the 24 hours previous to the cruise end time. 
A Sea-Bird Electronics Seagauge was deployed on the ADCP frame, and configured to record pressure every $3 \mathrm{hrs}$. Significant Wave Height (SWH) was calculated as $4 \mathrm{x}$ the square root of the sea surface spectrum between periods of 4 30 seconds. We calculated the $24-\mathrm{hr}$ SWH average in the same way as previously described for currents.

\subsubsection{Relationships between physical variables and larvae}

Relationships between relevant physical variables (mid-depth of the thermocline, thermal stratification, cross-shore thermal stratification, 24-hr currents, and 24-hr SWH) and larvae (larval density, MDD, MDS, and CDI) were analyzed using correlation and regression analyses. 


\subsection{Results}

\subsubsection{Physical variables}

Depth-averaged temperature across stations was similar between sampling periods in 2014 (Fig. 2.2A), ranging from 18.2 to $19.7^{\circ} \mathrm{C}$. However, fall-winter was significantly warmer than spring-summer in 2015 (Fig. 2.2B), with average station temperatures ranging from 16.9 to $20.8^{\circ} \mathrm{C}$. Temperature decreased with distance from shore in spring-summer during both years, while cross-shelf temperature variation was minimal in fall-winter. Thermal stratification increased with distance from shore during spring-summer cruises and was similar across stations during fall-winter cruises, but offshore stations were still slightly more stratified (Fig. 2.2C,D). Stratification was significantly stronger in spring-summer than fall-winter in both 2014 and 2015 , averaging $0.23( \pm 0.03)^{\circ} \mathrm{C} / \mathrm{m}$ in springsummer and $0.06( \pm 0.005){ }^{\circ} \mathrm{C} / \mathrm{m}$ in fall-winter. Numbers in parentheses throughout the manuscript represent one standard error

Depth-averaged 24-hr alongshore currents were southward on all but 7 cruise dates, ranging from -0.12 to $0.05 \mathrm{~m} / \mathrm{s}$ with a mean value of $0.006( \pm 0.007)$ $\mathrm{m} / \mathrm{s}$. Depth-averaged cross-shore currents were offshore during 15 cruises, and onshore during 12 cruises. Cross-shore currents were slower than alongshore currents, ranging from -0.02 to $0.007 \mathrm{~m} / \mathrm{s}$ with a mean of $-0.003( \pm 0.001) \mathrm{m} / \mathrm{s}$.

The minimum 24-hr SWH measurement was $0.33 \mathrm{~m}$ (in 2014 springsummer), while the maximum was $1.03 \mathrm{~m}$ (in 2015 spring-summer). Mean SWH at our site was $0.54( \pm 0.03) \mathrm{m}$. 


\subsubsection{Temporal patterns of larval concentrations}

Larval concentrations were higher for nauplii than cyprids, and varied by sampling period (Tables 2.1,2.2). Concentrations were higher overall in 2014 than 2015 (Table 2.3), and larvae were more abundant in spring-summer than fallwinter of 2014 (Tables 2.1,2.2). This pattern shifted in 2015, where larvae were more abundant in fall-winter than spring-summer (Tables 2.1,2.2). Most barnacle nauplii collected were early-stage; of the late-stage nauplii, most were identified as Chthamalus fissus but they were much less abundant than early-stage nauplii (Table 2.1). Six species of barnacle cyprids were identified at our study site, including C. fissus, Balanus glandula, Pollicipes polymerus, Tetraclita rubescens, Megabalanus californicus, and Balanus trigonus (Table 2.2). C. fissus comprised more than $86 \%$ of the cyprids in 2014 and fall-winter 2015, while in springsummer 2015 C. fissus comprised only $\sim 60 \%$ of the cyprids (Table 2.2 ). Overall, average cyprid concentrations were lower during this time period, but species evenness was slightly higher (Table 2.2). Given the low concentrations of latestage nauplii and cyprid species other than C. fissus, we did not examine the distribution patterns of these larvae. Hence, we analyzed the vertical and crossshore distribution patterns of only the early-stage nauplii and C. fissus cyprids. The abundances of early-stage nauplii and C. fissus cyprids were not significantly correlated with SWH ( $p>0.46)$, alongshore currents $(\mathrm{p}>0.67)$, cross-shore currents $(p>0.33)$, or thermal stratification $(p>0.27)$. 


\subsubsection{Vertical distributions of larvae}

The MDDs of early-stage nauplii and C. fissus cyprids were deeper with increasing bottom depth and distance from shore, and cyprid MDDs were generally deeper than those of early-stage nauplii during all four sampling periods

(Fig. 2.3). There was a significant difference between MDDs of early-stage nauplii and cyprids $(t=-5.547, \mathrm{p}<0.0001)$, but there were no significant differences between spring-summer and fall-winter, or between years. The MDDs of early-stage nauplii and $C$. fissus cyprids were not correlated with the mid-depth of the thermocline $(\mathrm{p}>0.14)$ or stratification $(\mathrm{p}>0.16)$ at any station, or $24-\mathrm{hr}$ alongshore $(\mathrm{p}>0.12)$ or cross-shore $(\mathrm{p}>0.22)$ currents at the 8 -m station, but early-stage nauplii MDD had a marginally significant negative correlation with SWH (Pearson's $r=-0.39, \mathrm{p}=0.047)$.

\subsubsection{Cross-shore distributions of larvae}

In general, the proportion of total early-stage nauplii at each station increased with distance from shore (Fig. 2.4A-D), while C. fissus cyprids proportions decreased with distance from shore (Fig. 2.4E-H). These patterns were more distinct during spring-summer periods than fall-winter periods. There were differences among stations for early-stage nauplii and C. fissus cyprids, with significantly more nauplii at the offshore stations and significantly more cyprids at the inshore stations (Table 2.4). There was also a significant difference between sampling periods for cyprids, with more cyprids at the $8 \mathrm{~m}$ station in fall-winter than spring-summer. 
Early-stage nauplii were distributed farther offshore than C. fissus cyprids (MDS was significantly greater: $t=5.350, \mathrm{p}<0.0001$; Fig. 2.5). Additionally, cyprids were closer to shore in spring-summer than fall-winter (comparing minimum and median MDS values). The CDI revealed that cyprid densities were higher than average (i.e., CDI $>0$ ) at the two inshore stations during five of the 17 cruises when all five stations were sampled (Fig. 2.6). Four of these five cruises were in spring-summer (two in 2014, two in 2015), and one was in 2015 fallwinter. The highest CDI measurement (0.536) coincided with the highest crossshore stratification $\left(0.505^{\circ} \mathrm{C} / \mathrm{m}\right)$. The average cross-shore stratification was a significant predictor of the CDI and MDS for C. fissus cyprids (Fig. 2.6), but not early-stage nauplii $\operatorname{MDS}\left(R^{2}=0.024, \mathrm{p}=0.521\right)$.

\subsubsection{Summary of larval distribution patterns}

To summarize, MDDs of $C$. fissus cyprids were deeper than those of earlystage nauplii, and MDD values increased with depth/distance from shore for both larval stages. Densities of nauplii increased with distance from shore while densities of cyprids were higher nearshore, and nauplii were much more abundant than the cyprids. The majority of nauplii were found in plankton samples from offshore stations at a mid- to near- bottom depth, while the majority of cyprids were in samples from inshore stations at a near-bottom depth (Fig. 2.7). 


\subsection{Discussion}

Although larval concentrations varied from being high in 2014 springsummer, decreased in 2014 fall-winter, and remained low through 2015 springsummer until increasing in 2015 fall-winter, vertical and cross-shelf distribution patterns of early-stage nauplii and Chthamalus fissus cyprids remained consistent despite significant seasonal and annual variability. Mean larval concentrations decreased twofold for early-stage nauplii and fivefold for $C$. fissus cyprids from 2014 to 2015 , likely due to large-scale disturbances associated with a warm water anomaly commonly referred to as "the Blob," as well as El Niño conditions. Coastal sea surface temperatures began to warm in mid-2014, after the start of our sampling regime, and remained anomalously warm until spring in 2015 (Leising et al. 2015). El Niño impacted southern California starting in spring 2015 and intensified in fall-winter of 2015 , corresponding to the highest temperatures recorded at our site, lowest larval abundances, and the peak of the southern California coastal warm anomaly (Leising et al. 2015, Gentemann et al. 2017). Lower larval abundances in 2015 could be associated with environmental conditions that may have increased larval mortality or offshore advection, diminished onshore larval transport, decreased adult reproduction, or a combination of these factors.

Early-stage nauplii abundances were considerably larger than those of cyprids, likely reflecting loss due to larval mortality or advection (Rumrill 1990, Tapia \& Pineda 2007), and the potential species diversity of early-stage nauplii. In contrast, concentrations of cyprids were higher than those of late-stage nauplii 
during all sampling periods throughout the 2-yr study, suggesting that late-stage nauplii are advected farther away than our $12 \mathrm{~m}$ station ( $>1 \mathrm{~km}$ from shore) before transitioning to the cyprid stage and returning to the intertidal. It is important to note that when sampling began in spring-summer of 2014, an additional station at a $14 \mathrm{~m}$ depth was sampled during the first three cruises. This station was abandoned for the remainder of cruises due to plankton pump issues, but the mean density of late-stage nauplii (both $C$. fissus and other) at that station was $18.06( \pm 10.04) \mathrm{m}^{-2}$, while the mean density of late-stage nauplii in samples from all other stations was $1.22( \pm 0.73) \mathrm{m}^{-2}$, supporting previously-observed patterns of early-stage nauplii closer to shore and later stages farther offshore (Tapia \& Pineda 2007, Morgan et al. 2009).

While larval concentrations fluctuated by year and sampling period, general distribution patterns did not vary greatly throughout the study duration. Vertical distributions of early-stage nauplii and $C$. fissus cyprids moved deeper with increasing depth and distance from shore, suggesting that the larvae were tracking bottom depth. Cyprids were deeper than nauplii (as in Shanks \& Shearman 2009, Tapia et al. 2010, Bonicelli et al. 2016), which could be due to the positively phototactic response of nauplii (Lang et al. 1979) as well as cyprids' negative buoyancy. Non-feeding cyprids may also seek deeper, cooler waters to lower their metabolic rate, thus maintaining storage reserves and remaining competent longer before finding a suitable place to settle. Nauplii have been shown to remain near the surface (Tapia et al. 2010), as well as in upper to middle depths (Bonicelli et al. 2016) and middle to bottom depths (Shanks \& 
Shearman 2009, Morgan \& Fisher 2010). However, early-stage nauplii (stages II and III $\sim 300 \mu \mathrm{m}$ maximum dimension for most species sampled) passed through the net used by Morgan and Fisher (2010) (mesh aperture $335 \mu \mathrm{m})$ and the surface net used by Shanks and Shearman (2009) (mesh aperture $330 \mu \mathrm{m}$ ). Further, all of these previous studies were conducted in deeper water using coarser sampling intervals (ranging from 5 to $30 \mathrm{~m}$, in contrast to our $2 \mathrm{~m}$ depth intervals). Early-stage nauplii from our study were located in middle depths, and it could be possible that nauplii assume a more surface-oriented distribution as they move farther offshore, as vertical distribution of larval stages varies with ontogeny. Additionally, vertical distribution is likely to be species-specific (Morgan \& Fisher 2010, Bonicelli et al. 2016) but this cannot be discerned here. Larval depth distributions were not related to the mid-depth of the thermocline or station-specific thermal stratification, suggesting that there is not a temperature effect on vertical distribution. The MDD of early-stage nauplii was shallower when SWH was higher, which could be a result of specific naupliar behaviors including an upward shift in swimming direction and increased swimming rate (Yule 1984) in response to increasing pressure.

Cross-shore distribution patterns varied with larval stage: early-stage nauplii densities increased and C. fissus cyprid densities decreased with distance from shore. These distribution patterns were more distinct in spring-summer when stratification was higher. As cross-shore thermal stratification increased, the CDI increased, indicating there were higher abundances of cyprids nearshore when stratification was higher. This relationship is further exemplified by the effect of 
decreasing cyprid MDS values with increasing stratification. These results provide evidence that cyprids are constrained closer to shore when cross-shore stratification is higher, and expand farther offshore when the water column is more well-mixed. Higher stratification may enhance the behavioral control of horizontal distribution by allowing cyprids to exploit vertically sheared flows. Additionally, these findings could be related to shoreward transport of cyprids by the internal tide, motions that require water column stratification (Pineda 1999, Pfaff et al. 2015), and explain the results of Pineda and López (2002) that changes in stratification are positively correlated with changes in barnacle settlement. It is possible that stratification did not significantly predict MDS for nauplii because they do not have sufficient swimming speeds to exploit such hydrodynamic motions (Helfrich \& Pineda 2003, Scotti \& Pineda 2007).

Our results indicate that larval densities and distributions were not related to alongshore or cross-shore current velocities. However, depth-averaged current measurements from an ADCP located between the 8 and $10 \mathrm{~m}$ stations may not accurately reflect currents throughout our site due to small-scale variability at the nearshore (reviewed in Lentz \& Fewings 2012).

In summary, distribution patterns of barnacle larvae within $1 \mathrm{~km}$ of the coast of La Jolla, southern California were upheld across 27 sampling cruises over a 2-yr period despite varying environmental conditions from two large-scale disturbances: the warm "Blob" and El Niño. For cyprids, cross-shore patterns varied seasonally. Our results support the inference that behavior plays a substantial role in facilitating transport during pelagic larval stages. Cross-shore 
distributions of cyprids were related to thermal stratification, but currents and SWH did not significantly affect spatial patterns. These results support the hypothesis that the more thermal stratification there is, the more behavioral control can be exerted by cyprids to accumulate closer to shore, and that stratification is an important determinant of the successful transport of cyprid larvae. Nearshore accumulation of cyprid larvae has been previously observed (dos Santos et al. 2007, Tapia \& Pineda 2007, Shanks \& Shearman 2009). We hypothesize that thermal stratification mediates constrained larval distributions in nearshore waters. Vertically, larvae might maintain their positioning in more stratified waters. We propose that cross-shore stratification allows the internal tide to propagate shoreward, and where stratification breaks down, larvae will accumulate. In our case, accumulation of cyprids occurred at our most inshore station (4 $\mathrm{m}$ deep and $280 \mathrm{~m}$ from the coast), where stratification was weak during both spring-summer and fall-winter sampling periods. We hypothesize that higher stratification will allow larvae to better maintain more constrained distributions, both in the nearshore, and we expect settlement to be higher during these conditions (Pineda \& López 2002). 


\subsection{Literature cited}

Archambault P, Bourget E (1999) Influence of shoreline configuration on spatial variation of meroplanktonic larvae, recruitment and diversity of benthic subtidal communities. J Exp Mar Biol Ecol 238:161-184

Bonicelli J, Tyburczy J, Tapia FJ, Finke GR, Parragué M, Dudas S, Menge BA, Navarrete SA (2016) Diel vertical migration and cross-shore distribution of barnacle and bivalve larvae in the central Chile inner-shelf. J Exp Mar Biol Ecol 485:35-46

Bradbury IR, Snelgrove PV (2001) Contrasting larval transport in demersal fish and benthic invertebrates: The roles of behaviour and advective processes in determining spatial pattern. Can J Fish Aquat Sci 58:811-823

Branscomb ES, Vedder K (1982) A description of the naupliar stages of the barnacles, Balanus glandula Darwin, Balanus cariosus Pallas, and Balanus crenatus Bruguière (Cirripedia, Thoracica). Crustaceana 42:83-95

Brown SK, Roughgarden J (1985) Growth, morphology, and laboratory culture of larvae of Balanus glandula (Cirripedia: Thoracica). J Crust Biol 5:574-590

Butler IV MJ, Paris CB, Goldstein JS, Matsuda H, Cowen RK (2011) Behavior constrains the dispersal of long-lived spiny lobster larvae. Mar Ecol Prog Ser 422:223-237

Cowen RK, Sponaugle S (2009) Larval dispersal and marine population connectivity. Annu Rev Mar Sci 1:443-466

Cowen RK, Gawarkiewicz G, Pineda J, Thorrold SR, Werner FE (2007) Population connectivity in marine systems an overview. Oceanography 20:14-21

Daigle RM, Metaxas A (2012) Modeling of the larval response of green sea urchins to thermal stratification using a random walk approach. J Exp Mar Biol Ecol 438:14-23

Daigle RM, Metaxas A (2011) Vertical distribution of marine invertebrate larvae in response to thermal stratification in the laboratory. J Exp Mar Biol Ecol 409:89-98

DiBacco C, Fuchs HL, Pineda J, Helfrich K (2011) Swimming behavior and velocities of barnacle cyprids in a downwelling flume. Mar Ecol Prog Ser 433:131-148 
dos Santos A, Santos AMP, Conway DV (2007) Horizontal and vertical distribution of cirripede cyprid larvae in an upwelling system off the Portuguese coast. Mar Ecol Prog Ser 329:145-155

Epifanio CE, Cohen JH (2016) Behavioral adaptations in larvae of brachyuran crabs: A review. J Exp Mar Biol Ecol 482:85-105

Helfrich KR. Pineda J (2003) Accumulation of particles in propagating fronts. Limnol Oceanogr 48:1509-1520

Hines AH (1976) Comparative reproductive ecology of three species of intertidal barnacles. PhD dissertation, University of California, Berkeley, CA

Hines AH (1978) Reproduction in three species of intertidal barnacles from central California. Biol Bull 154:262-281

Hoffman DL (1989) Settlement and recruitment patterns of a pedunculate barnacle, Pollicipes polymerus Sowerby, off La Lolla, California. J Exp Mar Biol Ecol 125:83-98

Jeffery C, Underwood A (2000) Consistent spatial patterns of arrival of larvae of the honeycomb barnacle Chamaesipho tasmanica Foster and Anderson in New South Wales. J Exp Mar Biol Ecol 252:109-127

Lang WH, Forward Jr RB, Miller DC (1979) Behavioral responses of Balanus improvisus nauplii to light intensity and spectrum. Biol Bull 157:166-181

Leising AW, Schroeder ID, Bograd SJ, Abell J, Durazo R, Gaxiola-Castro G, Bjorkstedt EP, Field J, Sakuma K, Robertson RR (2015) State of the California Current 2014-15: Impacts of the warm-water "Blob". CalCOFI Rep. 56:31-68

Lentz SJ, Fewings MR (2012) The wind- and wave- driven inner-shelf circulation. Annu Rev Mar Sci 4:317-343

Lewis C (1975) Development of the gooseneck barnacle Pollicipes polymerus (Cirripedia: Lepadomorpha): Fertilization through settlement. Mar Biol $32: 141-153$

Lloyd MJ, Metaxas A (2012) Patterns in vertical distribution and their potential effects on transport of larval benthic invertebrates in a shallow embayment. Mar Ecol Prog Ser 469:37-52

Metaxas A (2001) Behaviour in flow: Perspectives on the distribution and dispersion of meroplanktonic larvae in the water column. Can J Fish Aquat Sci 58:86-98 
Miller J, Shanks A (2004) Evidence for limited larval dispersal in black rockfish (Sebastes melanops): Implications for population structure and marinereserve design. Can J Fish Aquat Sci 61:1723-1735

Miller KM, Roughgarden J (1994) Descriptions of the larvae of Tetraclita rubescens and Megabalanus californicus with a comparison of the common barnacle larvae of the central California coast. J Crust Biol 14:579-600

Miller KM, Blower SM, Hedgecock D, Roughgarden J (1989) Comparison of larval and adult stages of Chthamalus dalli and Chthamalus fissus (Cirripedia: Thoracica). J Crust Biol 9:242-256

Morgan SG, Fisher JL (2010) Larval behavior regulates nearshore retention and offshore migration in an upwelling shadow and along the open coast. Mar Ecol Prog Ser 404:109-126

Morgan SG, Fisher JL, Miller SH, McAfee ST, Largier JL (2009) Nearshore larval retention in a region of strong upwelling and recruitment limitation. Ecology 90:3489-3502

Palacios DM, Bograd SJ, Mendelssohn R, Schwing FB (2004) Long-term and seasonal trends in stratification in the California Current, 1950-1993. J Geophys Res 109:C10016

Paris CB, Cowen RK (2004) Direct evidence of a biophysical retention mechanism for coral reef fish larvae. Limnol Oceanogr 49:1964-1979

Pfaff MC, Branch GM, Fisher JL, Hoffmann V, Ellis AG, Largier JL (2015) Delivery of marine larvae to shore requires multiple sequential transport mechanisms. Ecology 96:1399-1410

Pineda J (1991) Predictable upwelling and the shoreward transport of planktonic larvae by internal tidal bores. Science 253:548-551

Pineda J (1994) Spatial and temporal patterns in barnacle settlement rate along a southern California rocky shore. Mar Ecol Prog Ser 107:125-138

Pineda J (1999) Circulation and larval distribution in internal tidal bore warm fronts. Limnol Oceanogr 44:1400-1414

Pineda J, López M (2002) Temperature, stratification and barnacle larval settlement in two Californian sites. Cont Shelf Res 22:1183-1198

Pineda J, Reyns NB (2017) Larval transport in the coastal zone: biological and physical processes. In: Carrier TJ, Reitzel AM, Heyland A (eds) 
Evolutionary ecology of marine invertebrate larvae. Oxford University Press, p 141-159

Reyns NB, Eggleston DB, Luettich RA (2007) Dispersal dynamics of post-larval blue crabs, Callinectes sapidus, within a wind-driven estuary. Fish Oceanogr $16: 257-272$

Rumrill SS (1990) Natural mortality of marine invertebrate larvae. Ophelia 32:163-198

Ryan J, Harvey J, Zhang Y, Woodson C (2014) Distributions of invertebrate larvae and phytoplankton in a coastal upwelling system retention zone and peripheral front. J Exp Mar Biol Ecol 459:51-60

Scotti A, Pineda J (2007) Plankton accumulation and transport in propagating nonlinear internal fronts. J Mar Res 65:117-145

Shanks AL (ed) (2001) An identification guide to the larval marine invertebrates of the Pacific Northwest. Oregon State University Press, Corvallis, OR

Shanks AL, Shearman RK (2009) Paradigm lost? Cross-shelf distributions of intertidal invertebrate larvae are unaffected by upwelling or downwelling. Mar Ecol Prog Ser 385:189-204

Shanks AL, Grantham BA, Carr MH (2003) Propagule dispersal distance and the size and spacing of marine reserves. Ecol Appl 13(1):S159-S169

Shanks AL, Morgan SG, MacMahan J, Reniers AJ (2010) Surf zone physical and morphological regime as determinants of temporal and spatial variation in larval recruitment. J Exp Mar Biol Ecol 392:140-150

Tapia FJ, DiBacco C, Jarrett J, Pineda J (2010) Vertical distribution of barnacle larvae at a fixed nearshore station in southern California: Stage-specific and diel patterns. Estuar Coast Shelf Sci 86:265-270

Tapia FJ, Pineda J (2007) Stage-specific distribution of barnacle larvae in nearshore waters: Potential for limited dispersal and high mortality rates. Mar Ecol Prog Ser 342:177-190

Tremblay MJ, Sinclair M (1990) Sea scallop larvae Placopecten magellanicus on Georges Bank: Vertical distribution in relation to water column stratification and food. Mar Ecol Prog Ser 61:1-15

Walley LJ, Rees E (1969) Studies on the larval structure and metamorphosis of Balanus balanoides (L.). Philos Trans R Soc Lond, B 256:237-280 
Weidberg N, Porri F, Von der Meden CEO, Jackson JM, Goschen W, McQuaid CD (2015) Mechanisms of nearshore retention and offshore export of mussel larvae over the Agulhas Bank. J Mar Sys 144:70-80

Winant CD, Bratkovich A (1981) Temperature and currents in the southern California shelf: a description of the variability. J Phys Oceanogr 11:71-86

Yule A (1984) The effect of temperature on the swimming activity of barnacle nauplii. Mar Biol Lett 5:1-11 
Table 2.1 Nauplii concentration summaries for all sampling periods: 2014 springsummer ( $\mathrm{N}=149$ samples), 2014 fall-winter $(\mathrm{N}=108$ samples), 2015 springsummer $(\mathrm{N}=136$ samples), 2015 fall-winter $(\mathrm{N}=78$ samples $)$. 


\begin{tabular}{|c|c|c|c|c|}
\hline Nauplii & $\begin{array}{l}2014 \text { spring- } \\
\text { summer }\end{array}$ & $\begin{array}{l}2014 \text { fall- } \\
\text { winter }\end{array}$ & $\begin{array}{l}2015 \text { spring- } \\
\text { summer }\end{array}$ & $\begin{array}{l}2015 \text { fall- } \\
\text { winter }\end{array}$ \\
\hline & \multicolumn{4}{|c|}{ Maximum concentration (no. larvae $\mathrm{m}^{-3}$ ) } \\
\hline Early-stage & 2104.15 & 165.90 & 135.92 & 651.63 \\
\hline $\begin{array}{l}\text { Late-stage } \\
\text { Chthamalus fissus }\end{array}$ & 0 & 5.99 & 11.99 & 3.99 \\
\hline \multirow[t]{2}{*}{ Late-stage other } & 4.04 & 0 & 1.99 & 5.99 \\
\hline & \multicolumn{4}{|c|}{ Mean concentration $\left(\right.$ no. larvae $\left.\mathrm{m}^{-3}\right) \pm \mathrm{SE}$} \\
\hline Early-stage & $91.23 \pm 21.66$ & $16.41 \pm 3.04$ & $9.81 \pm 1.73$ & $50.49 \pm 13.45$ \\
\hline $\begin{array}{l}\text { Late-stage } \\
\text { Chthamalus fissus }\end{array}$ & 0 & $0.09 \pm 0.06$ & $0.15 \pm 0.09$ & $0.36 \pm 0.11$ \\
\hline \multirow[t]{2}{*}{ Late-stage other } & $0.10 \pm 0.04$ & 0 & $0.02 \pm 0.02$ & $0.17 \pm 0.09$ \\
\hline & \multicolumn{4}{|c|}{ Percent of total nauplii (\%) } \\
\hline Early-stage & 99.90 & 99.44 & 98.34 & 98.97 \\
\hline $\begin{array}{l}\text { Late-stage } \\
\text { Chthamalus fissus }\end{array}$ & 0 & 0.56 & 1.47 & 0.70 \\
\hline Late-stage other & 0.10 & 0 & 0.18 & 0.33 \\
\hline
\end{tabular}


Table 2.2 Cyprid concentration summaries for all sampling periods: 2014 springsummer ( $\mathrm{N}=149$ samples), 2014 fall-winter ( $\mathrm{N}=108$ samples), 2015 springsummer $(\mathrm{N}=136$ samples), 2015 fall-winter $(\mathrm{N}=78$ samples $)$. 


\begin{tabular}{|c|c|c|c|c|}
\hline Cyprids & $\begin{array}{l}2014 \text { spring- } \\
\text { summer }\end{array}$ & $\begin{array}{l}2014 \text { fall- } \\
\text { winter }\end{array}$ & $\begin{array}{l}2015 \text { spring- } \\
\text { summer }\end{array}$ & $\begin{array}{l}2015 \text { fall- } \\
\text { winter }\end{array}$ \\
\hline & \multicolumn{4}{|c|}{ Maximum concentration (no. larvae $\mathrm{m}^{-3}$ ) } \\
\hline Chthamalus fissus & 427.76 & 116.93 & 21.98 & 85.95 \\
\hline Balanus glandula & 9.99 & 1.09 & 3.99 & 3.99 \\
\hline $\begin{array}{l}\text { Pollicipes } \\
\text { polymerus }\end{array}$ & 11.99 & 17.98 & 13.14 & 7.99 \\
\hline $\begin{array}{l}\text { Tetraclita } \\
\text { rubescens }\end{array}$ & 19.98 & 1.99 & 3.99 & 0 \\
\hline $\begin{array}{l}\text { Megabalanus } \\
\text { californicus }\end{array}$ & 9.99 & 1.99 & 14.99 & 3.99 \\
\hline Balanus trigonus & 11.99 & 0 & 0.49 & 3.99 \\
\hline \multirow[t]{2}{*}{ Unknown } & 5.99 & 0 & 3.99 & 0 \\
\hline & \multicolumn{4}{|c|}{ Mean concentration $\left(\right.$ no. larvae $\left.\mathrm{m}^{-3}\right) \pm \mathrm{SE}$} \\
\hline Chthamalus fissus & $20.48 \pm 4.34$ & $4.12 \pm 1.25$ & $1.86 \pm 0.32$ & $4.76 \pm 1.48$ \\
\hline Balanus glandula & $0.58 \pm 0.13$ & $0.01 \pm 0.01$ & $0.08 \pm 0.04$ & $0.16 \pm 0.08$ \\
\hline $\begin{array}{l}\text { Pollicipes } \\
\text { polymerus }\end{array}$ & $0.37 \pm 0.11$ & $0.24 \pm 0.17$ & $0.52 \pm 0.15$ & $0.36 \pm 0.14$ \\
\hline $\begin{array}{l}\text { Tetraclita } \\
\text { rubescens }\end{array}$ & $0.75 \pm 0.21$ & $0.04 \pm 0.03$ & $0.06 \pm 0.04$ & 0 \\
\hline $\begin{array}{l}\text { Megabalanus } \\
\text { californicus }\end{array}$ & $0.67 \pm 0.14$ & $0.04 \pm 0.03$ & $0.49 \pm 0.17$ & $0.08 \pm 0.06$ \\
\hline Balanus trigonus & $0.11 \pm 0.08$ & 0 & $0.01 \pm 0.01$ & $0.16 \pm 0.08$ \\
\hline \multirow[t]{2}{*}{ Unknown } & $0.26 \pm 0.07$ & 0 & $0.06 \pm 0.04$ & 0 \\
\hline & \multicolumn{4}{|c|}{ Percent of total cyprids (\%) } \\
\hline Chthamalus fissus & 88.11 & 92.56 & 60.51 & 86.29 \\
\hline Balanus glandula & 2.51 & 0.23 & 2.63 & 2.90 \\
\hline $\begin{array}{l}\text { Pollicipes } \\
\text { polymerus }\end{array}$ & 1.61 & 5.46 & 16.77 & 6.51 \\
\hline $\begin{array}{l}\text { Tetraclita } \\
\text { rubescens }\end{array}$ & 3.21 & 0.82 & 1.91 & 0 \\
\hline $\begin{array}{l}\text { Megabalanus } \\
\text { californicus }\end{array}$ & 2.87 & 0.94 & 16.02 & 1.39 \\
\hline Balanus trigonus & 0.46 & 0 & 0.24 & 2.90 \\
\hline Unknown & 1.12 & 0 & 1.91 & 0 \\
\hline
\end{tabular}


Table 2.3 Mean larval concentration (no. larvae $\mathrm{m}^{-3}$ ) $\pm \mathrm{SE}$ of nauplii and cyprids in $2014(\mathrm{~N}=257$ samples $)$ and $2015(\mathrm{~N}=214$ samples $)$. 


\begin{tabular}{|lcc|}
\hline & 2014 & 2015 \\
\hline Nauplii & & \\
Early-stage & $59.79 \pm 12.81$ & $24.64 \pm 5.18$ \\
Late-stage Chthamalus fissus & $0.04 \pm 0.03$ & $0.22 \pm 0.07$ \\
Late-stage other & $0.06 \pm 0.02$ & $0.07 \pm 0.03$ \\
Cyprids & & \\
Chthamalus fissus & $13.61 \pm 2.62$ & $2.92 \pm 0.58$ \\
Balanus glandula & $0.34 \pm 0.08$ & $0.11 \pm 0.04$ \\
Pollicipes polymerus & $0.32 \pm 0.10$ & $0.46 \pm 0.11$ \\
Tetraclita rubescens & $0.45 \pm 0.12$ & $0.04 \pm 0.02$ \\
Megabalanus californicus & $0.40 \pm 0.08$ & $0.34 \pm 0.11$ \\
Balanus trigonus & $0.06 \pm 0.05$ & $0.06 \pm 0.03$ \\
Unknown & $0.15 \pm 0.04$ & $0.04 \pm 0.02$ \\
\hline
\end{tabular}


Table 2.4 Results of 2-factor ANOVAs testing for among-station and between sampling period differences in proportions of early-stage nauplii and Chthamalus fissus cyprids. Significant differences are indicated in bold, and post hoc test results are shown for group pairs with significant differences. 


\begin{tabular}{|c|c|c|c|}
\hline Factor & $F$ & $\mathrm{p}$ & Post hoc test results \\
\hline \multicolumn{4}{|c|}{$\begin{array}{l}\text { Early-stage nauplii } \\
(\mathrm{df}=1,115)\end{array}$} \\
\hline Station & 26.210 & $<0.00001$ & $\begin{array}{l}12 \mathrm{~m}>4 \mathrm{~m}, 12 \mathrm{~m}>6 \mathrm{~m}, 10 \mathrm{~m}>4 \mathrm{~m} \\
8 \mathrm{~m}>4 \mathrm{~m}\end{array}$ \\
\hline Period & 0.775 & 0.380 & \\
\hline Station:Period & 1.534 & 0.218 & \\
\hline \multicolumn{4}{|c|}{$\begin{array}{l}\text { Chthamalus fissus } \\
\text { cyprids }(\mathrm{df}=1,105)\end{array}$} \\
\hline Station & 20.907 & $<0.0001$ & $\begin{array}{l}4 m>12 m, 4 m>10 m, 6 m>12 m \\
6 m>10 m\end{array}$ \\
\hline Period & 0.102 & 0.749 & \\
\hline Station:Period & 5.704 & 0.018 & $\begin{array}{l}8 \mathrm{~m} \text { fall-winter }>8 \mathrm{~m} \text { spring-summer } \\
(\mathrm{df}=1,22 ; \mathrm{F}=18.247, \mathbf{p}<\mathbf{0 . 0 0 1})\end{array}$ \\
\hline
\end{tabular}


Figure 2.1 Study site offshore of Bird Rock, La Jolla, southern California, USA. Circles indicate plankton sampling stations $280,460,640,820$, and $1000 \mathrm{~m}$ from shore at a bottom depth of $4,6,8,10$, and $12 \mathrm{~m}$, respectively moving offshore from right to left. $\mathrm{X}$ indicates location of $\mathrm{ADCP}$ to measure currents, and pressure sensor to measure waves. Lidar data from the 2013 NOAA Coastal California TopoBathy Merge Project, https://data.noaa.gov/dataset/2013-noaa-coastalcalifornia-topobathy-merge-project. 
Depth (m)

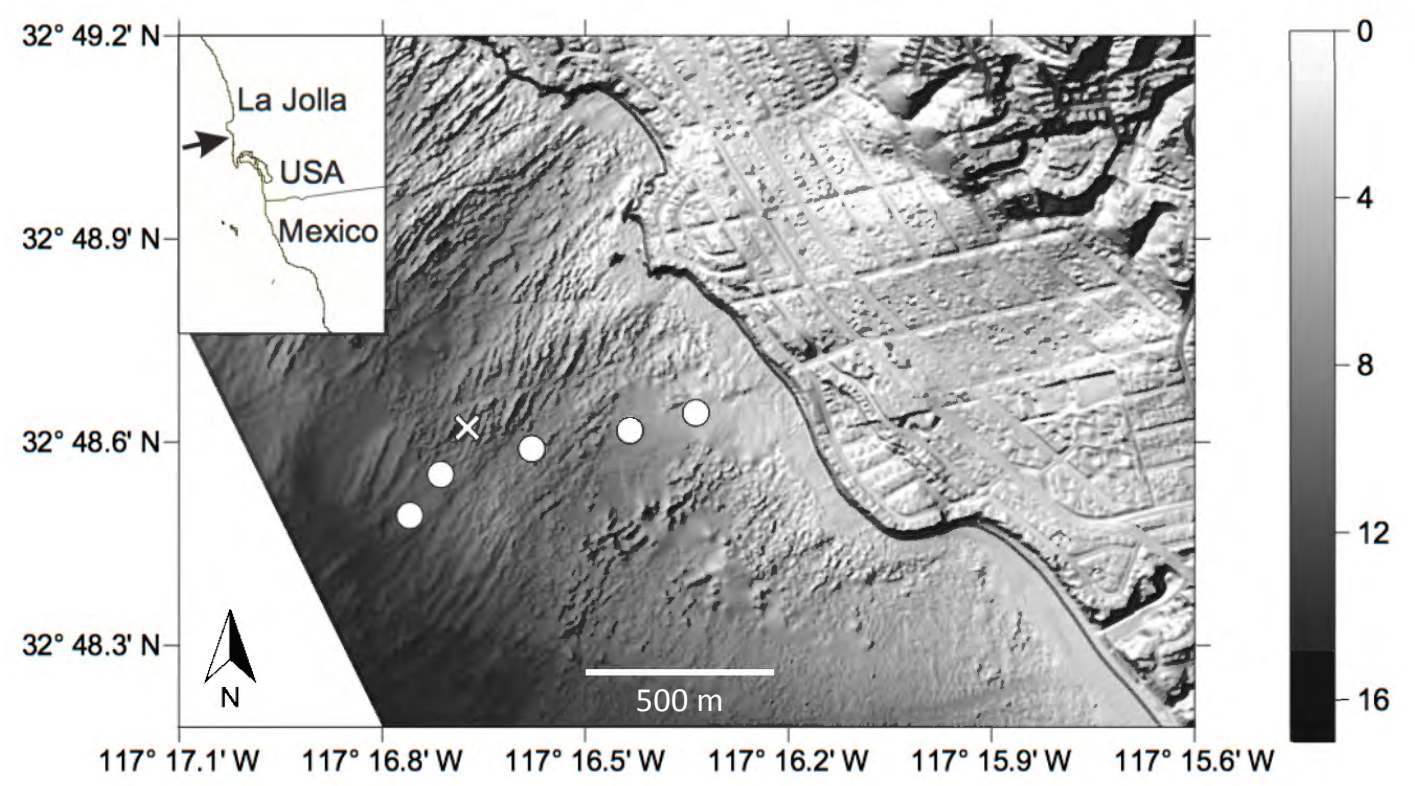


Figure 2.2 Depth-averaged temperature $\pm \mathrm{SE}(\mathrm{A}, \mathrm{B})$ and average thermal stratification \pm SE (C, D) at each station during 2014 and 2015 spring-summer and fall-winter sampling periods. Note that distance from shore increases from right to left (westward) to reflect the orientation of our study site. 

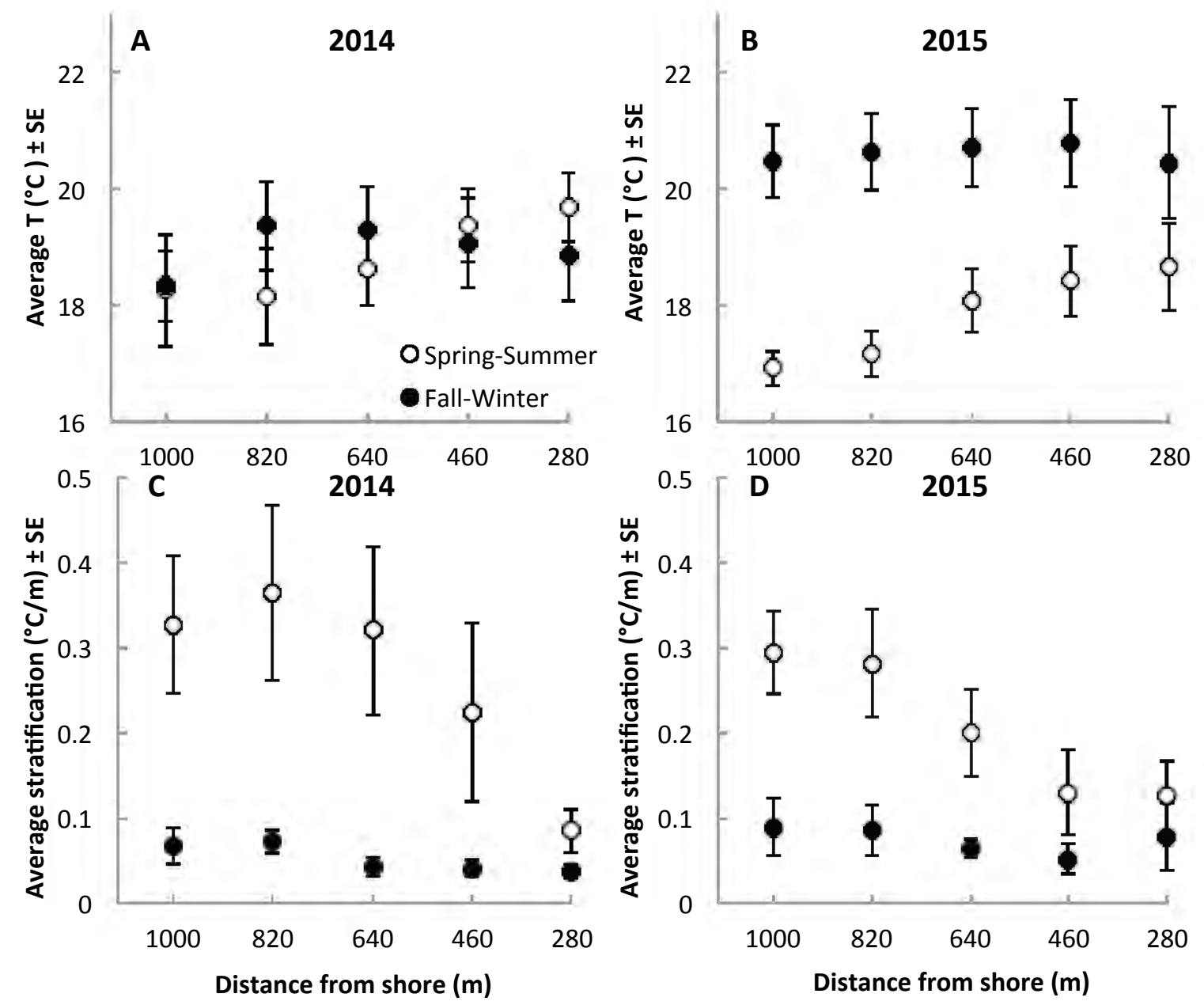
Figure 2.3 Vertical distributions of barnacle larvae. Average Mean Depth Distributions (MDDs) of early-stage nauplii and Chthamalus fissus cyprids at sampling stations during 2014 spring-summer ( $\mathrm{N}=9$ cruises) (A), 2014 fallwinter ( $N=6$ cruises) (B), 2015 spring-summer $(N=8$ cruises $)(C)$, and 2015 fall-winter ( $\mathrm{N}=4$ cruises) (D). Bottom depths of stations 280, 460, 820, and 1000 $\mathrm{m}$ from shore are $4,6,8,10$, and $12 \mathrm{~m}$, respectively, and are shown by the solid black line. 


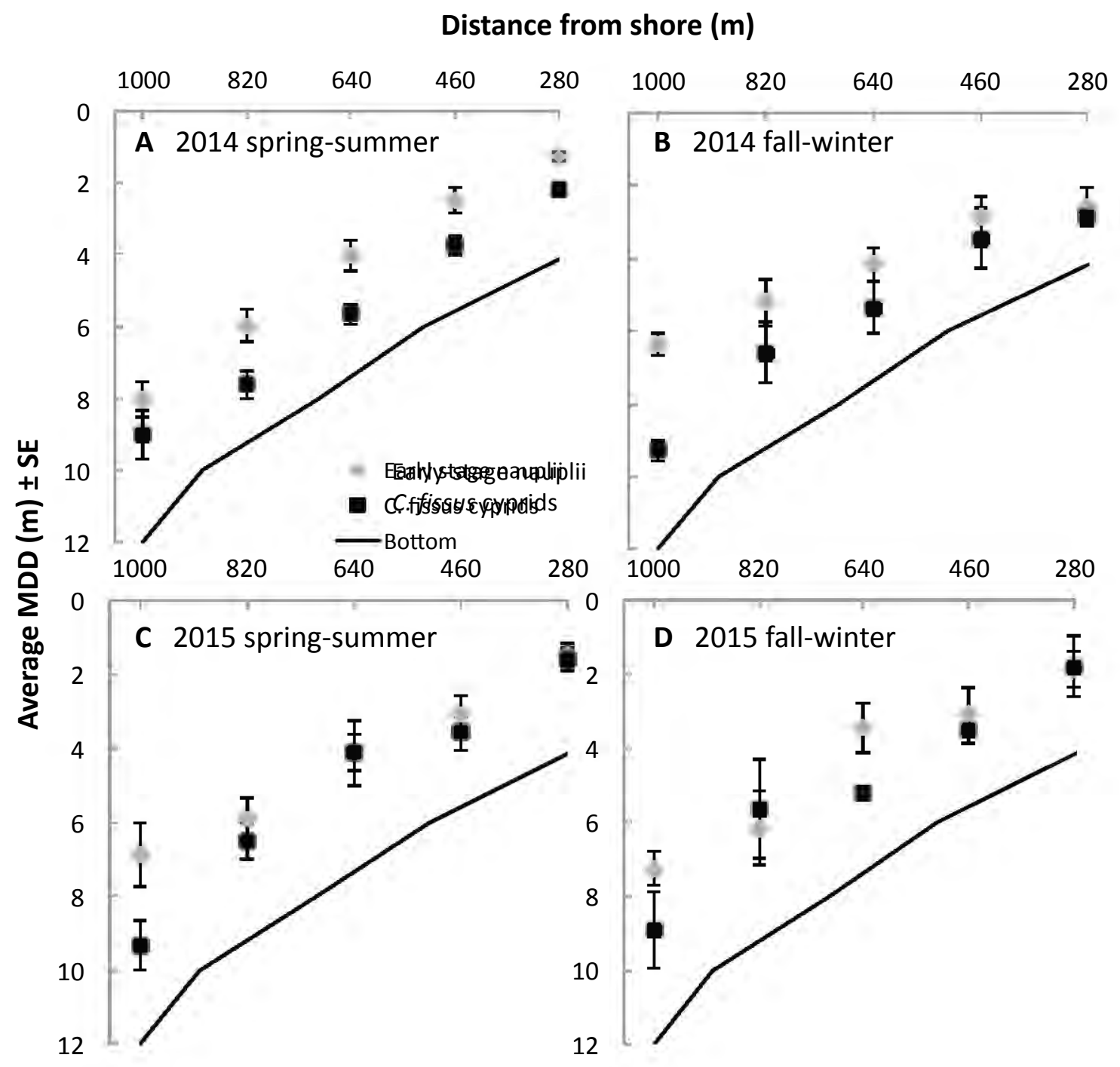


Figure 2.4 Cross-shelf distributions of barnacle larvae. Average proportion of total early-stage nauplii (A-D) and Chthamalus fissus cyprids (E-H) present at each of the five stations during sampling periods (spring-summer versus fallwinter) by year (2014 versus 2015). 

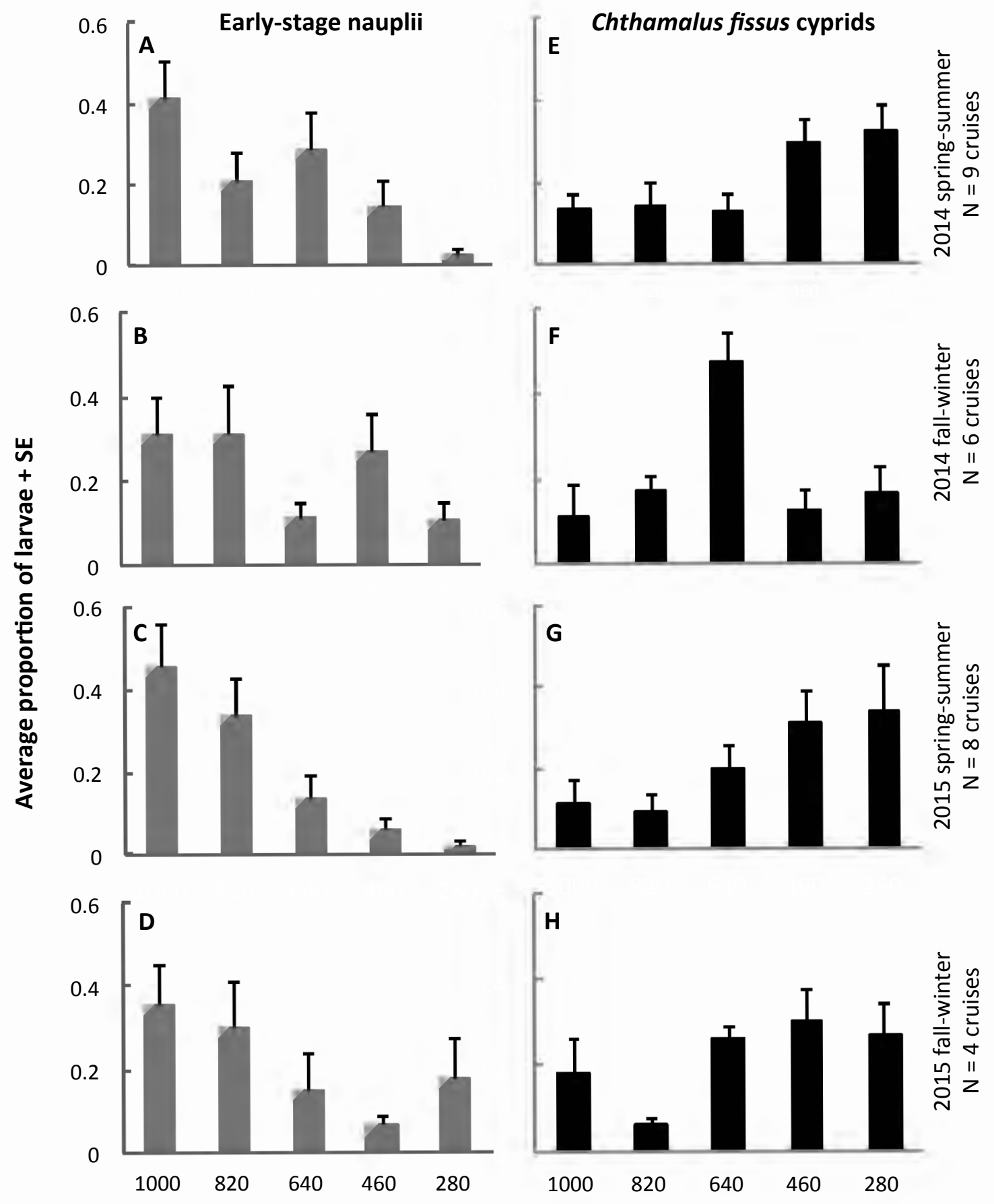

Distance from shore (m)

Fig. 4 
Figure 2.5 Box plots of Mean Distance from Shore (MDS) patterns of early-stage nauplii (A) and Chthamalus fissus cyprids (B) by sampling period and year. Lower and upper box limits are the first and third quartile, respectively and box midline is median. Whiskers extend up to $1.5 \mathrm{x}$ the interquartile range to farthest data point within that distance. Any data beyond that is shown individually as an outlying point. 


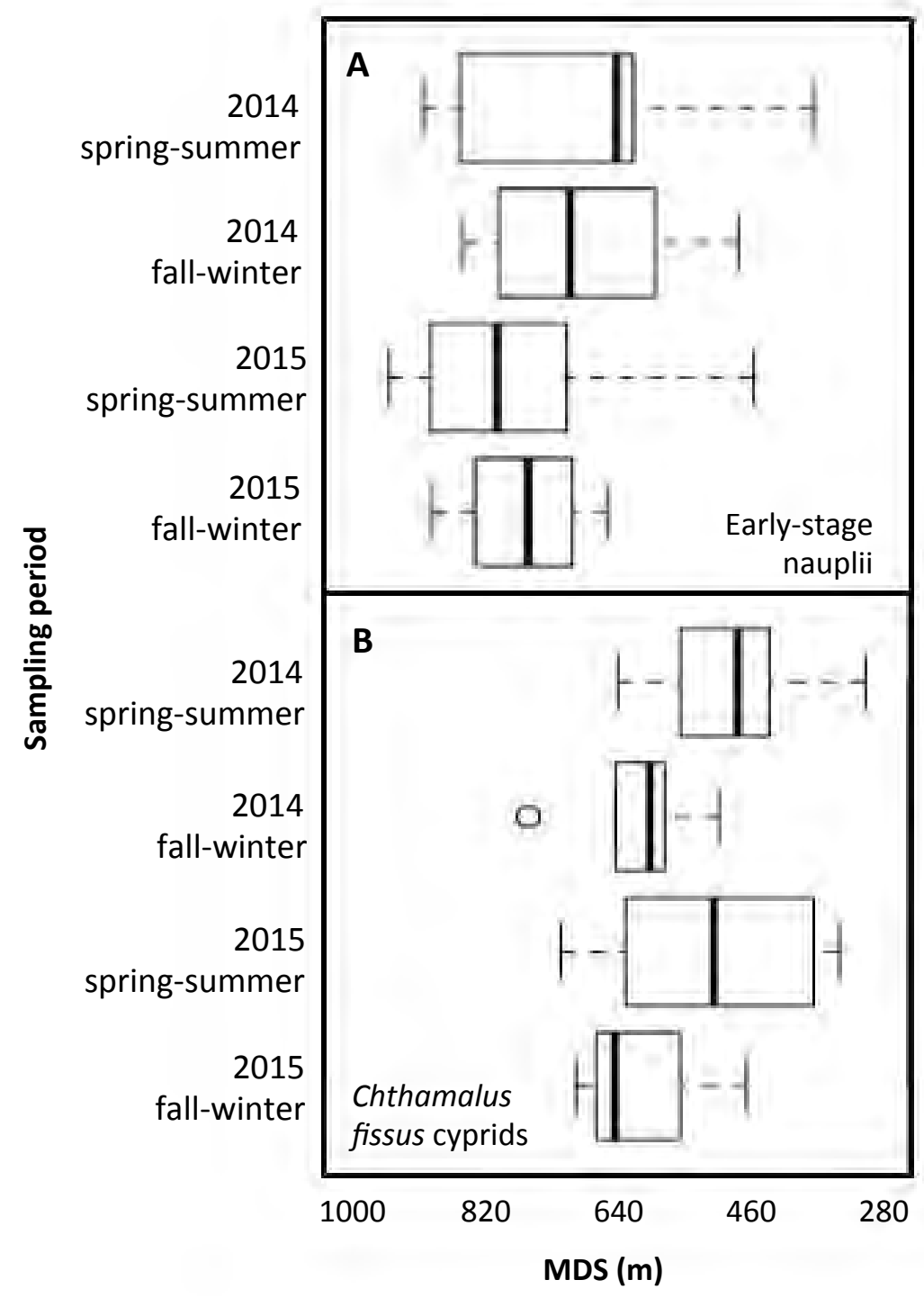

Fig. 5 
Figure 2.6 Effect of cross-shore stratification (average stratification at 8, 10, and $12 \mathrm{~m}$ stations) on Chthamalus fissus Mean Distance from Shore (MDS) (A) and Constrained-Distribution Index (CDI) (B). CDI was calculated for the 17 cruise dates where all five stations were sampled. Only 15 data points are shown because no $C$. fissus cyprids were collected on two of the 17 cruise dates. 


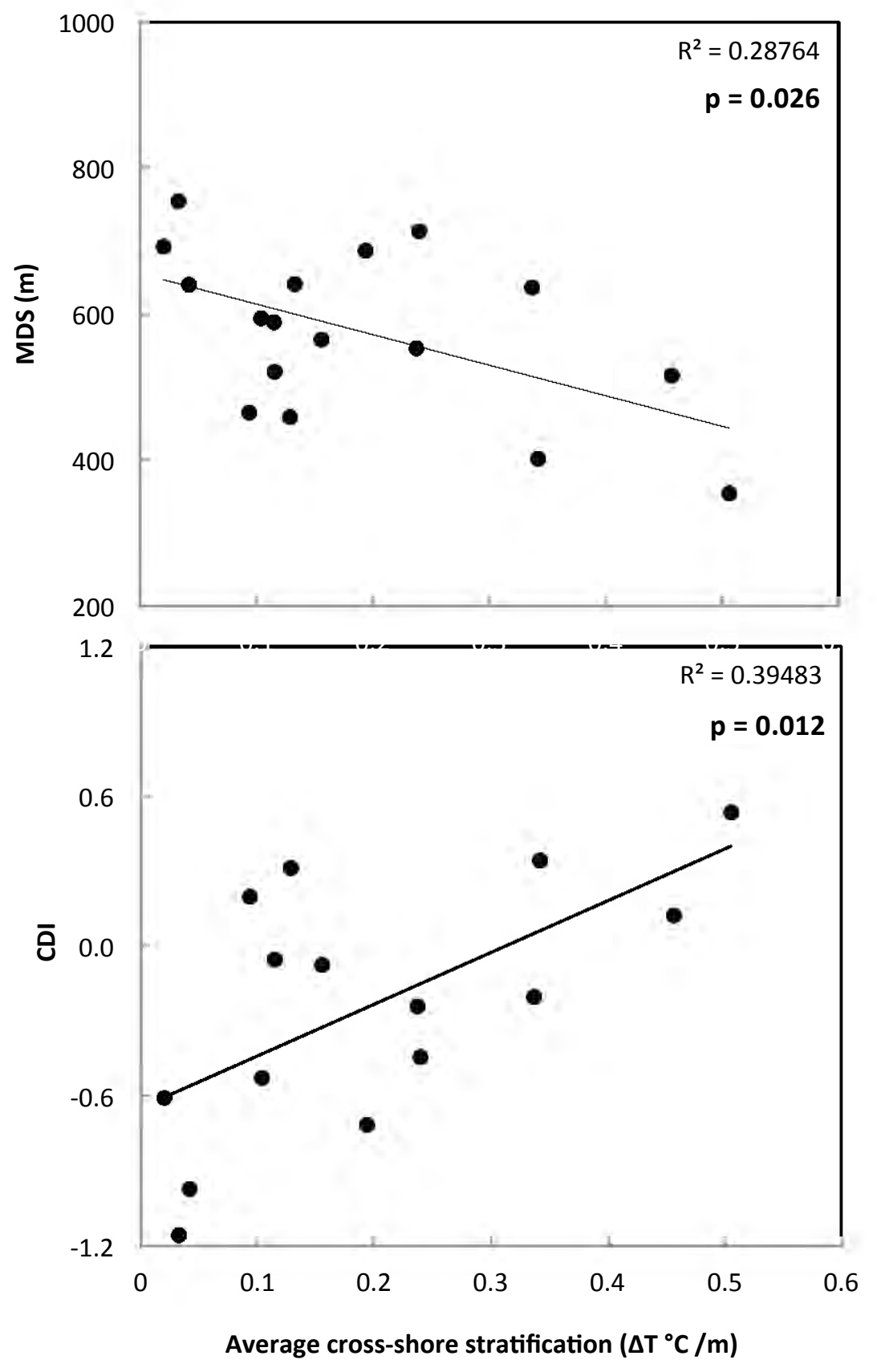


Figure 2.7 Summary figures for all sampling periods averaged for both 2014 and $2015(\mathrm{~N}=27$ cruises): overall vertical distribution patterns, with average Mean Depth Distributions (MDDs) of early-stage nauplii and Chthamalus fissus cyprids at sampling stations (A); overall cross-shore distribution patterns, showing average densities of early-stage nauplii and C. fissus cyprids at each station (B); average concentrations of early-stage nauplii (C) and $C$. fissus cyprids (D) in each plankton sample; average proportions of early-stage nauplii (E) and C. fissus cyprids $(\mathrm{F})$ in each plankton sample. Open circles in $\mathrm{C}-\mathrm{F}$ represent SE. 

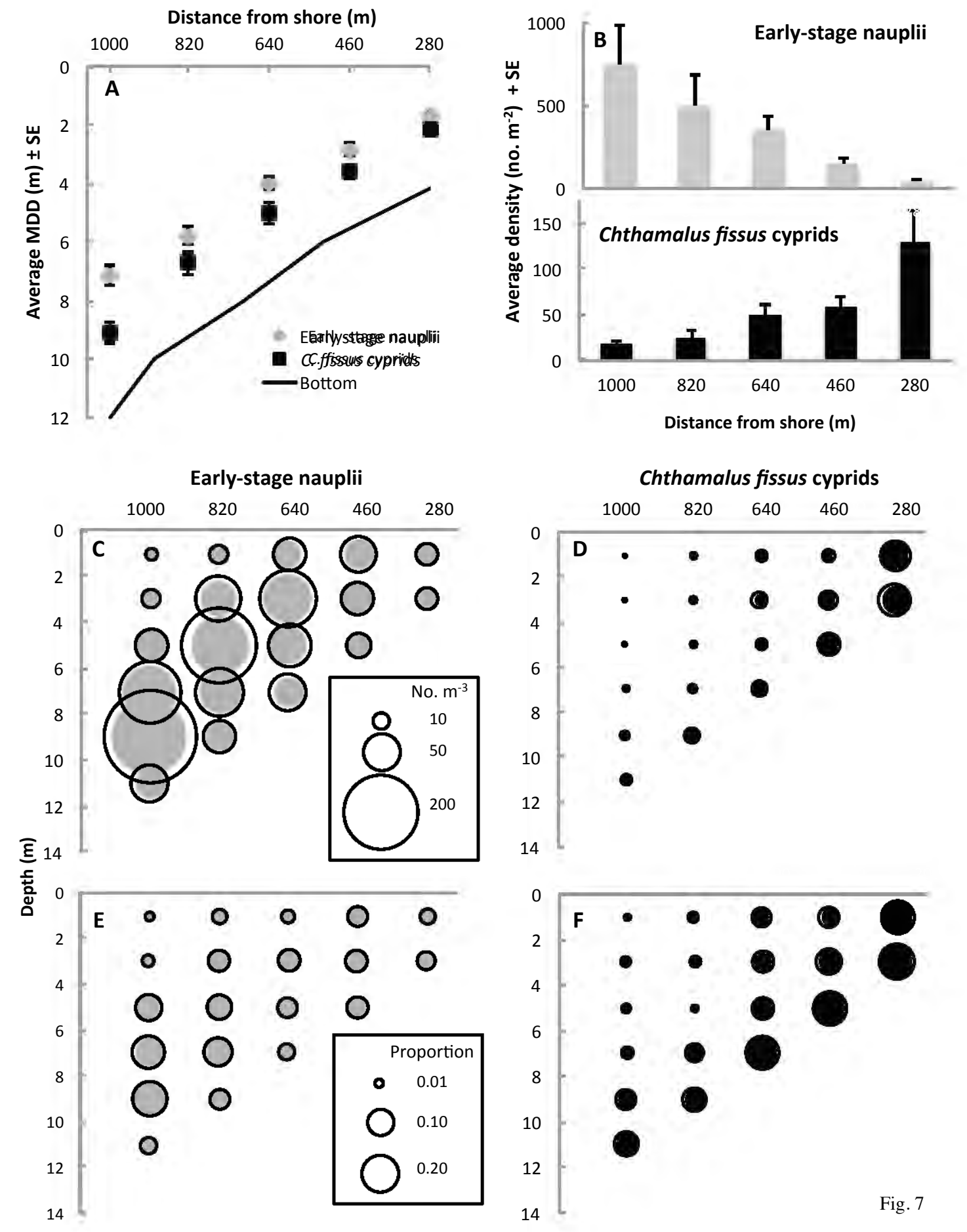


\section{CHAPTER 3: Conclusion}

To summarize, the research questions addressed and corresponding results are as follows:

1. Is there a pattern in barnacle larval distributions and abundances in La Jolla nearshore waters over a 2-yr period?

- Yes, there were cross-shore and vertical distribution patterns that remained consistent throughout 2014 and 2015.

- Early-stage nauplii and Chthamalus fissus cyprids were distributed deeper with increasing depth and distance from shore.

- Early-stage nauplii were more abundant offshore while $C$. fissus cyprids were more abundant nearshore.

- C. fissus cyprids accumulated more at nearshore stations during springsummer sampling periods when stratification was higher than during fallwinter when stratification weakened.

- Early-stage nauplii were much more abundant than cyprids, and larval abundances decreased overall from 2014 to 2015 .

2. How do changes in hydrographic and hydrodynamic conditions (temperature, pressure, currents, depth, distance from shore) in La Jolla nearshore waters impact the spatiotemporal distribution and abundance of barnacle larvae?

- Early-stage nauplii were not impacted by cross-shore thermal stratification, but $C$. fissus cyprids were more constrained at the inshore sampling stations when stratification was higher. 
- Cross-shore distributions and abundances of nauplii and cyprids were not impacted by Significant Wave Height (SWH; calculated from pressure measurements), or current velocities.

- Higher abundances of early-stage nauplii were located in deeper waters farther offshore, while abundances of $C$. fissus cyprids decreased with increasing depth and distance from shore.

3. Does vertical distribution of barnacle larvae depend on ontogenetic stage and changing environmental conditions?

- Later stage larvae (cyprids) were distributed deeper than earlier stages (nauplii).

- Early-stage nauplii and C. fissus cyprids moved deeper with increasing depth and distance from shore.

- The depth of the thermocline, thermal stratification, and current velocities did not impact vertical distributions of early-stage nauplii or C. fissus cyprids.

- SWH did not affect vertical distributions of cyprids, but early-stage nauplii were shallower when SWH was higher.

The findings of this study suggest that barnacle cyprids can better control their behavior to get to shore when thermal stratification is higher. Cross-shore stratification - defined here as average thermal stratification among the three offshore sampling stations - can be associated with shoreward propagation of the internal tide, which cyprids can exploit. The resulting hypothesis is that larvae 
will accumulate nearshore where stratification breaks down, and barnacle settlement to the intertidal is expected to increase during highly stratified conditions.

These results provoke more questions and open the door for future research. For example, can these distribution patterns be replicated for other species in other systems and locations? The larval depth distributions observed in La Jolla nearshore waters throughout 2014 and 2015 imply that depth/pressure may be the most important cue that influences vertical positioning of barnacle larvae, as they appeared to track bottom depth. Future research is needed to confirm this hypothesis. Further, more studies are needed to corroborate the notion that barnacle settlement will be higher when water stratification is stronger. 


\begin{abstract}
APPENDIX
Appendix A: Relationships between larval Mean Depth Distributions (MDDs) and mid-depth of thermocline. See pg. 23 for explanation of MDD calculation.
\end{abstract}

Figure A1. Mean Depth Distribution (MDD) of early-stage nauplii plotted against mid-depth of thermocline at all plankton sampling stations: 4-m, 6-m, 8-m, 10-m, and 12-m. 
Mid-depth of thermocline (m)
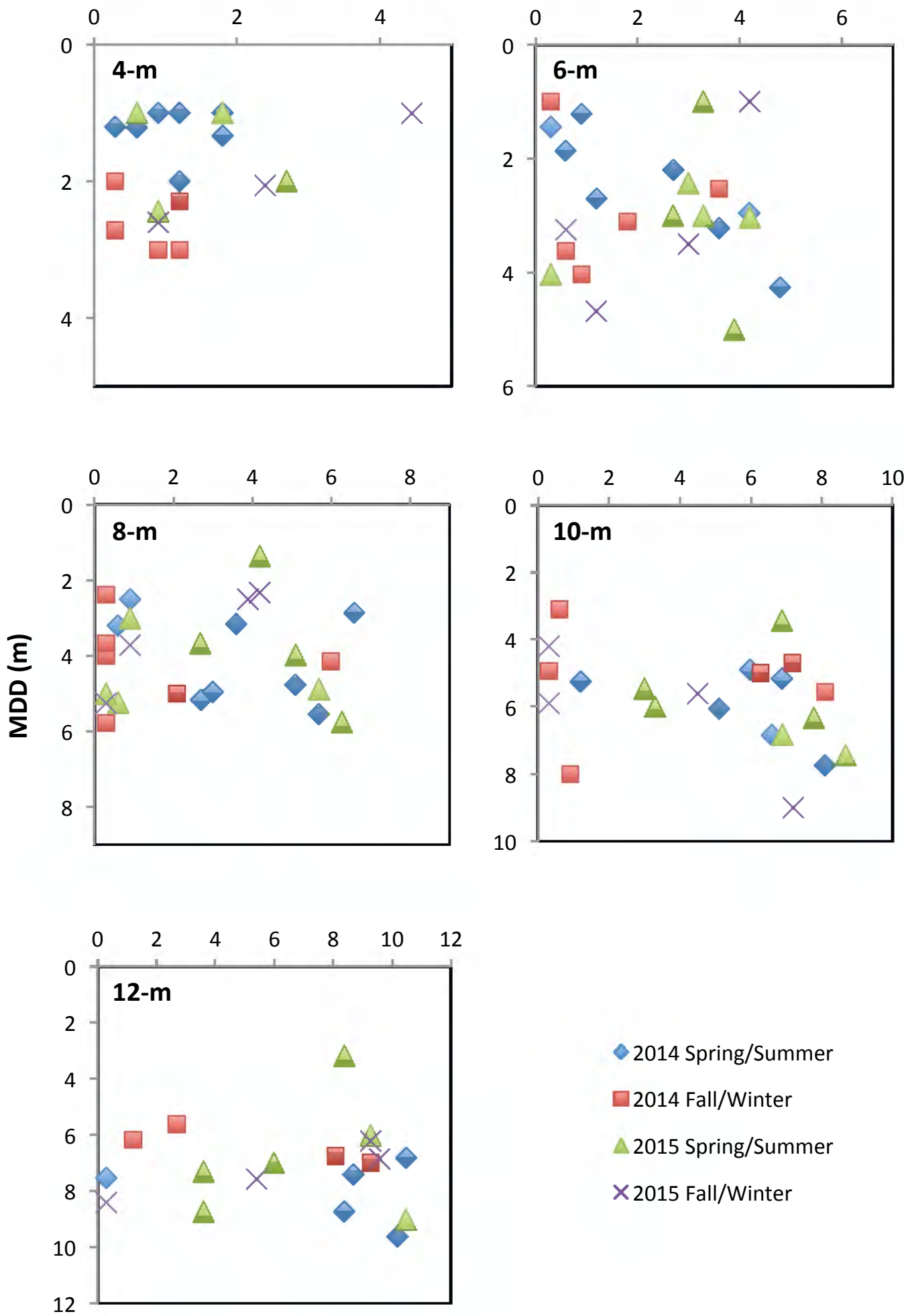
Figure A2. Mean Depth Distribution (MDD) of Chthamalus fissus cyprids plotted against mid-depth of thermocline at all plankton sampling stations: 4-m, 6-m, 8$\mathrm{m}, 10-\mathrm{m}$, and 12-m. 
Mid-depth of thermocline (m)
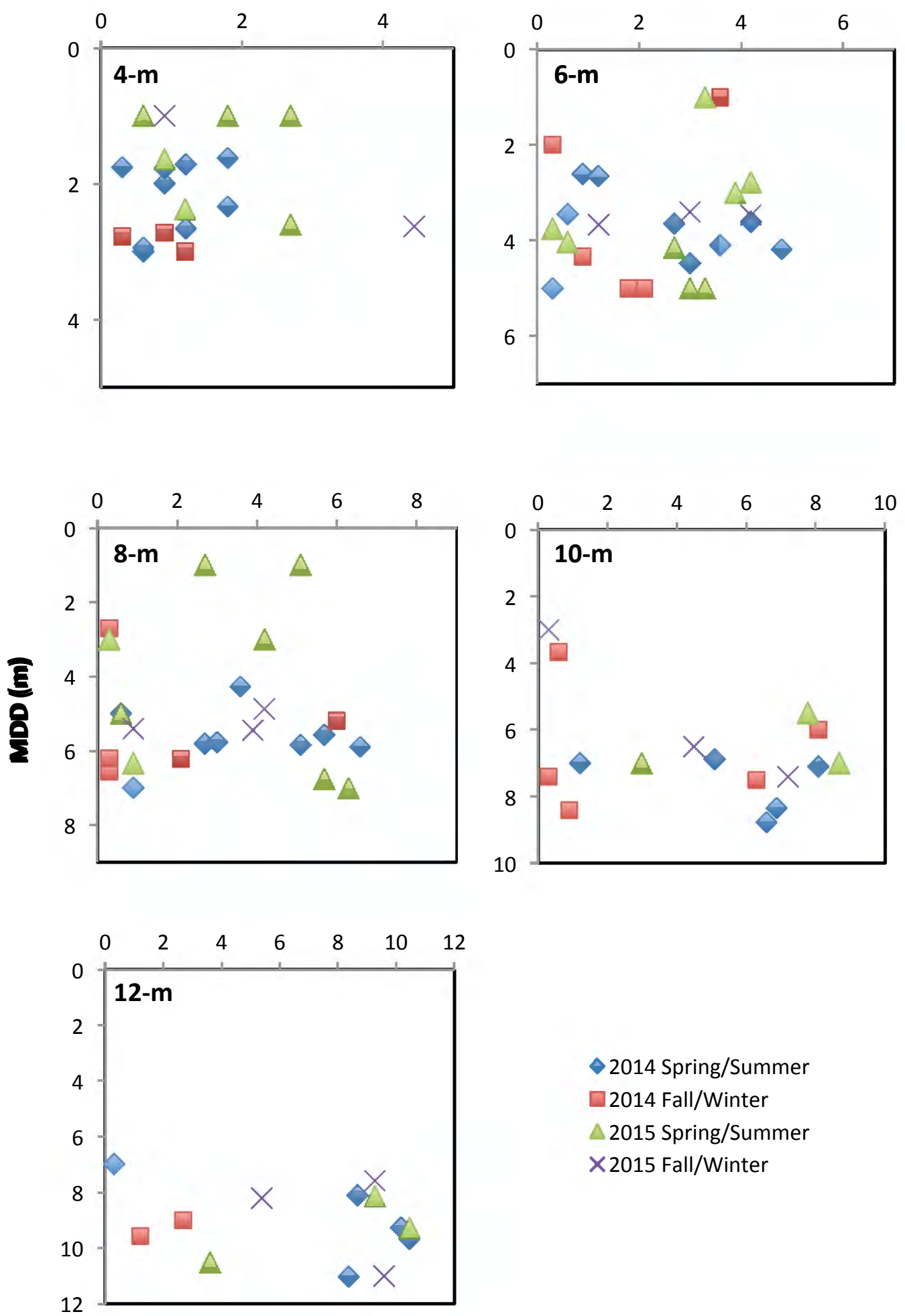

$$
\begin{aligned}
& \Delta 2014 \text { Spring/Summer } \\
& \square 2014 \text { Fall/Winter } \\
& \Delta 2015 \text { Spring/Summer } \\
& \times 2015 \text { Fall/Winter }
\end{aligned}
$$


Appendix B: Relationships between larval densities/distributions and thermal stratification.

Figure B1. Early-stage nauplii density plotted against thermal stratification during 2014 spring-summer (A), 2014 fall-winter (B), 2015 spring-summer (C), and 2015 fall-winter (D). $\mathrm{N}=27$ cruises. Note varying axes. 


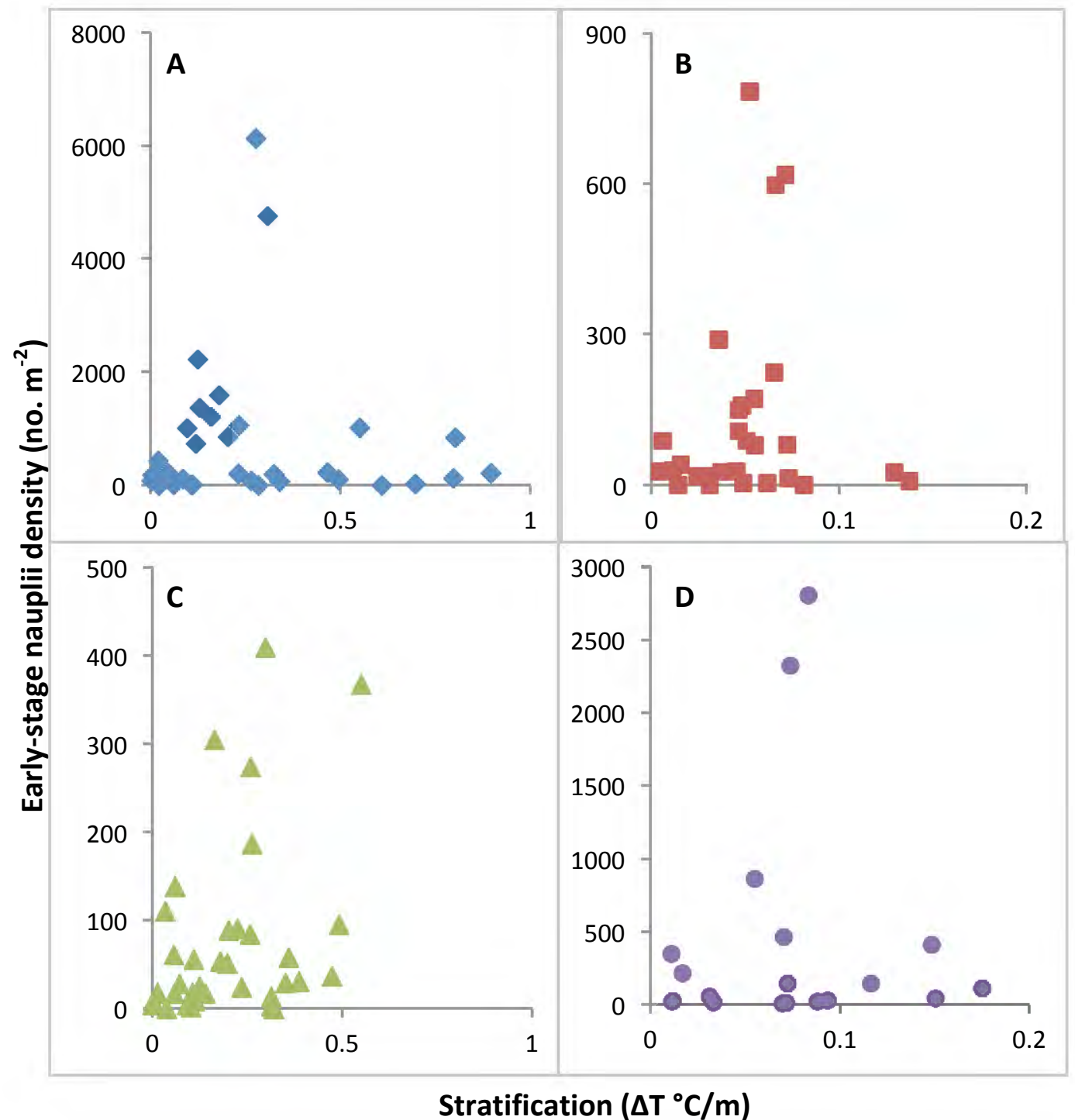


Figure B2. Chthamalus fissus cyprids density plotted against thermal stratification during 2014 spring-summer (A), 2014 fall-winter (B), 2015 spring-summer (C), and 2015 fall-winter (D). $\mathrm{N}=27$ cruises. Note varying axes. 


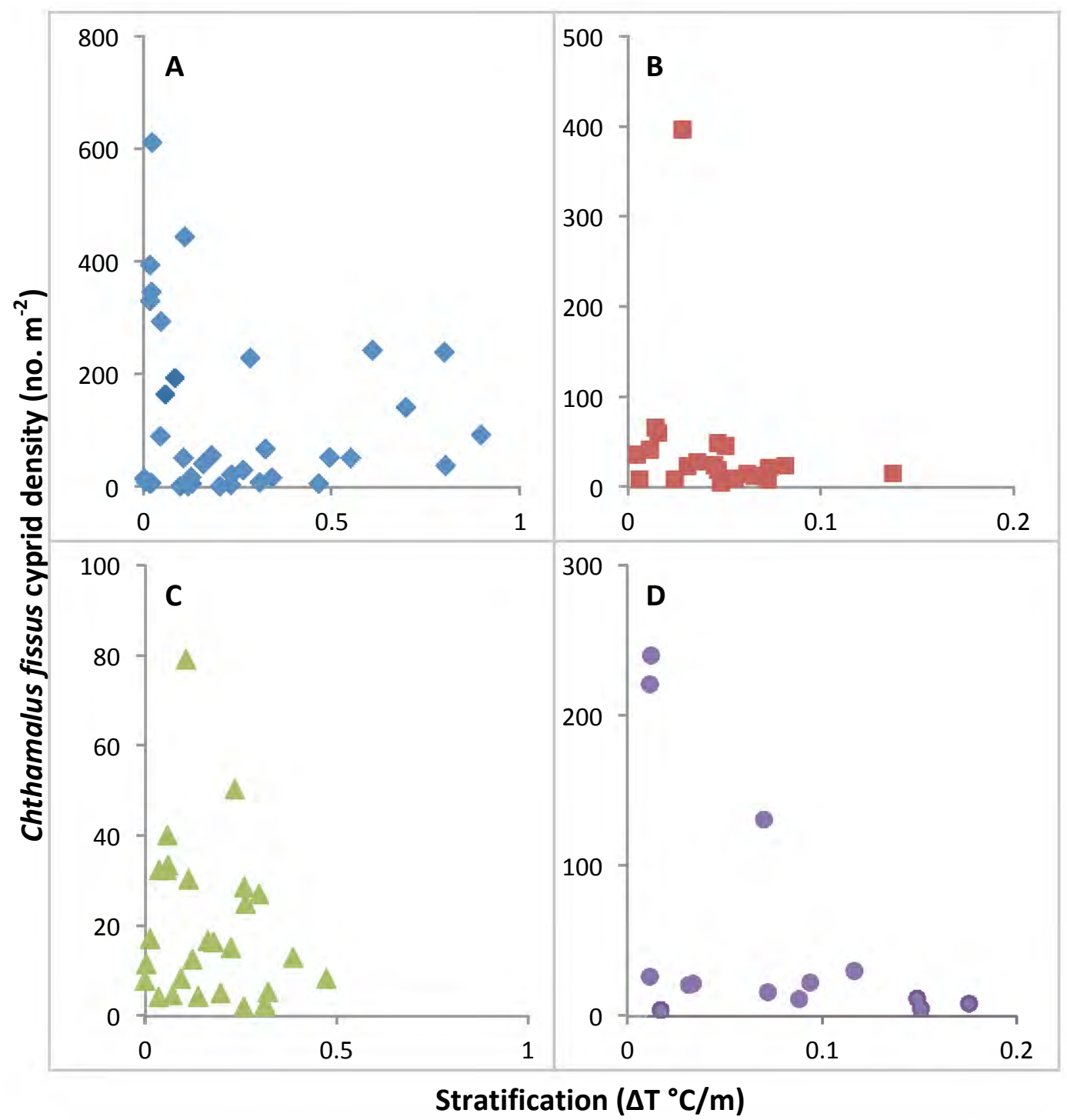


Figure B3. Mean Depth Distributions (MDDs) of early-stage nauplii plotted against thermal stratification at all plankton sampling stations: 4-m, 6-m, 8-m, 10m, and 12-m. See pg. 23 for explanation of MDD calculation. 


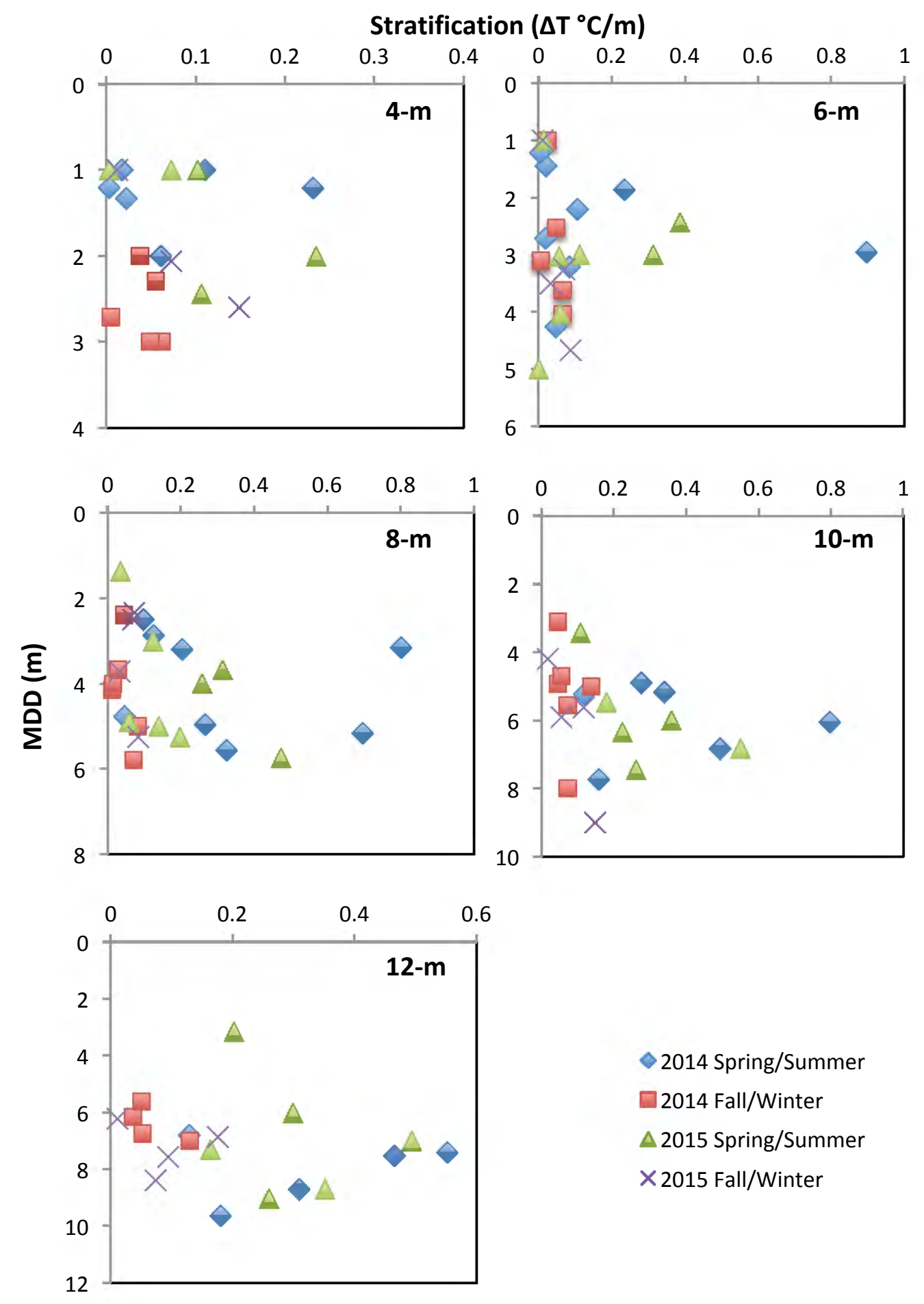


Figure B4. Mean Depth Distributions (MDDs) of Chthamalus fissus cyprids plotted against thermal stratification at all plankton sampling stations: 4-m, 6-m, 8-m, 10-m, and 12-m. See pg. 23 for explanation of MDD calculation. 


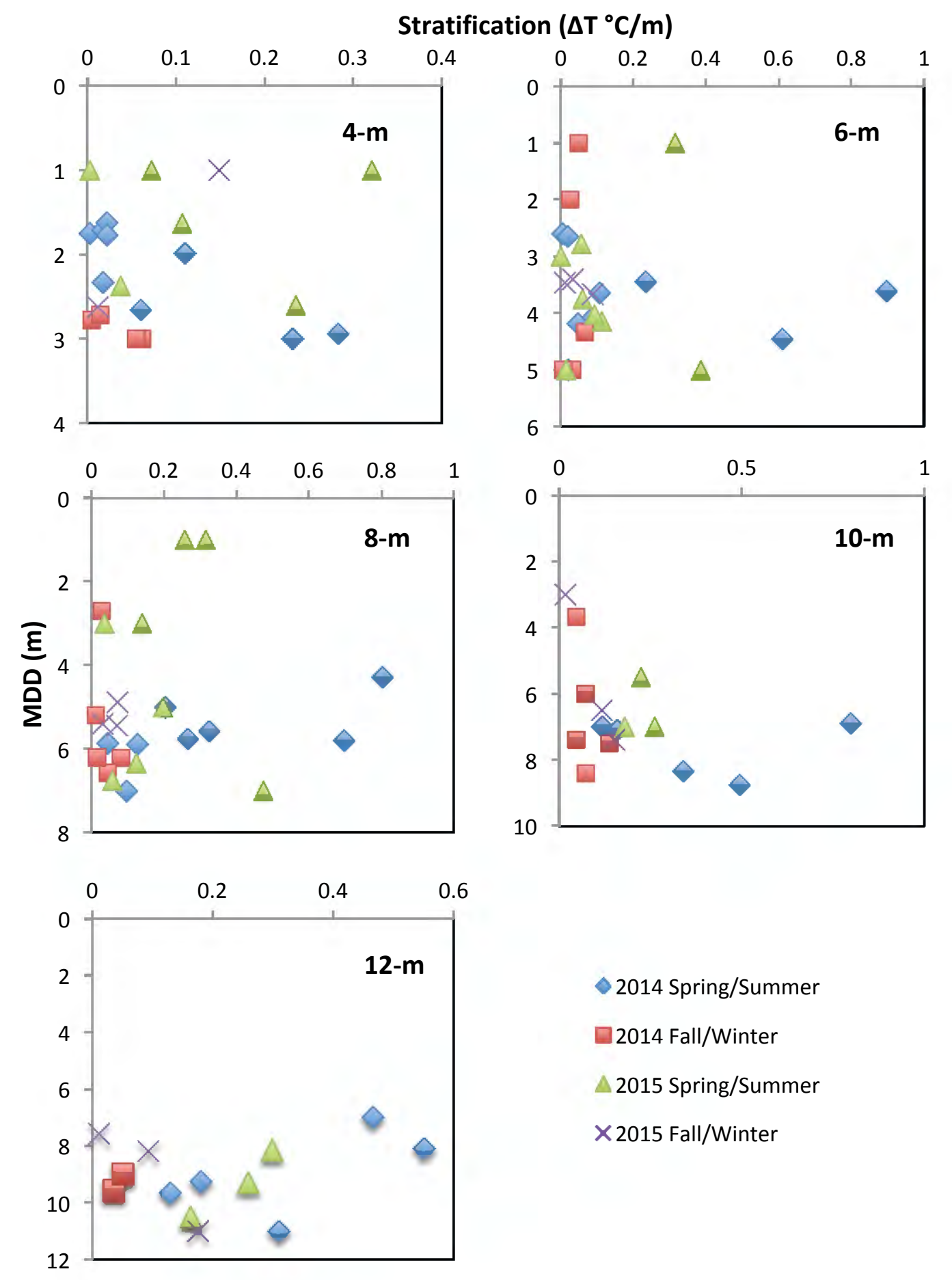


Figure B5. Mean Distance from Shore (MDS) of early-stage nauplii plotted against average cross-shore thermal stratification. $N=17$ cruises. See pg. 24 for explanation of MDS calculation and pg. 25 for explanation of cross-shore stratification calculation. 


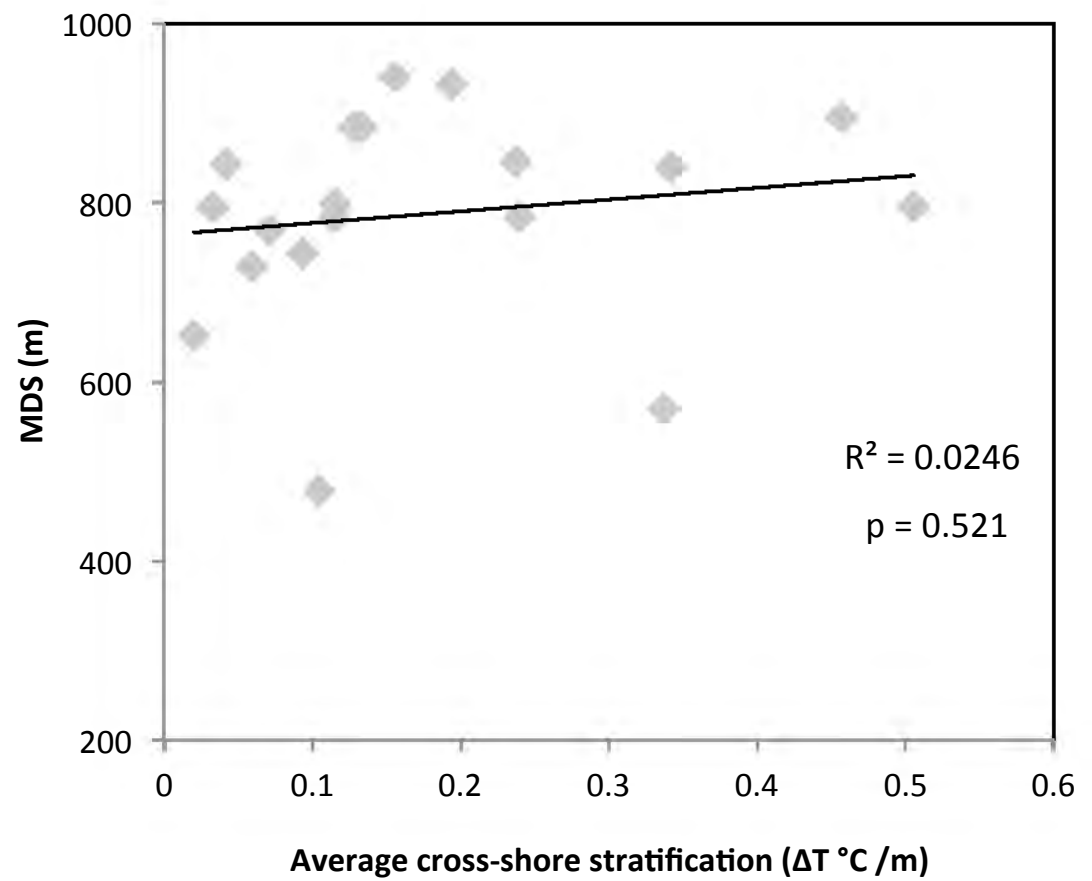


Appendix C: Current measurements, and relationships between larval

densities/distributions and currents. See pg. 25 for explanation of 24-hr average current velocity calculation for Figures C2-6.

Figure $\mathrm{C} 1$. Time series of depth-averaged alongshore (v, positive southward) and cross-shore (u, positive onshore) currents at 8-m sampling station in 2014: springsummer (A) and fall-winter (B). Black rectangles correspond with times of plankton sampling. 


\section{Date}
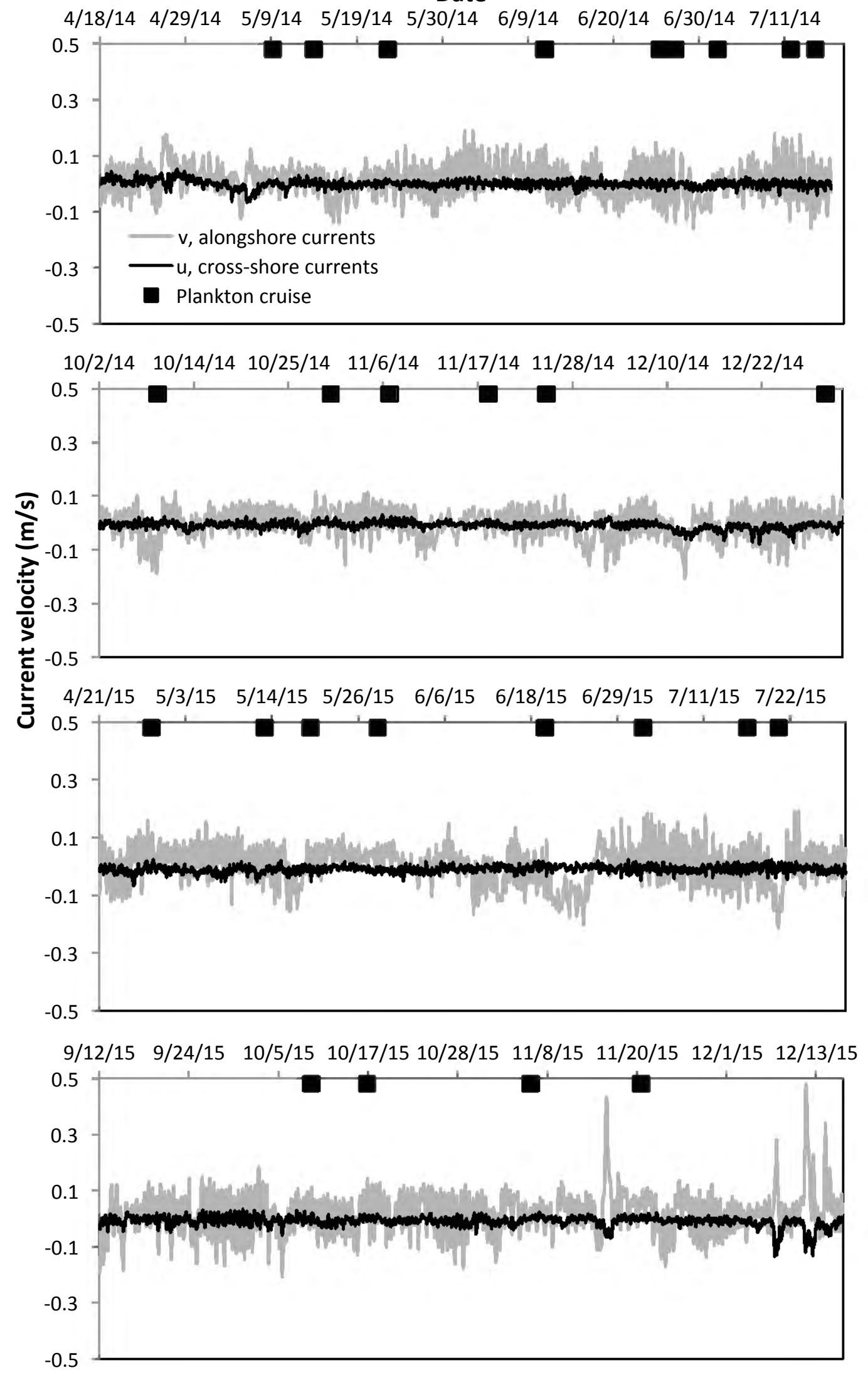
Figure C2. Average alongshore (v, positive southward) and cross-shore (u, positive onshore) currents during sampling days in 2014 and 2015. $\mathrm{N}=27$ cruises. 
Julian day starting April 1st

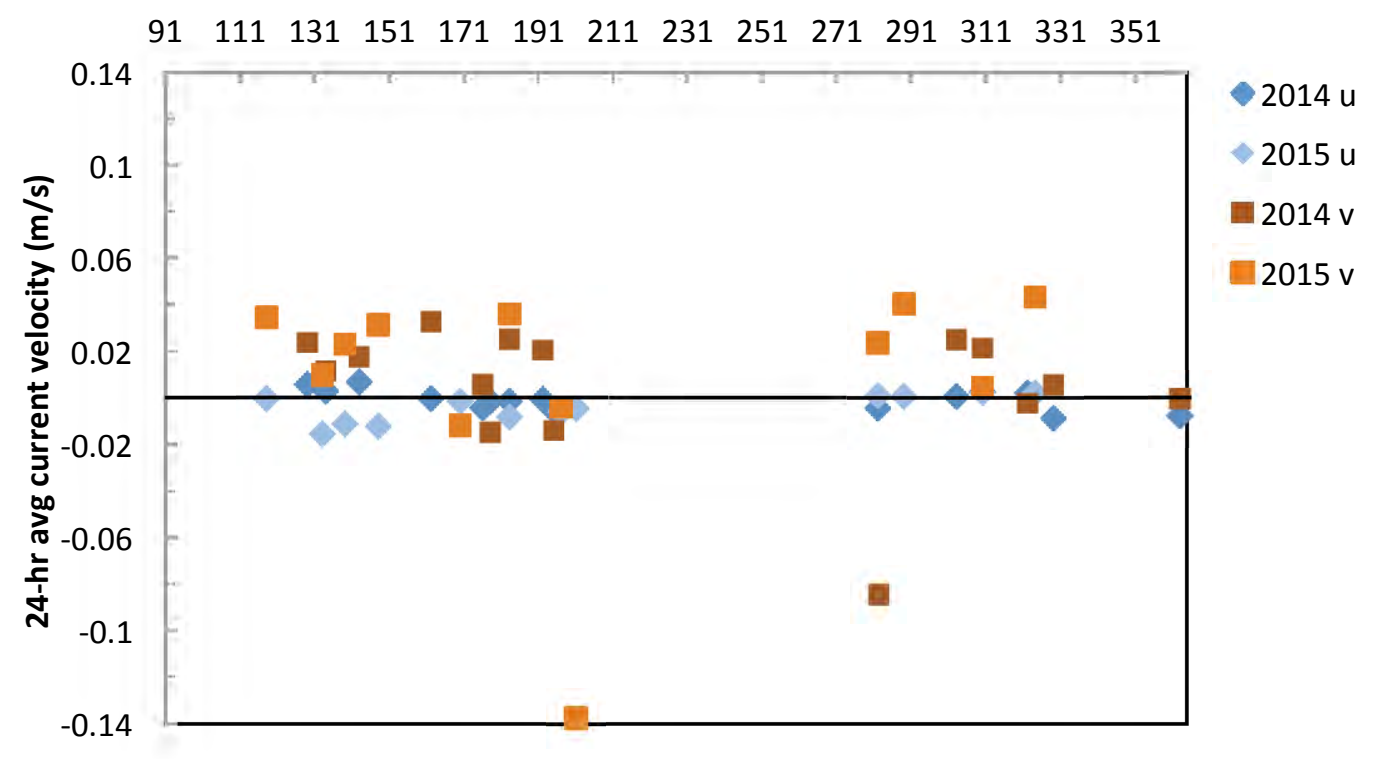


Figure C3. Larval densities plotted against currents: early-stage nauplii density vs. alongshore (A) and cross-shore (B) currents, Chthamalus fissus cyprids density vs. alongshore (C) and cross-shore (D) currents. $\mathrm{N}=27$ cruises. Note varying axes. 


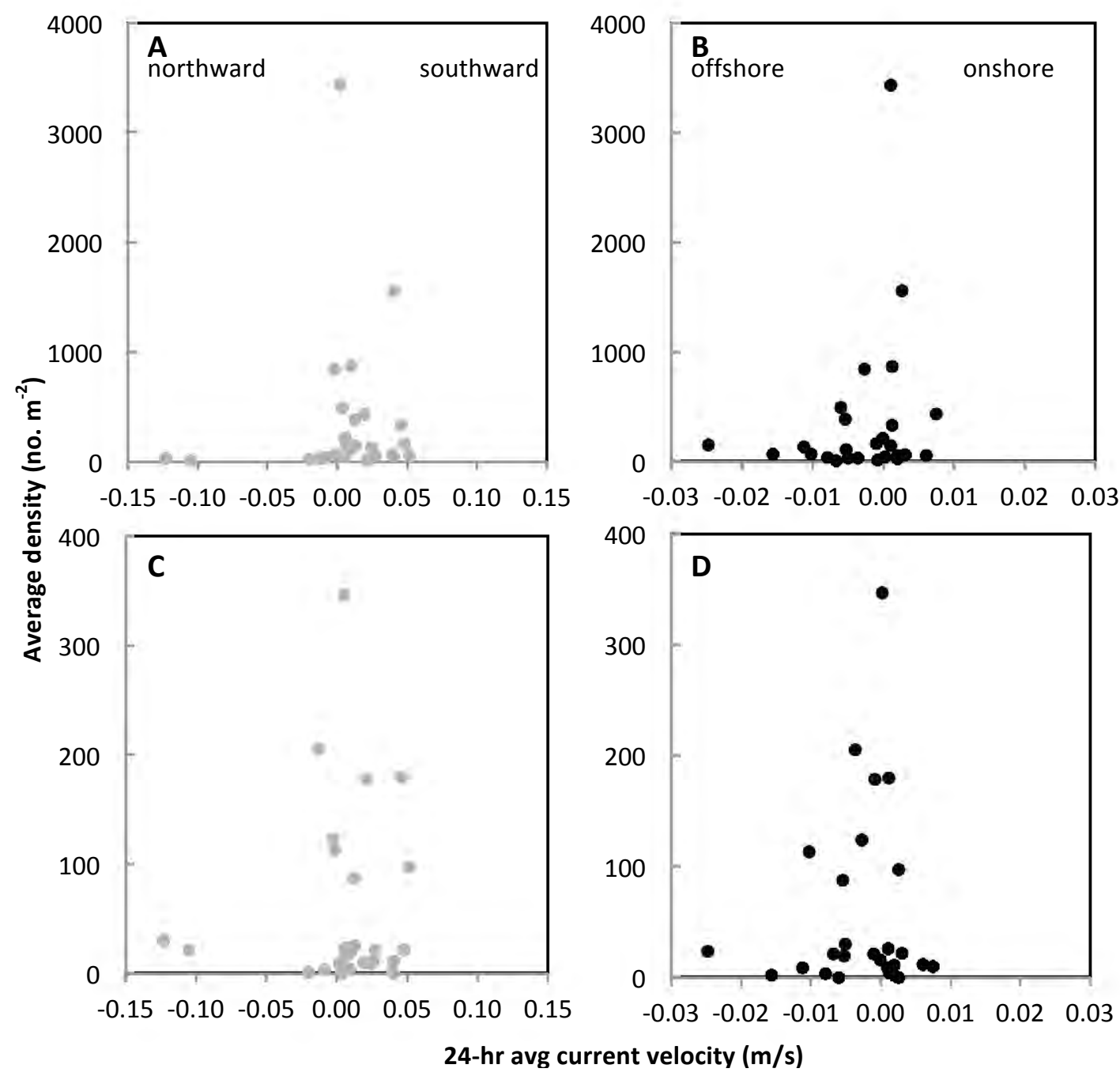


Figure C4. Larval Mean Depth Distributions (MDDs) at 8-m station plotted against currents: early-stage nauplii MDD vs. alongshore (A) and cross-shore (B) currents, Chthamalus fissus cyprids MDD vs. alongshore (C) and cross-shore (D) currents. $\mathrm{N}=27$ cruises. Note varying axes. See pg. 23 for explanation of MDD calculation. 


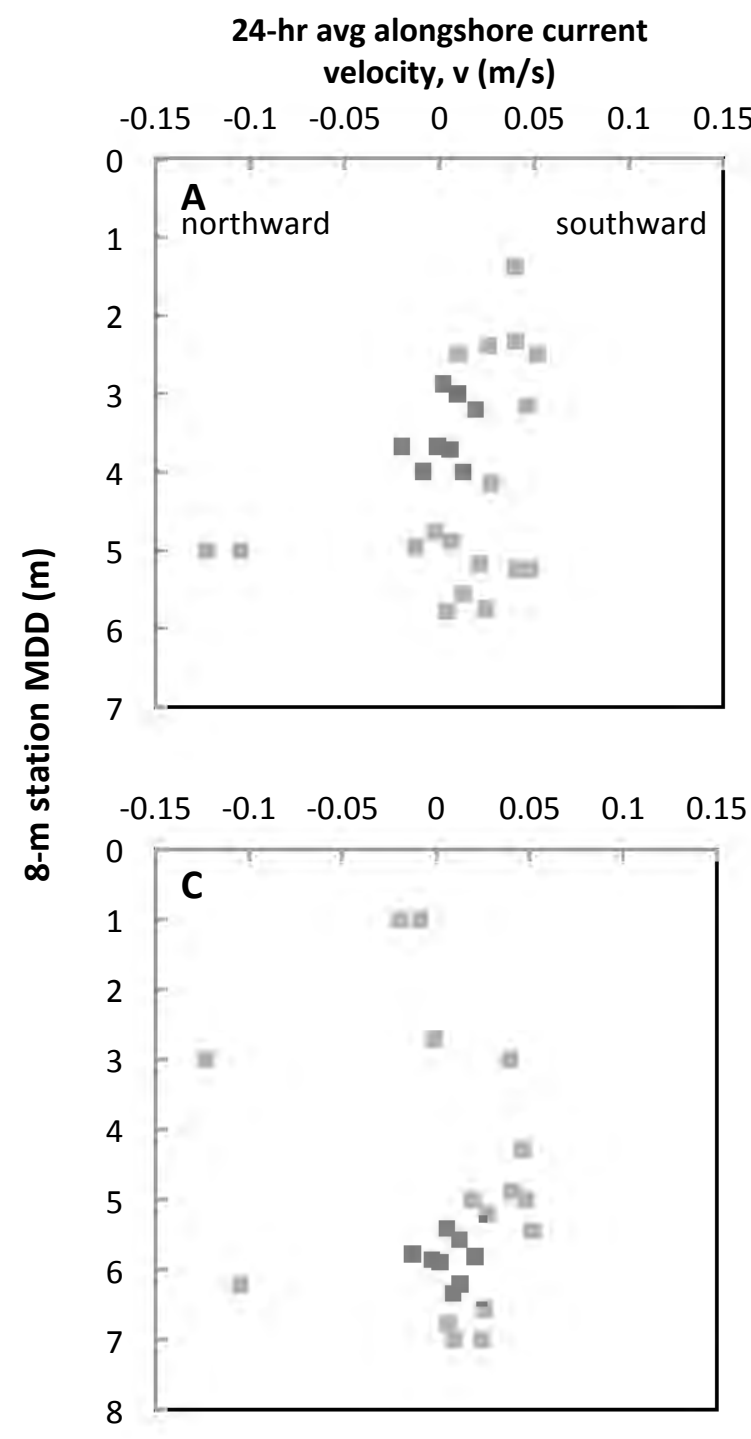

24-hr avg cross-shore current velocity, u (m/s)

$\begin{array}{lllllll}-0.03 & -0.02 & -0.01 & 0 & 0.01 & 0.02 & 0.03\end{array}$
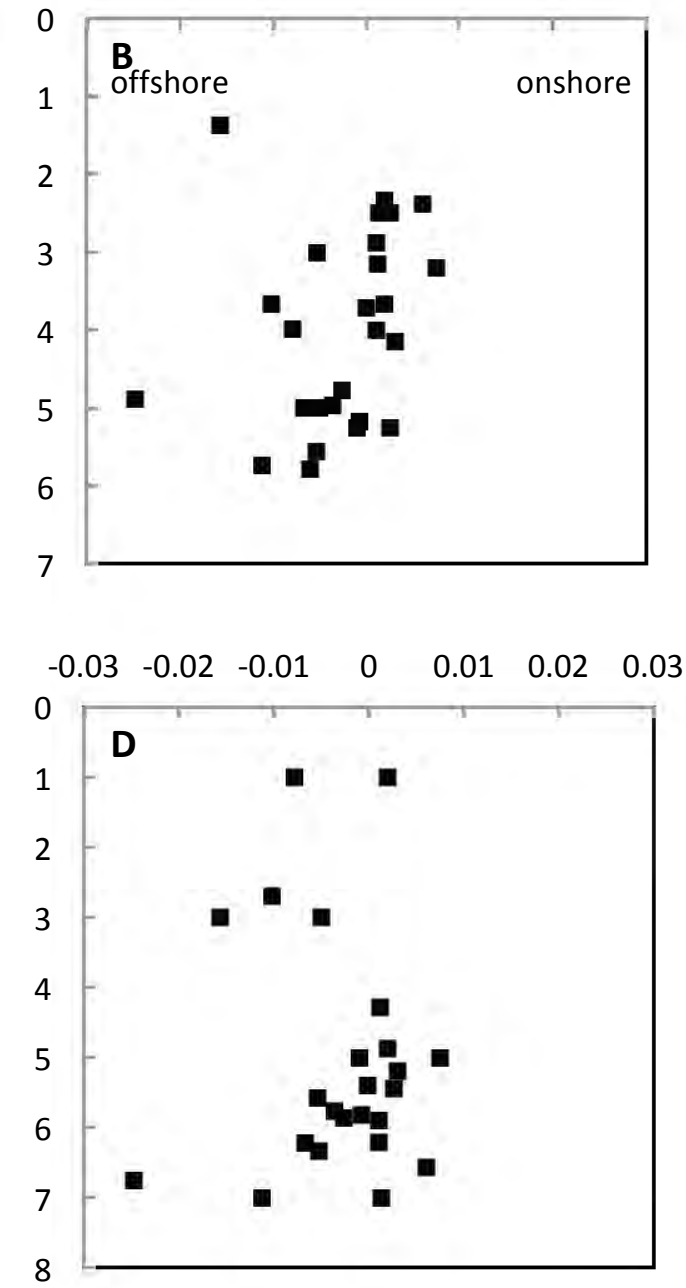
Figure C5. Larval Mean Distance from Shore (MDS) measurements plotted against currents: early-stage nauplii MDS vs. cross-shore (A) and alongshore (B) currents, Chthamalus fissus cyprids density vs. cross-shore (C) and alongshore (D) currents. $\mathrm{N}=27$ cruises. Note varying axes. See pg. 24 for explanation of MDS calculation. 

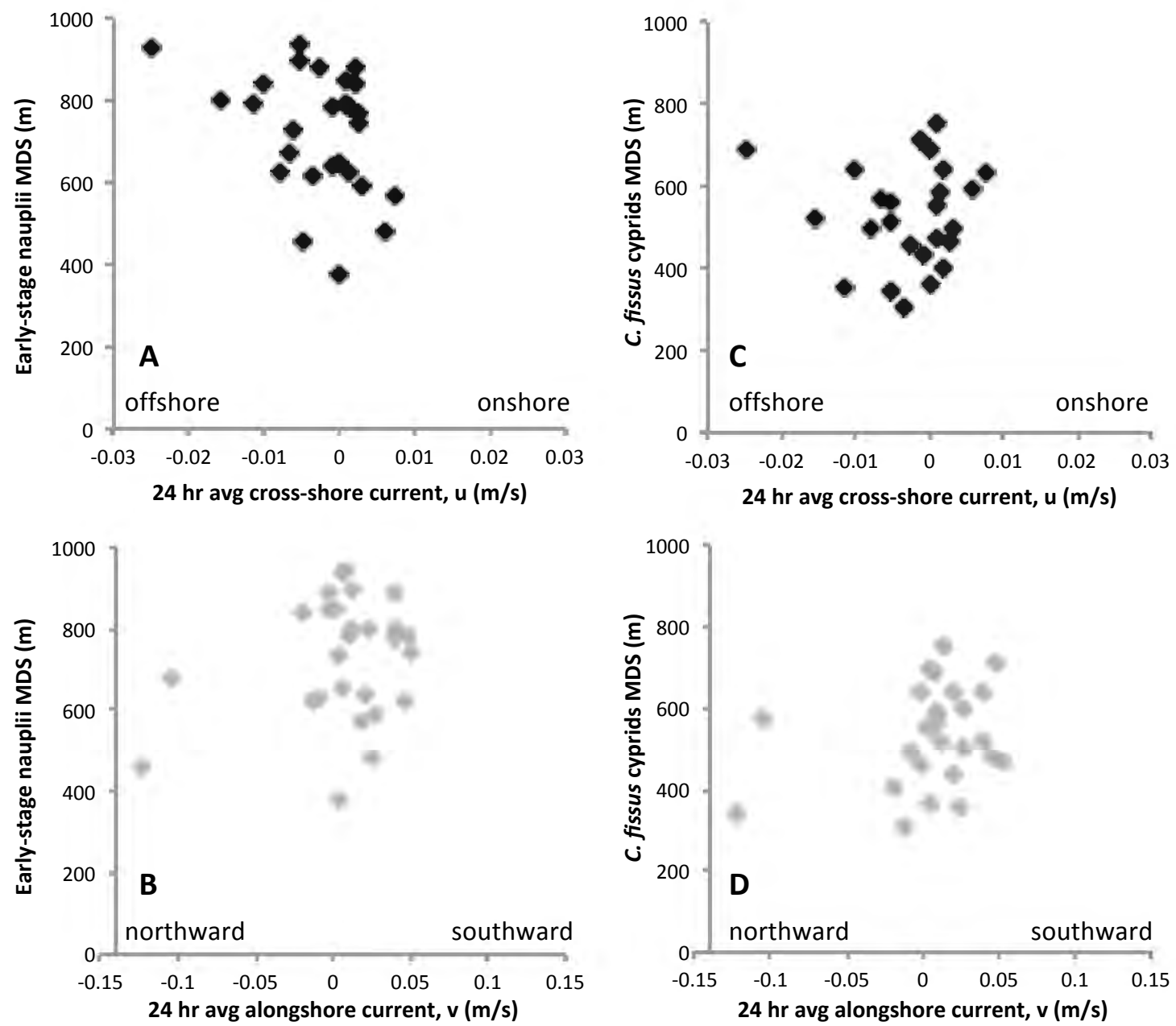
Figure C6. Constrained-Distribution Index (CDI) for Chthamalus fissus cyprids plotted against 24-hr average cross-shore (A) and alongshore (B) currents. See pg. 24 for explanation of CDI calculation. 

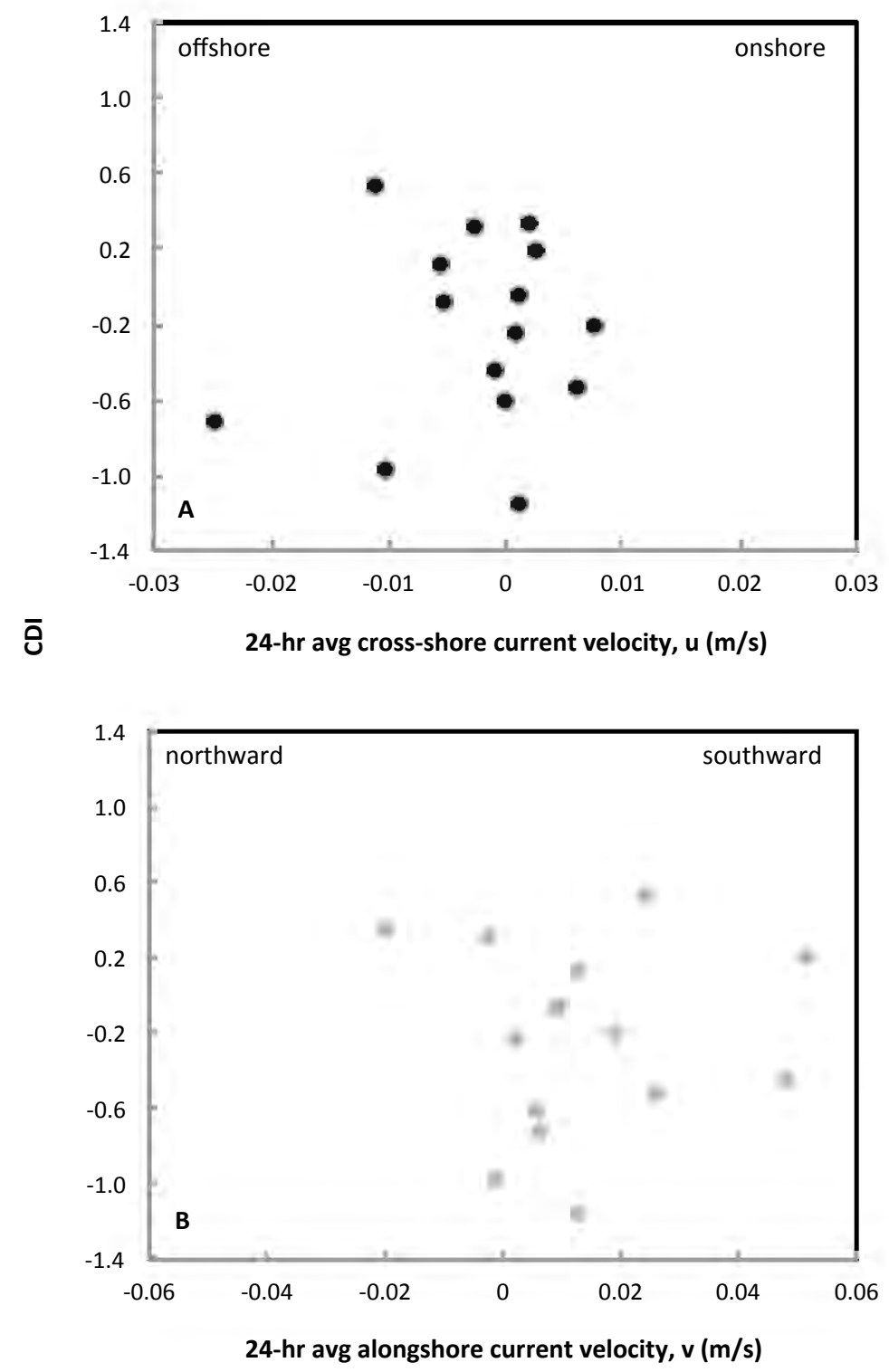
Appendix D: Significant Wave Height (SWH) measurements, and relationships between larval densities/distributions and SWH. See pg. 26 for explanation of 24hr average SWH calculation for Figures D2-6.

Figure D1. Time series of Significant Wave Height (SWH) during 2014 springsummer (A), 2014 fall-winter (B), 2015 spring-summer (C), and 2015 fall-winter (D) sampling periods. Gray rectangles correspond with times of plankton sampling. 

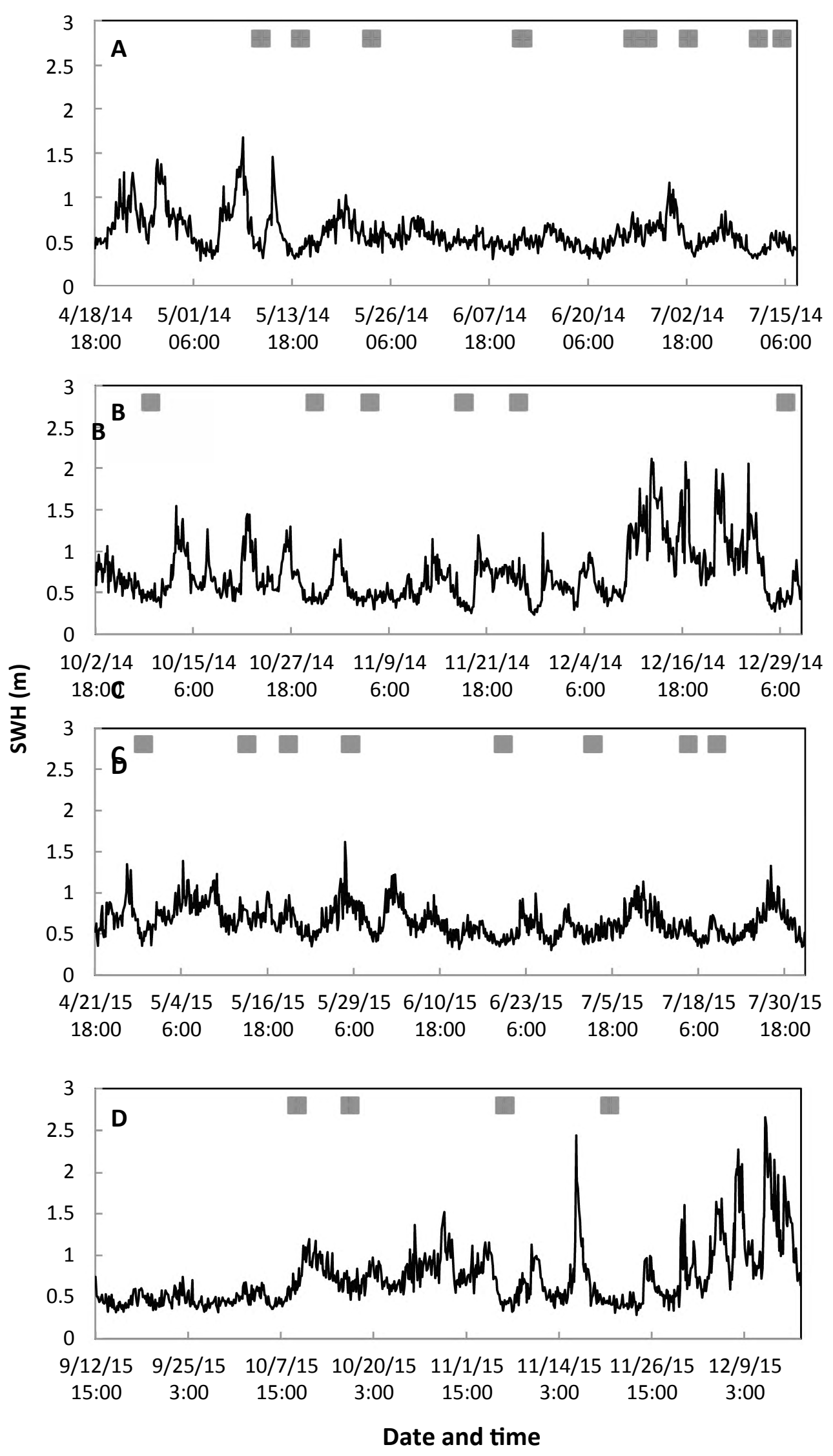
Figure D2. Average Significant Wave Height (SWH) during sampling days in 2014 and 2015. $\mathrm{N}=27$ cruises. 


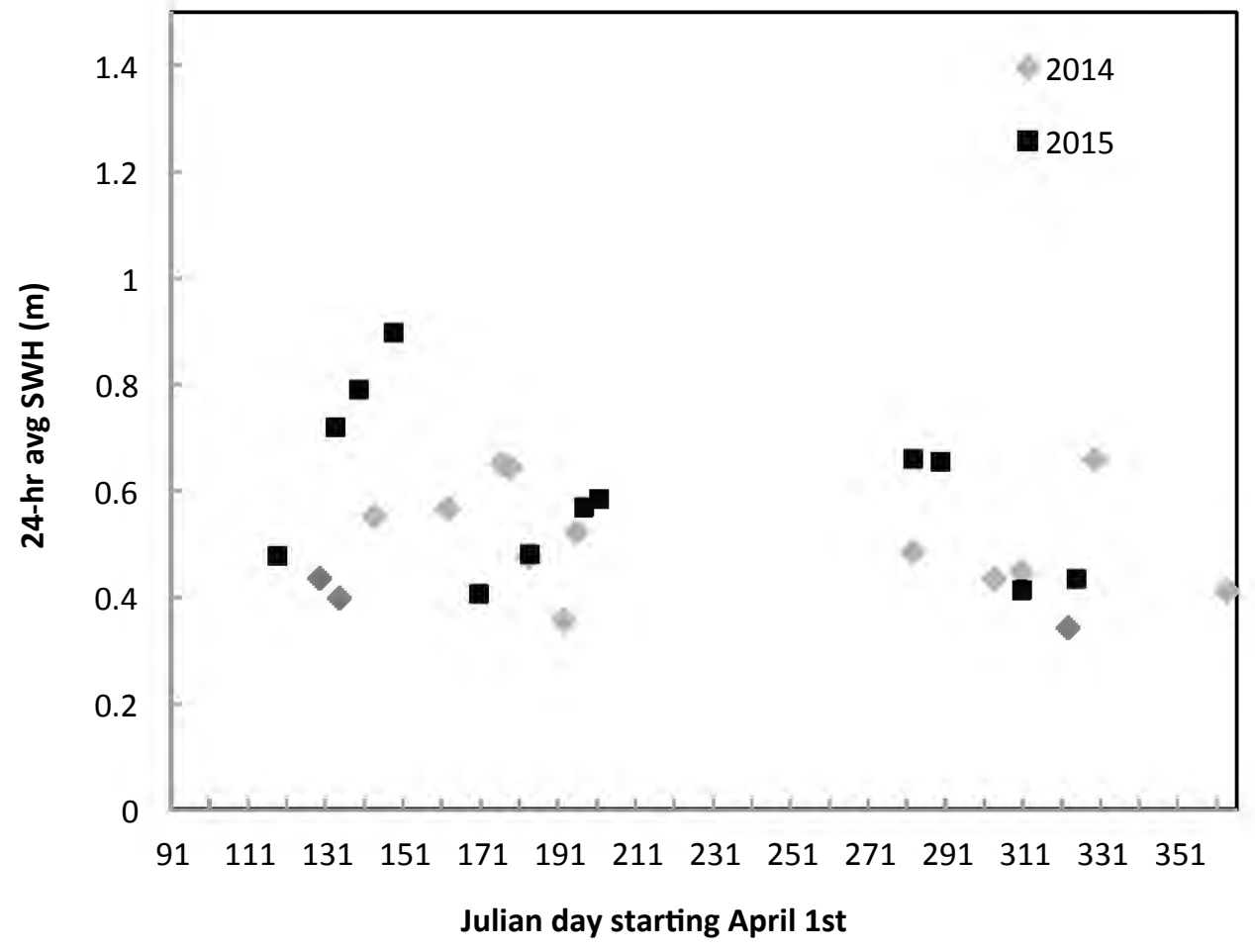


Figure D3. Early-stage nauplii (A) and Chthamalus fissus cyprids (B) densities plotted against 24-hr average Significant Wave Height (SWH) for all sampling periods during 2014 and 2015 ( $\mathrm{SS}=$ spring-summer, $\mathrm{FW}=$ fall-winter). $\mathrm{N}=27$ cruises. 


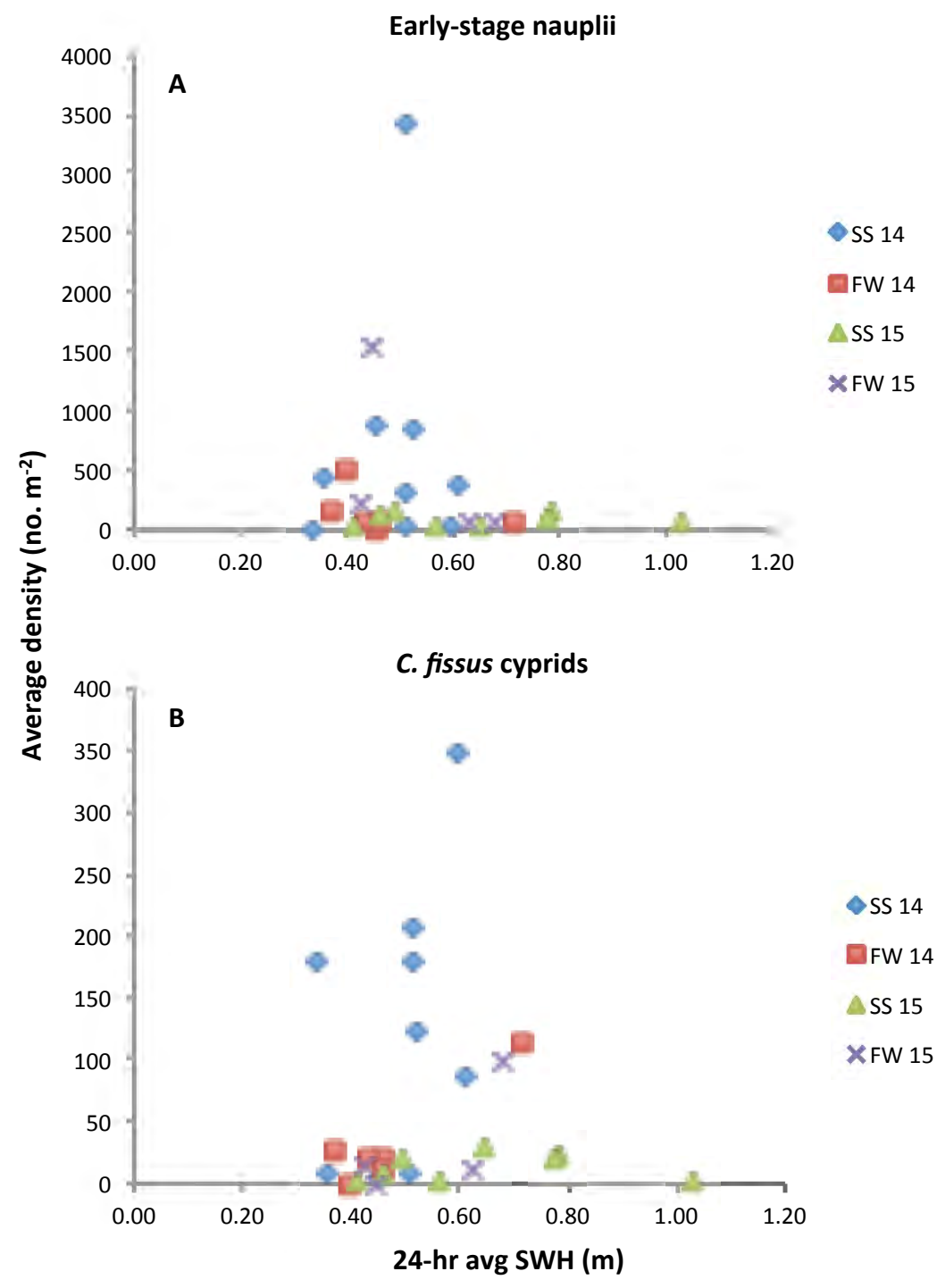


Figure D4. Mean Depth Distributions (MDDs) at 8-m station of early-stage nauplii (A) and Chthamalus fissus cyprids (B) plotted against 24-hr average Significant Wave Height (SWH) for all sampling periods during 2014 and 2015 ( $\mathrm{SS}=$ spring-summer, $\mathrm{FW}=$ fall-winter). $\mathrm{N}=27$ cruises. See pg. 23 for explanation of MDD calculation. 


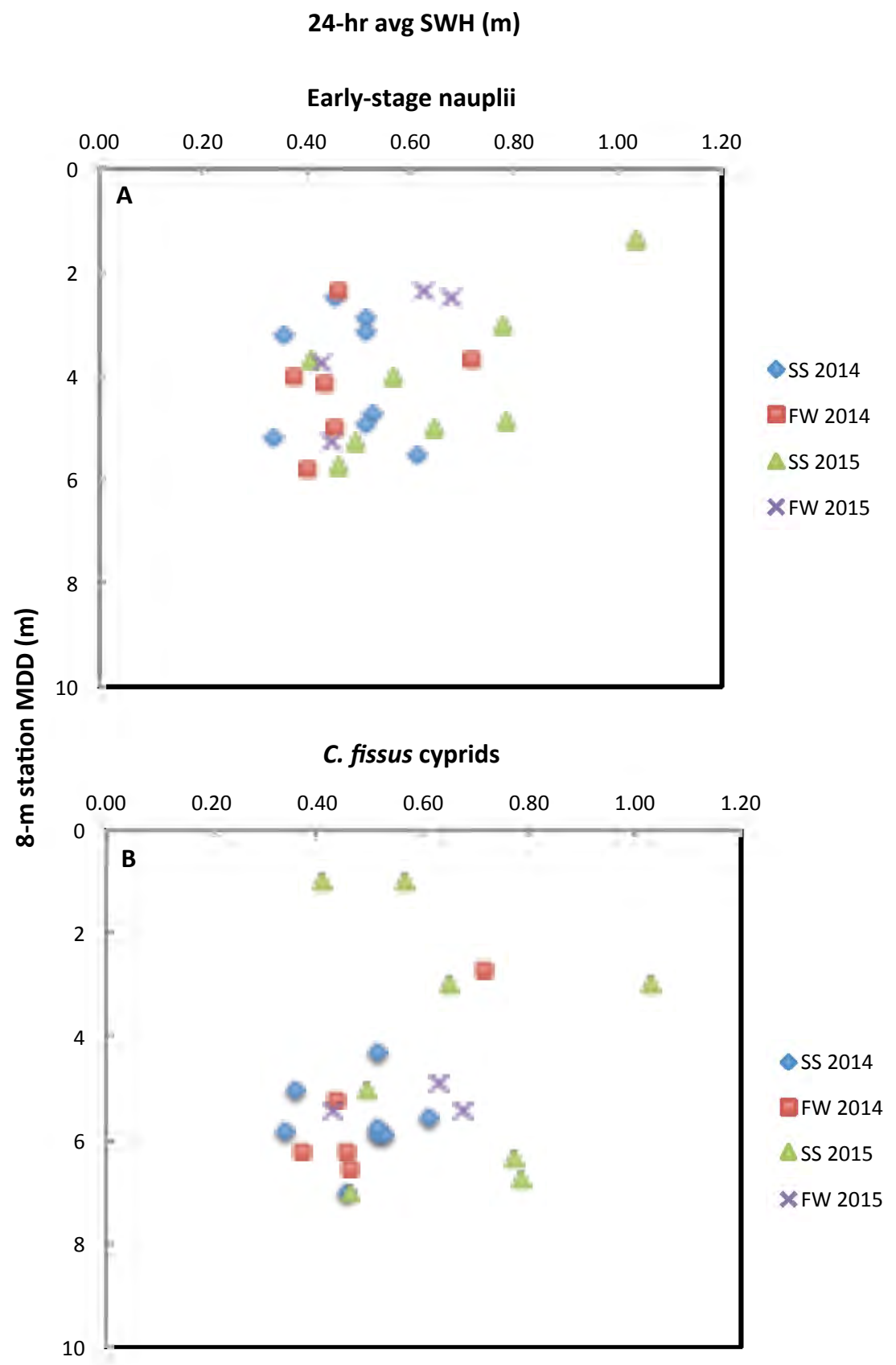


Figure D5. Mean Distance from Shore (MDS) of early-stage nauplii (A) and Chthamalus fissus cyprids (B) plotted against 24-hr average Significant Wave Height $(\mathrm{SWH}) . \mathrm{N}=27$ cruises. See pg. 24 for explanation of MDS calculation. 

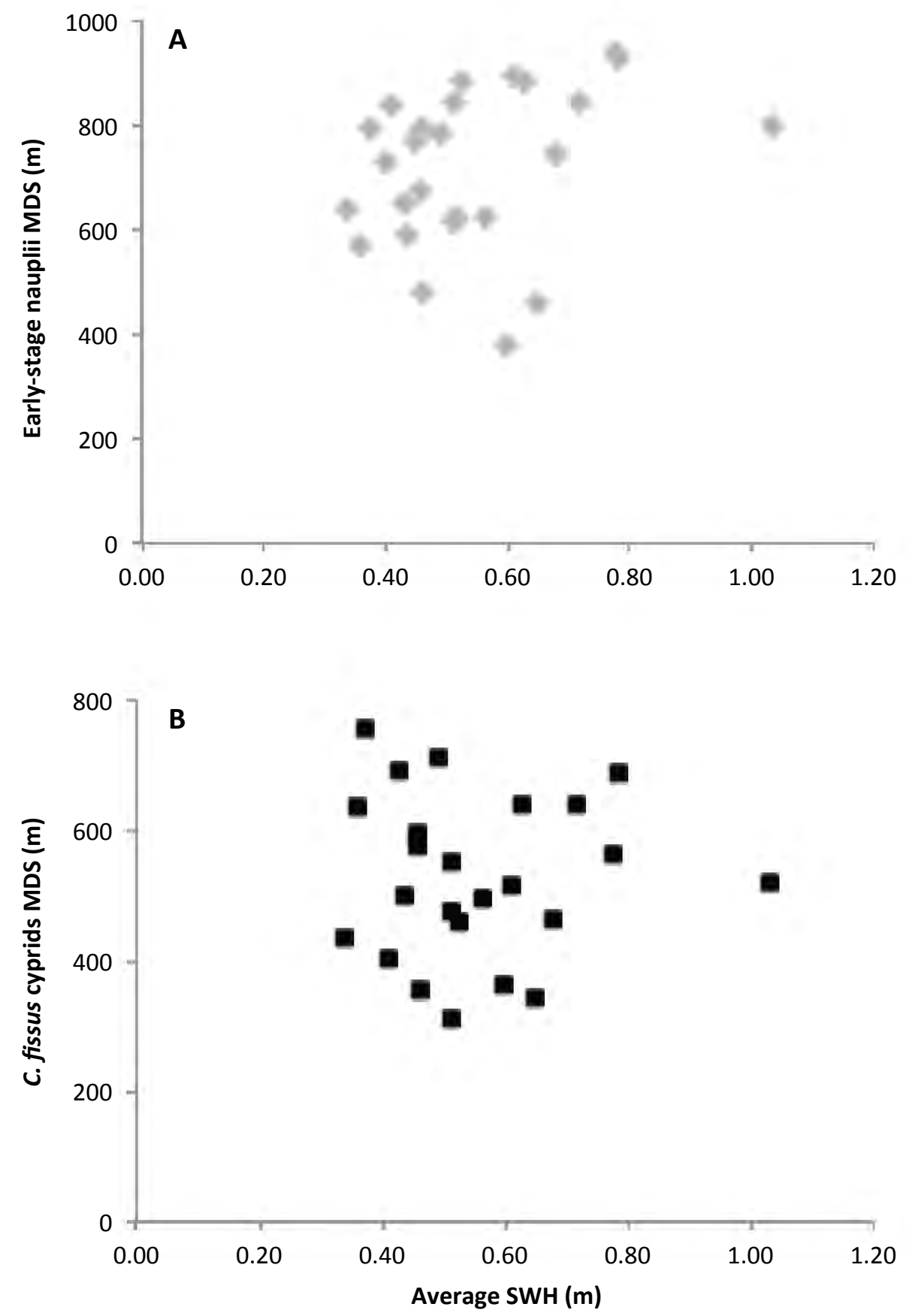
Figure D6. Constrained-Distribution Index (CDI) for Chthamalus fissus cyprids plotted against 24-hr average Significant Wave Height (SWH). N = 17 cruises. See pg. 24 for explanation of CDI calculation. 


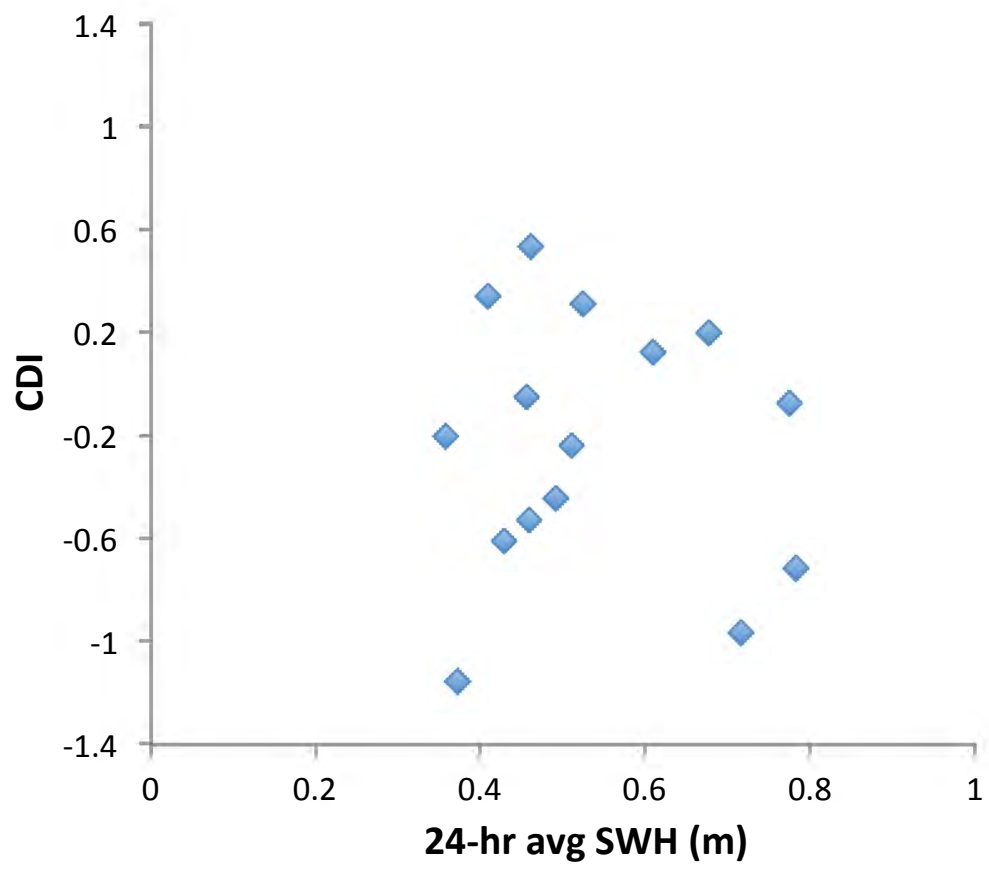


Appendix E: Larval densities and Mean Depth Distributions (MDDs) at each station during all cruises separated by stage, and by species for cyprids.

Figure E1. Densities of early- and late- stage nauplii at each station during all cruise dates in $2014.5 / 23 / 14$ is lightly shaded to indicate increased y-axis. 


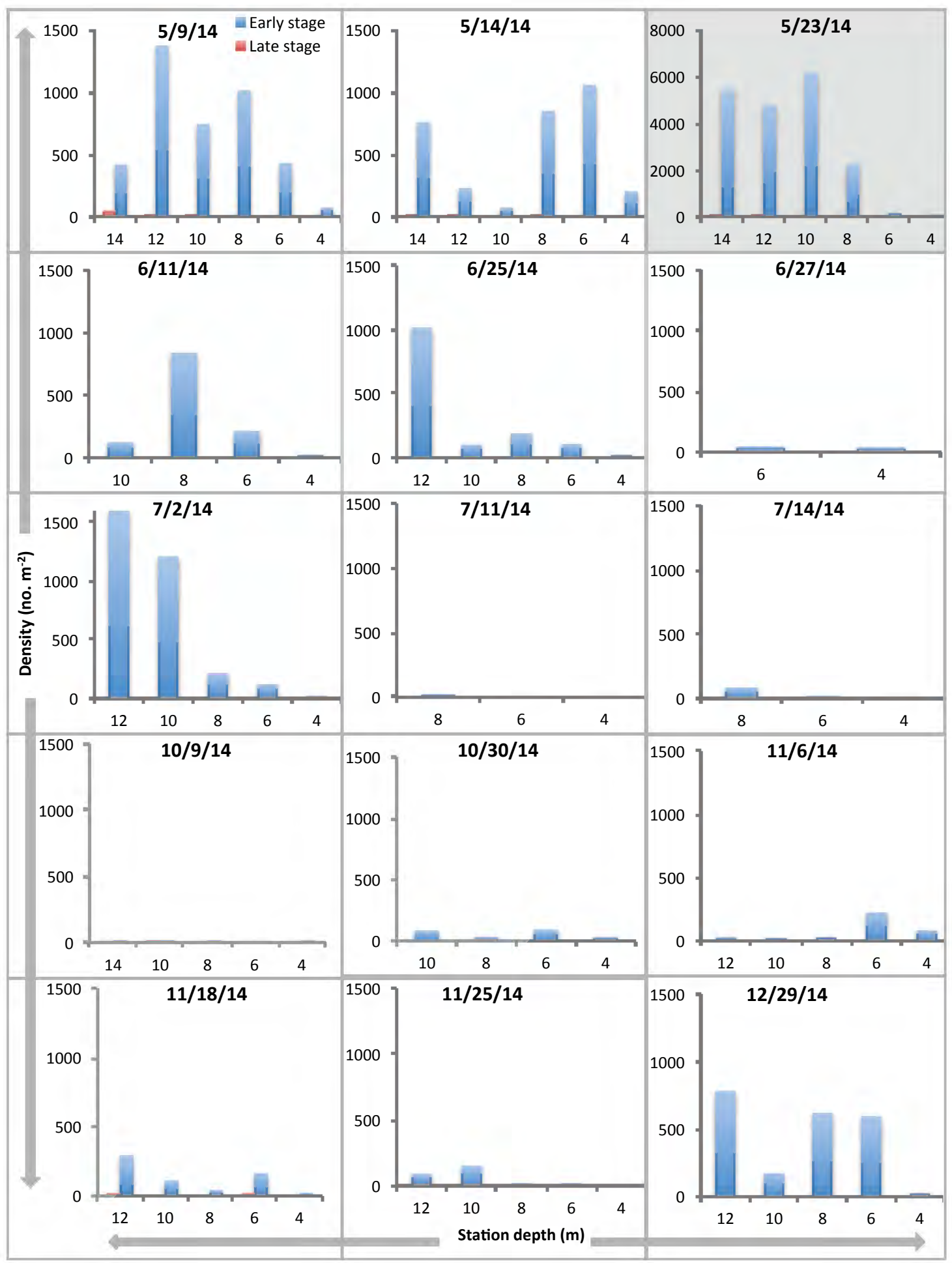


Figure E2. Mean Depth Distributions (MDDs) of early- and late- stage nauplii at each station during all cruise dates in 2014. 


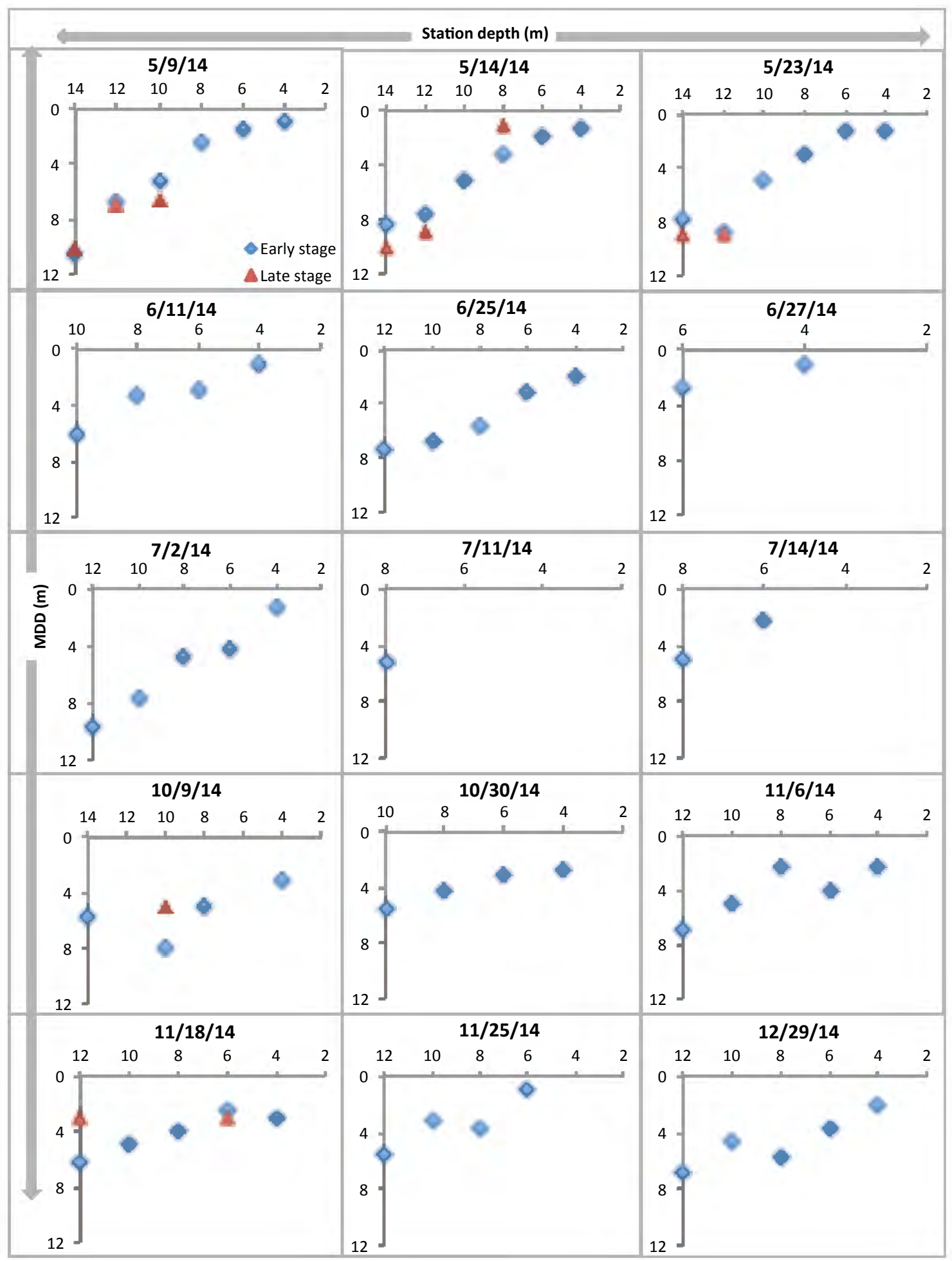


Figure E3. Densities of Chthamalus fissus cyprids at each station during all cruise dates in 2014. 


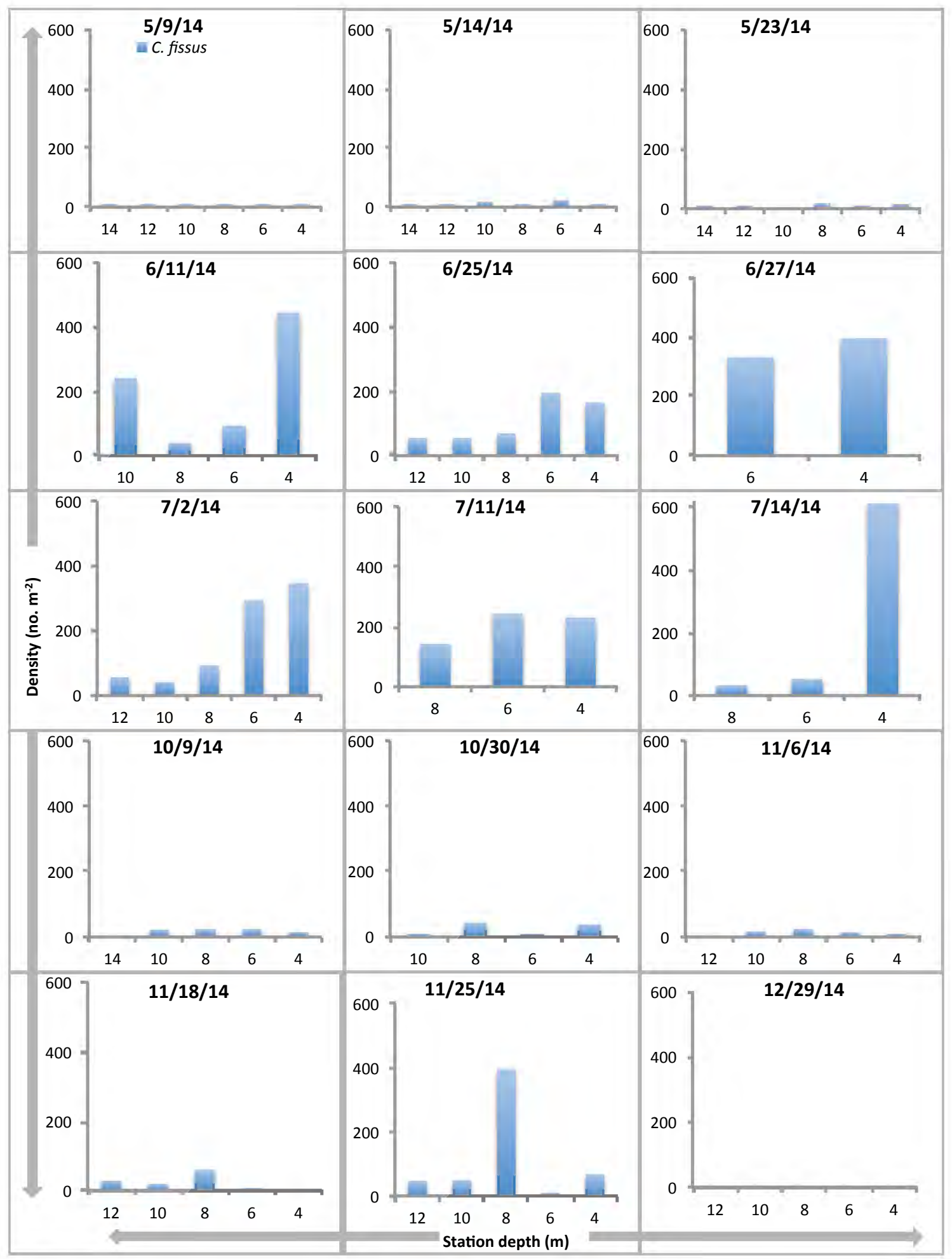


Figure E4. Densities of Balanus glandula cyprids at each station during all cruise dates in 2014. 


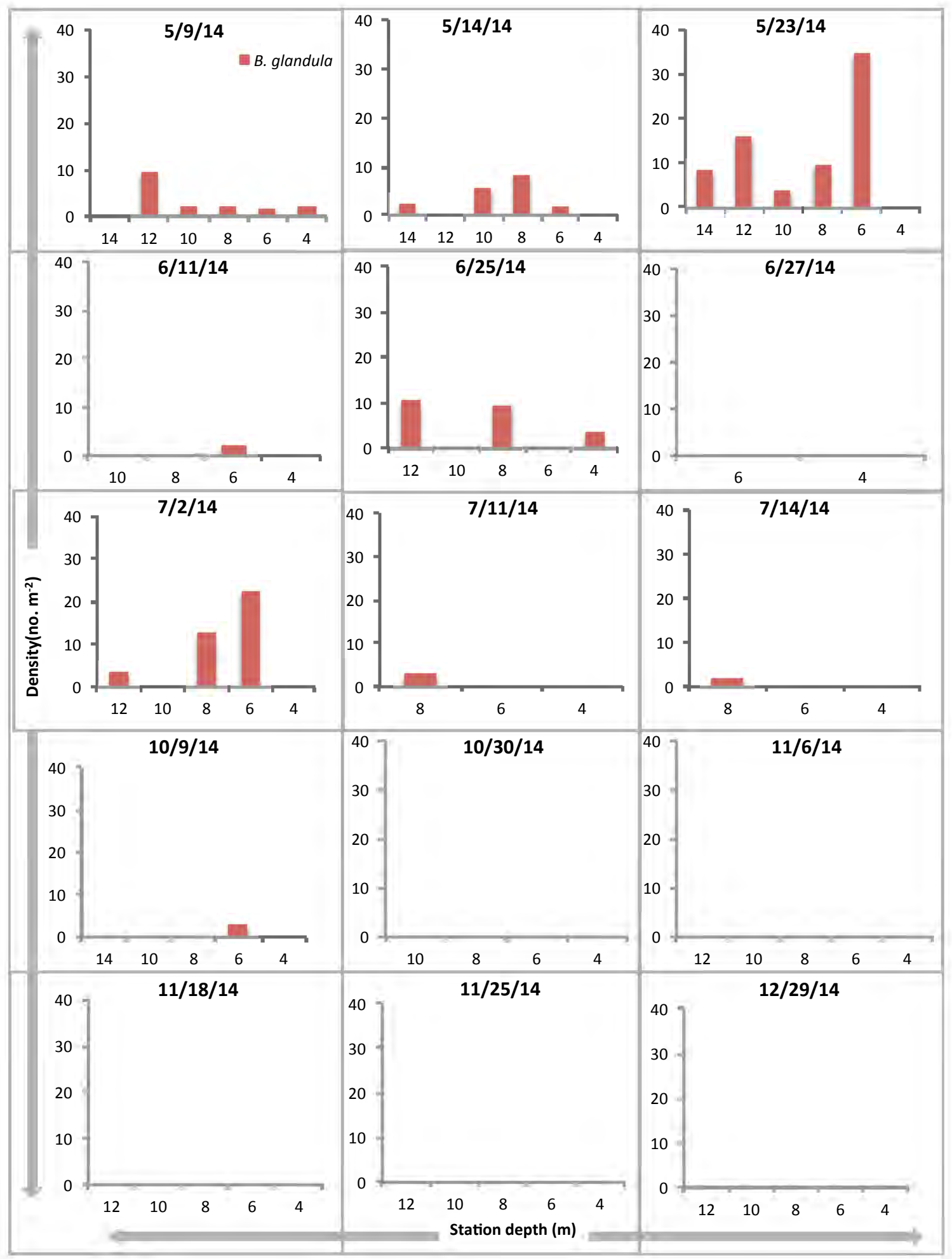


Figure E5. Densities of Pollicipes polymerus cyprids at each station during all cruise dates in 2014. 


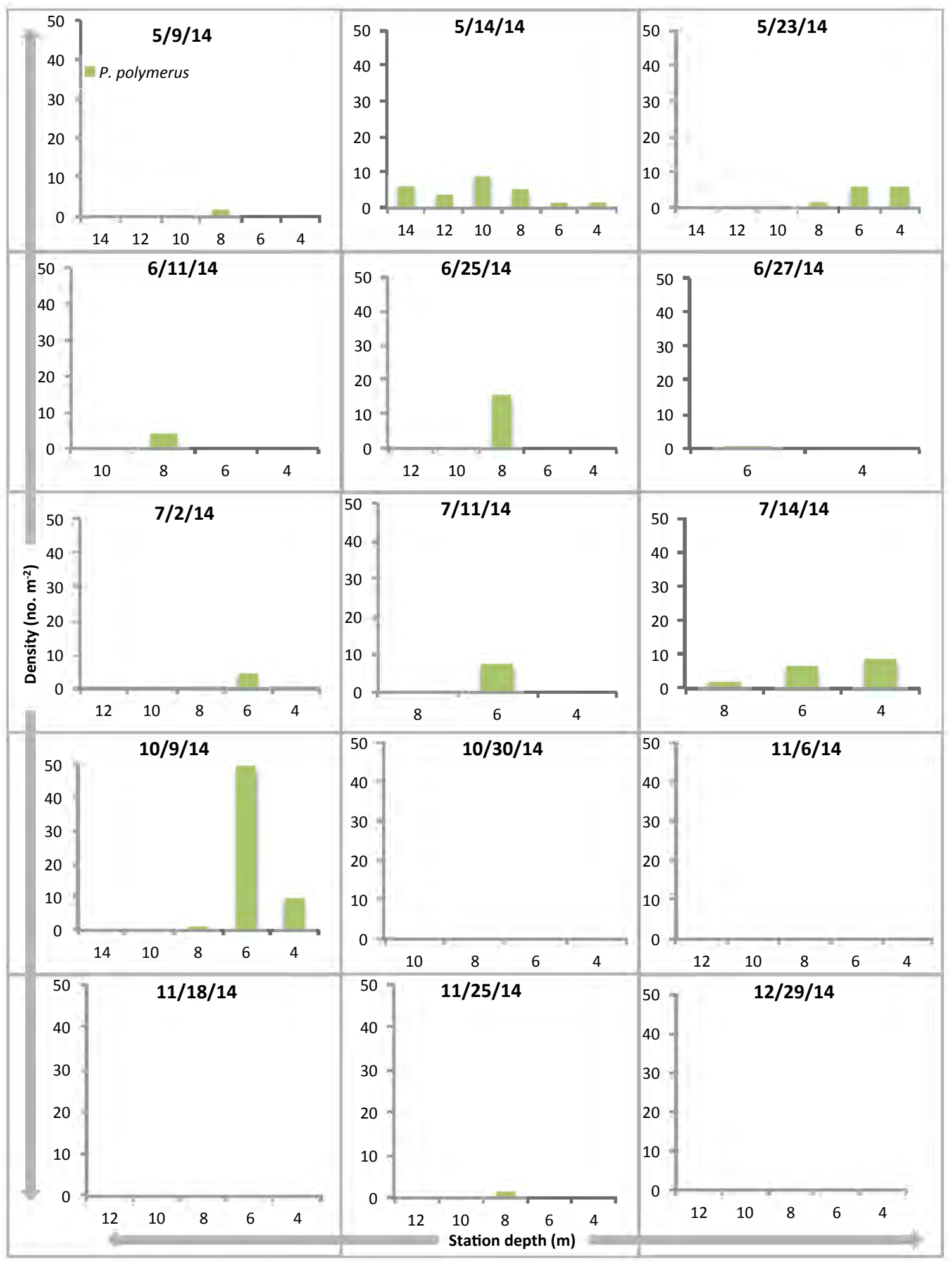


Figure E6. Densities of Tetraclita rubescens cyprids at each station during all cruise dates. 


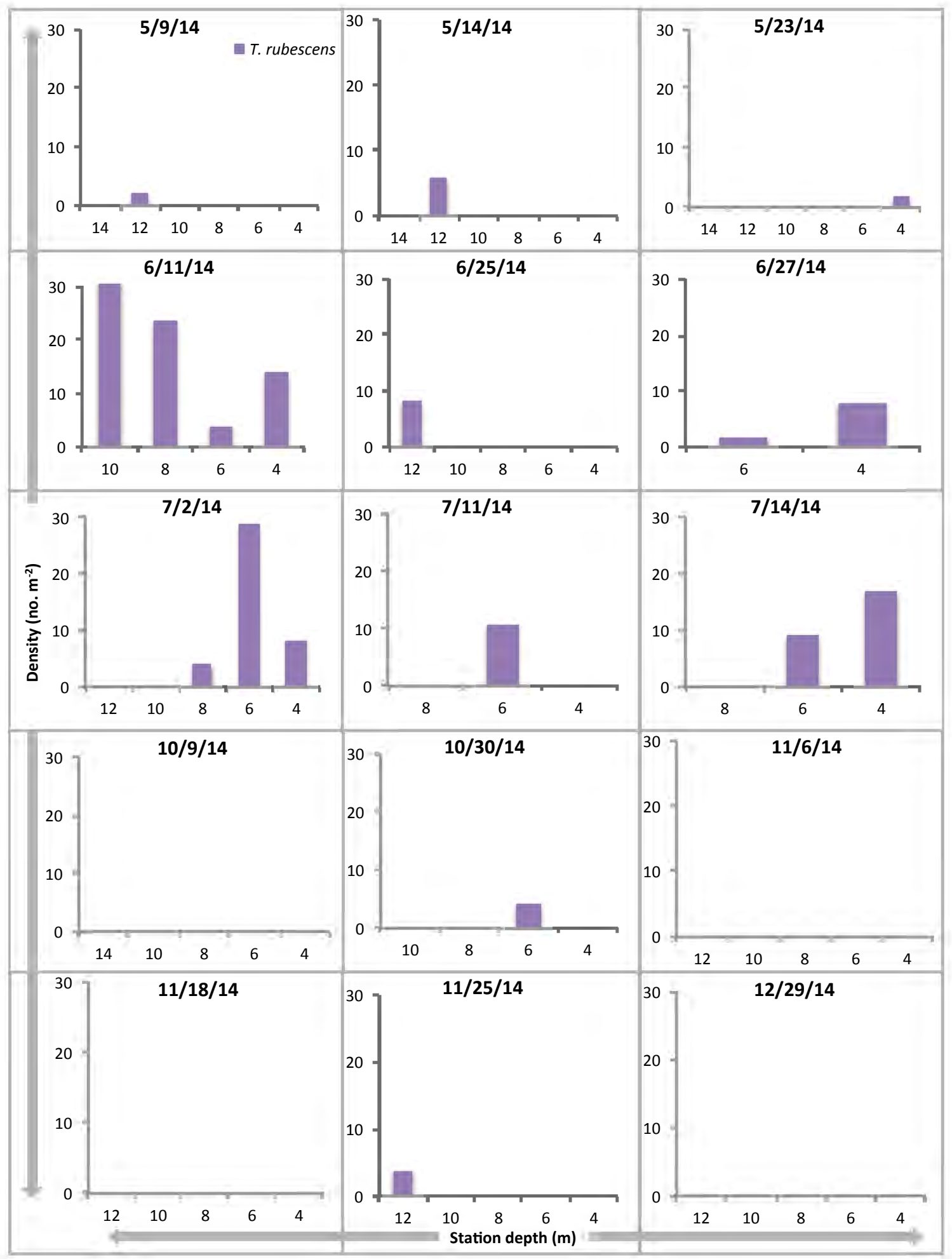


Figure E7. Densities of Megabalanus californicus cyprids at each station during all cruise dates in 2014 . 


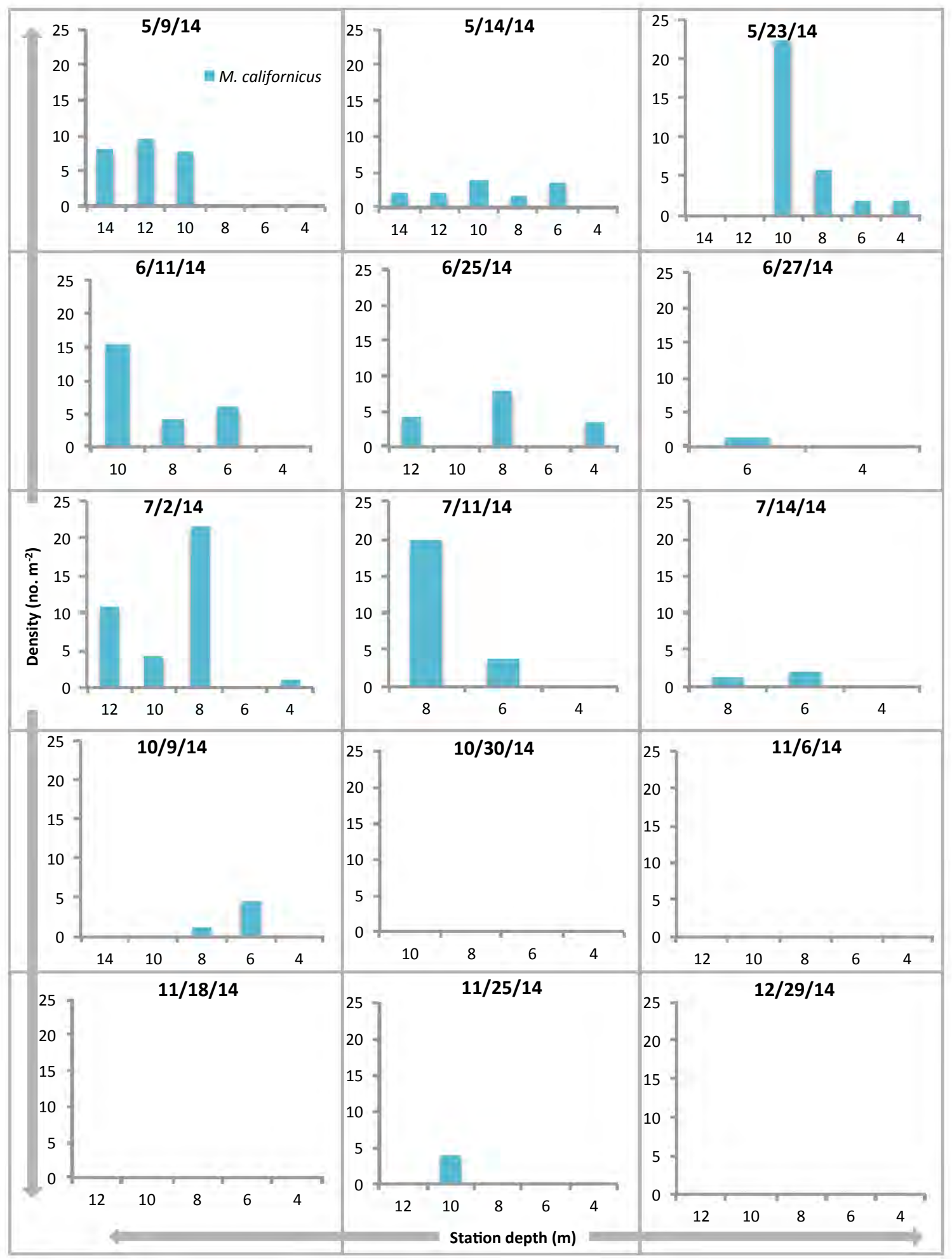


Figure. E8. Densities of Balanus trigonus cyprids at each station during all cruise dates in 2014. 


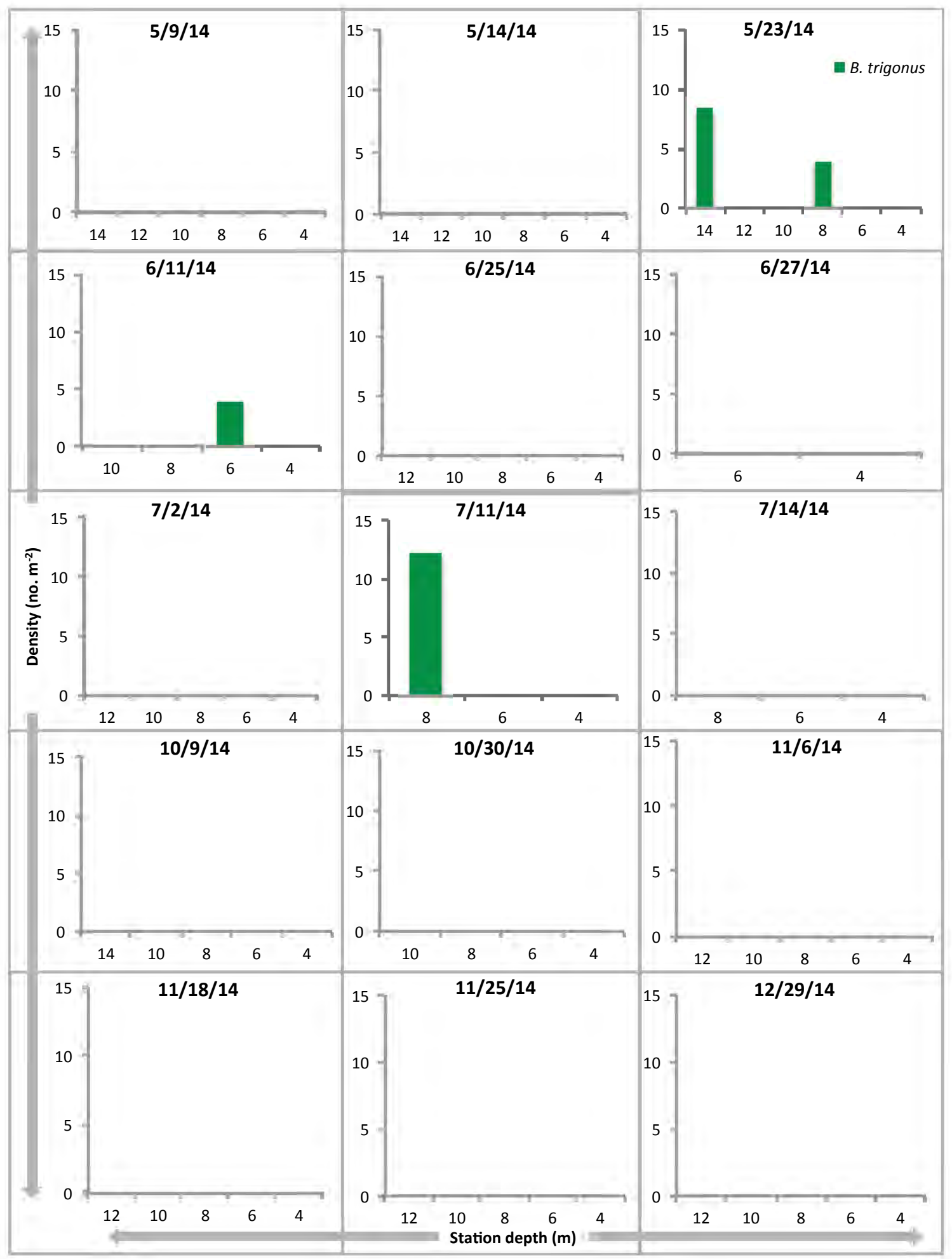


Figure E9. Mean Depth Distributions (MDDs) of Chthamalus fissus cyprids at each station during all cruise dates in 2014. 


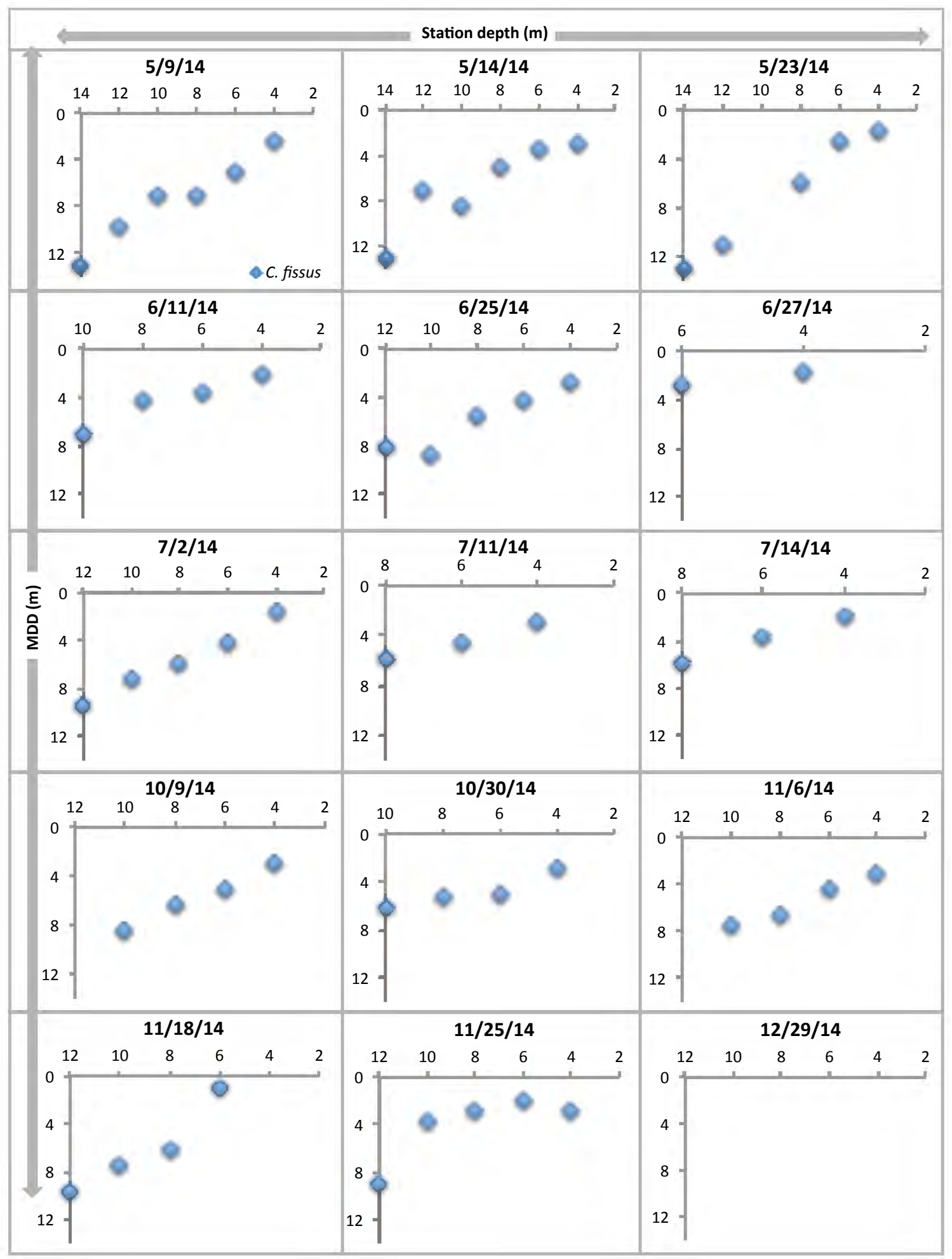


Figure E10. Mean Depth Distributions (MDDs) of Balanus glandula cyprids at each station during all cruise dates in 2014. 


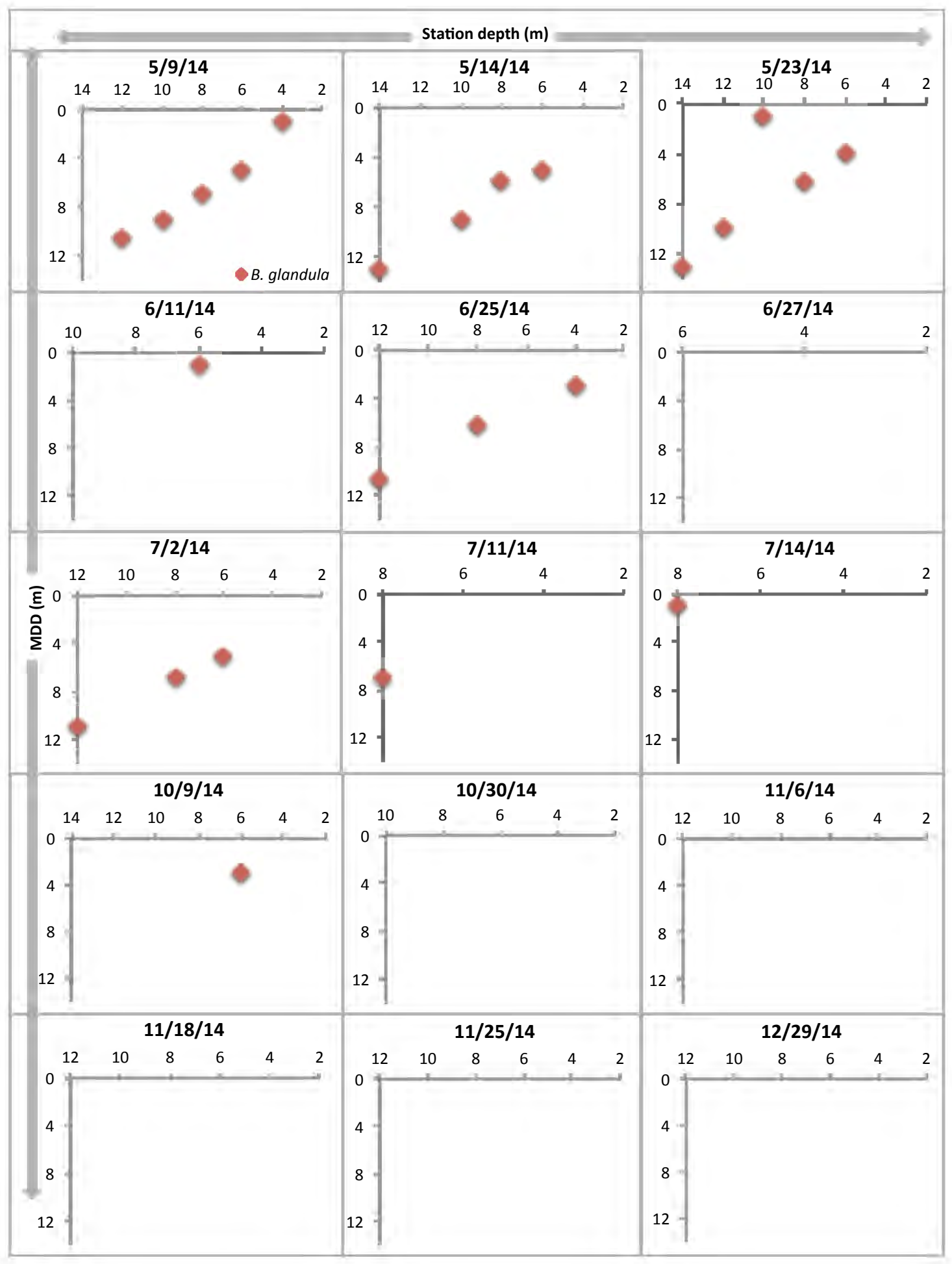


Figure E11. Mean Depth Distributions (MDDs) of Pollicipes polymerus cyprids at each station during all cruise dates in 2014. 


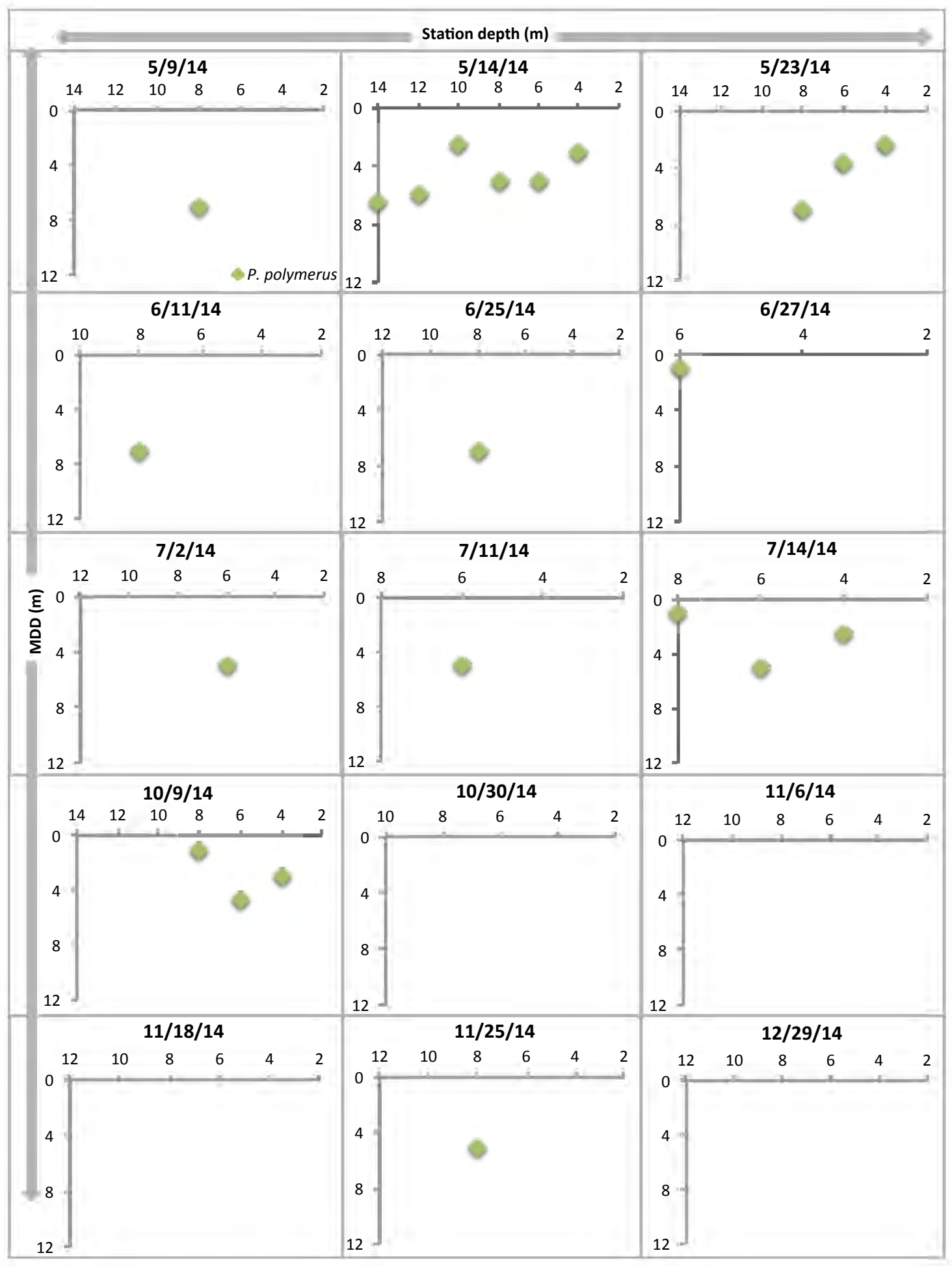


Figure E12. Mean Depth Distributions (MDDs) of Tetraclita rubescens cyprids at each station during all cruise dates in 2014. 


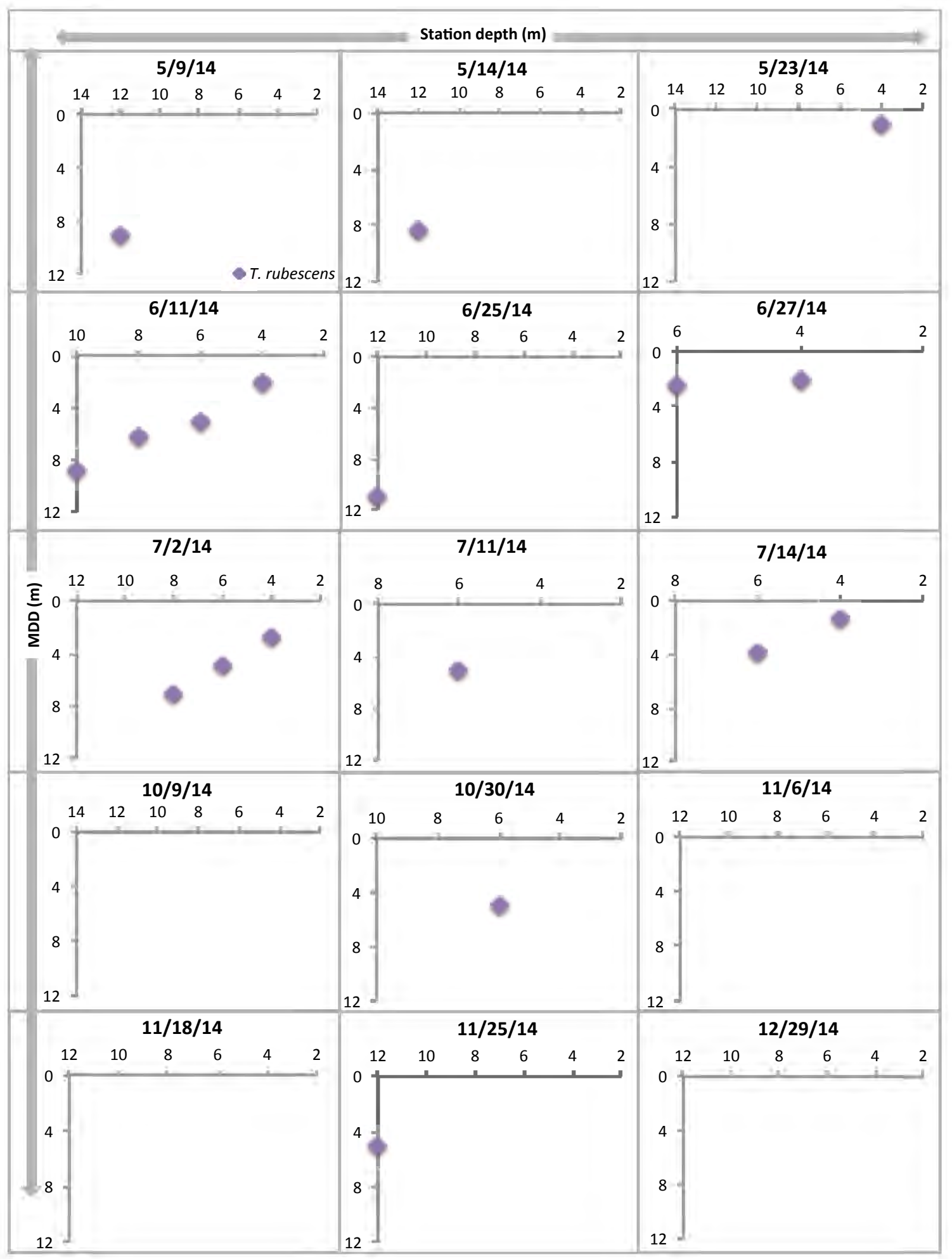


Figure E13. Mean Depth Distributions (MDDs) of Megabalanus californicus cyprids at each station during all cruise dates in 2014. 


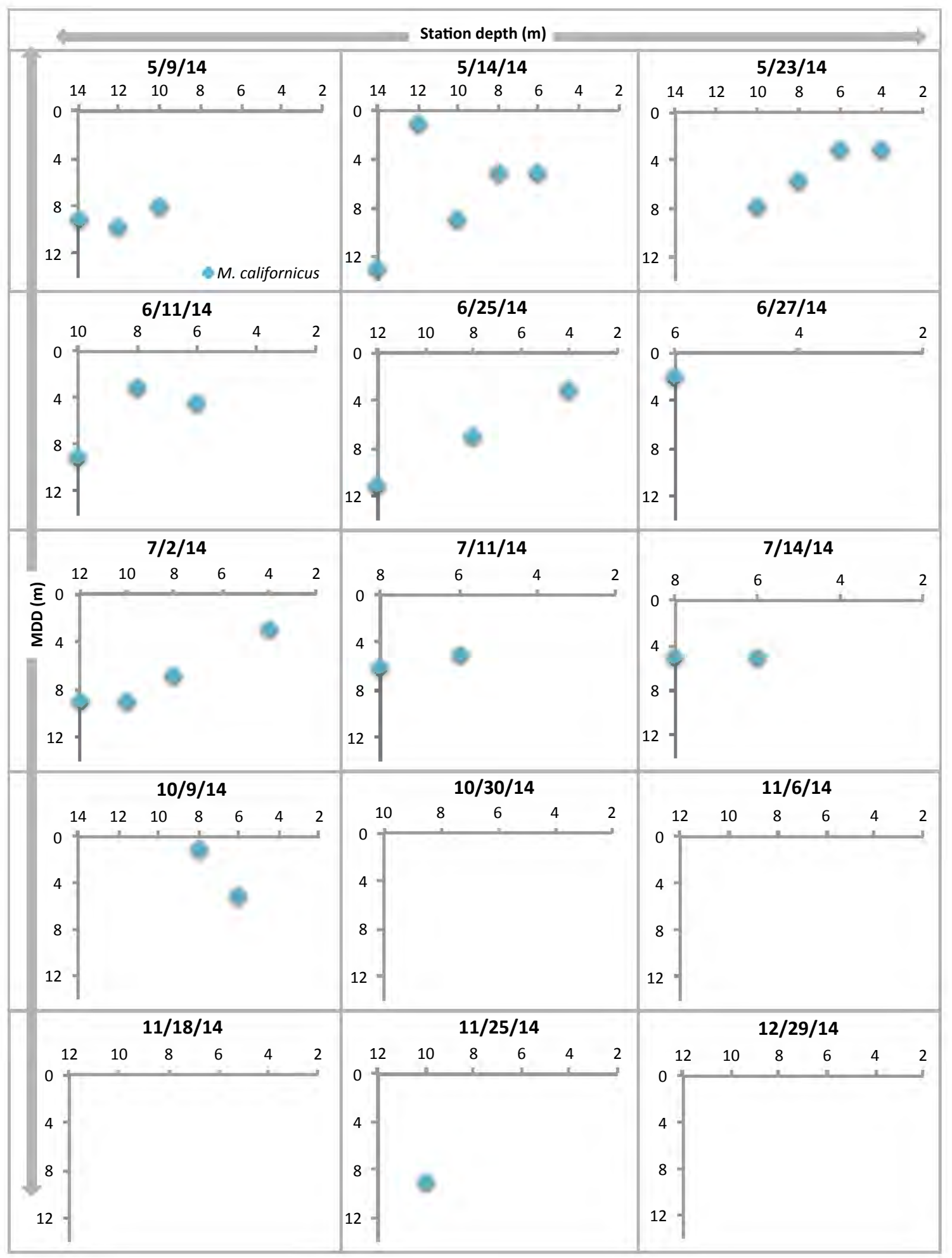


Figure E14. Mean Depth Distributions (MDDs) of Balanus trigonus cyprids at each station during all cruise dates in 2014. 


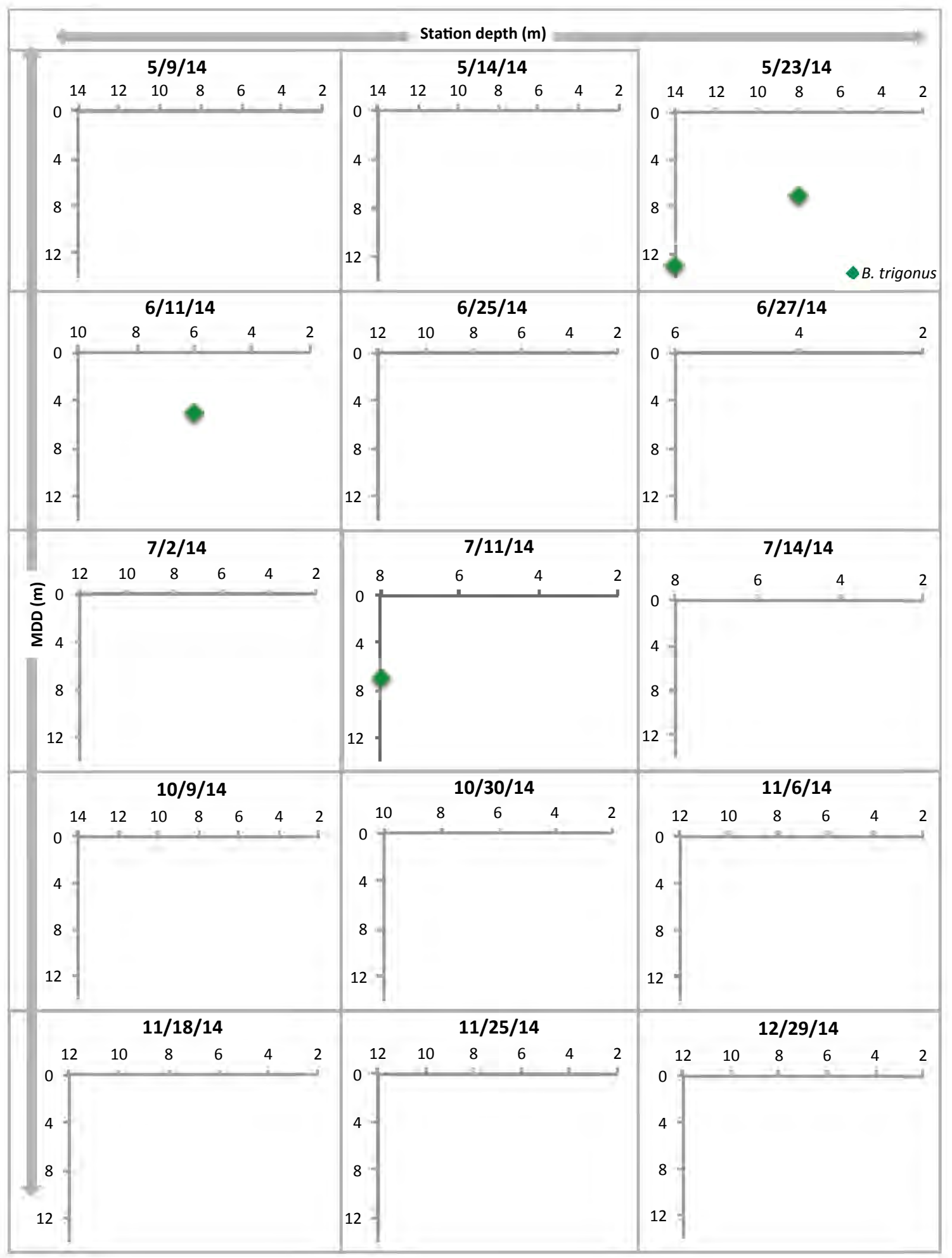


Figure E15. Densities of early- and late- stage nauplii at each station during all cruise dates in 2015. 11/20/15 is lightly shaded to indicate increased y-axis. 


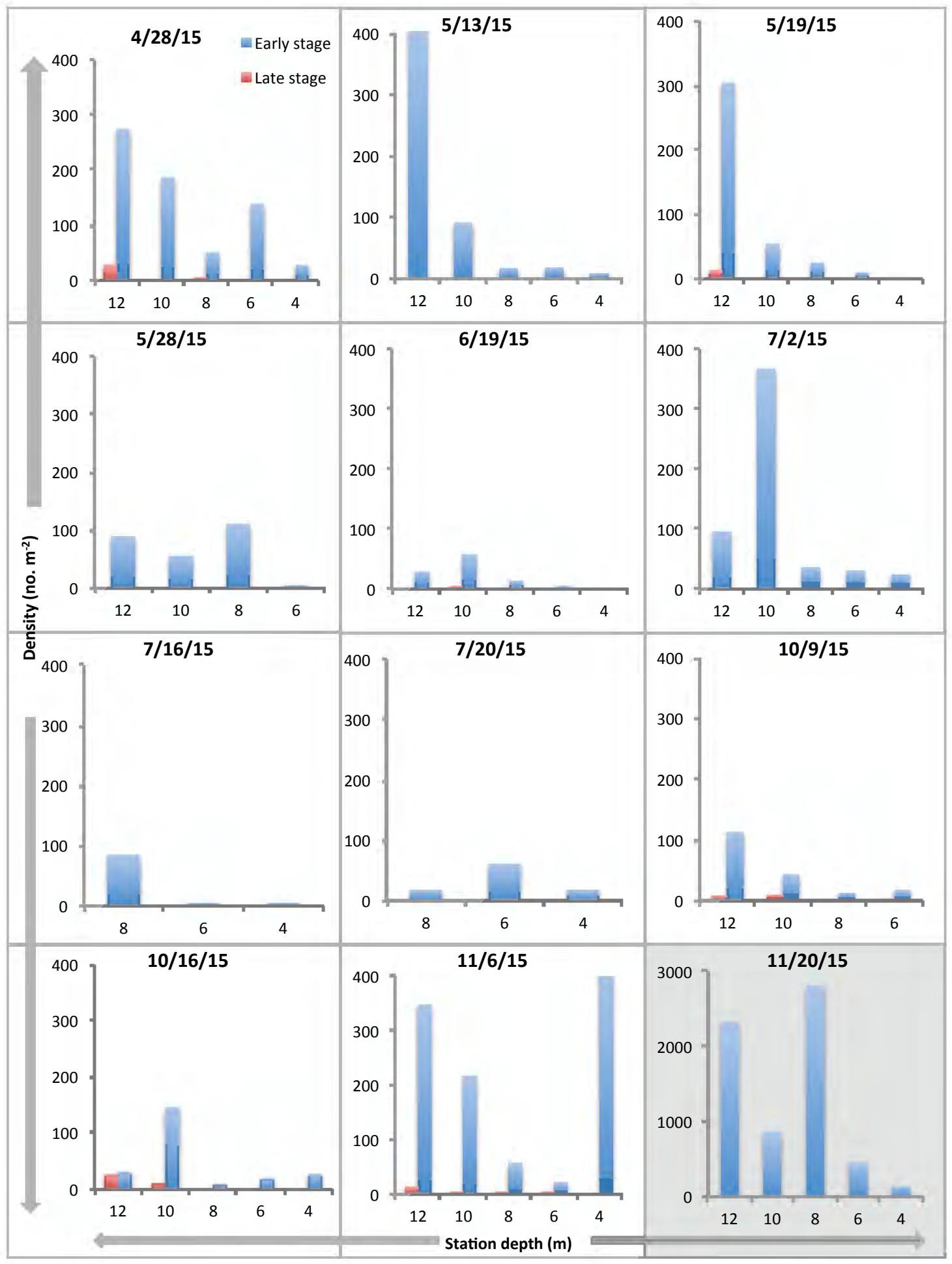


Figure E16. Mean Depth Distributions (MDDs) of early- and late- stage nauplii at each station during all cruise dates in 2015 . 


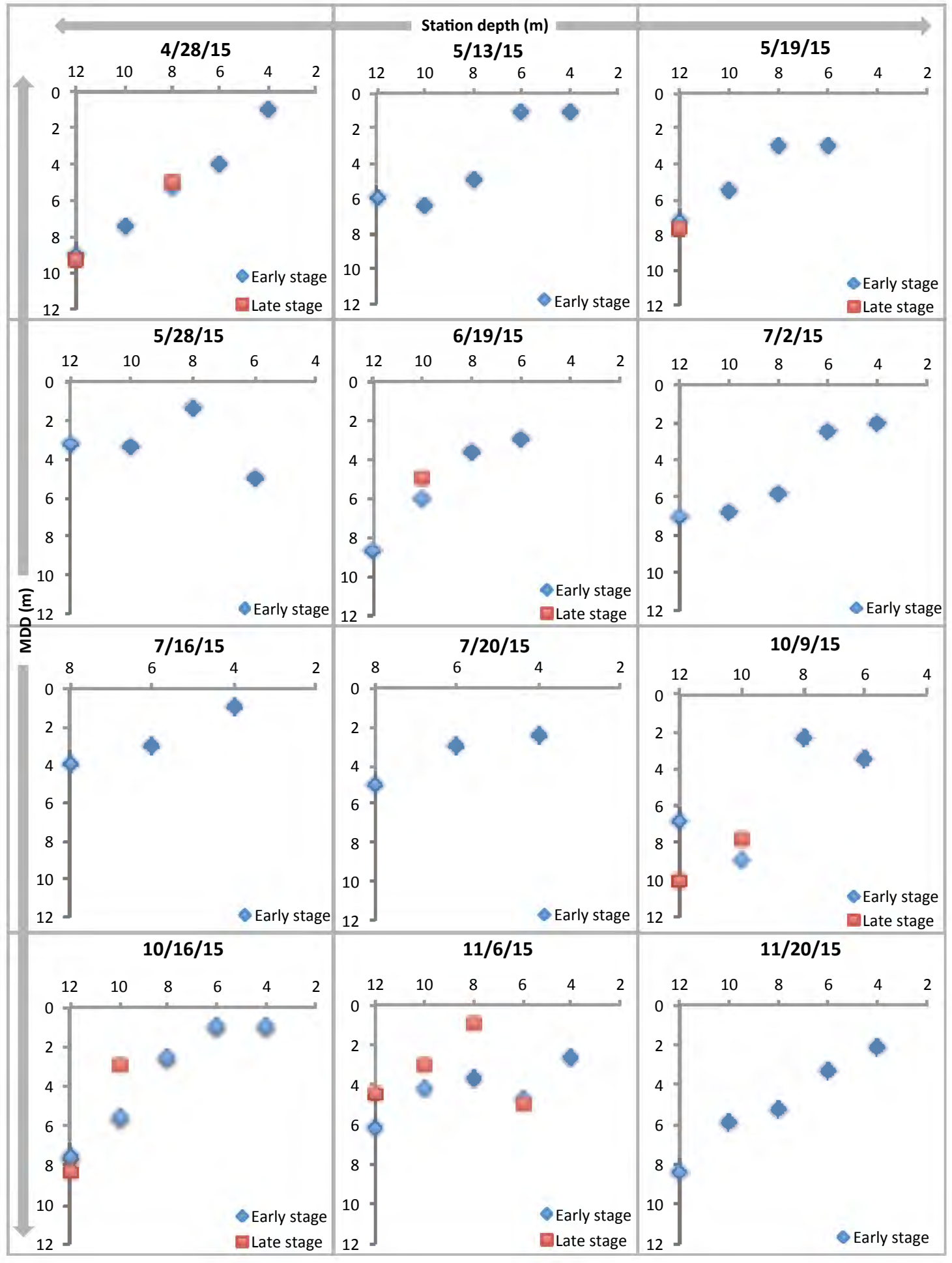


Figure E17. Densities of Chthamalus fissus cyprids at each station during all cruise dates in 2015 . 


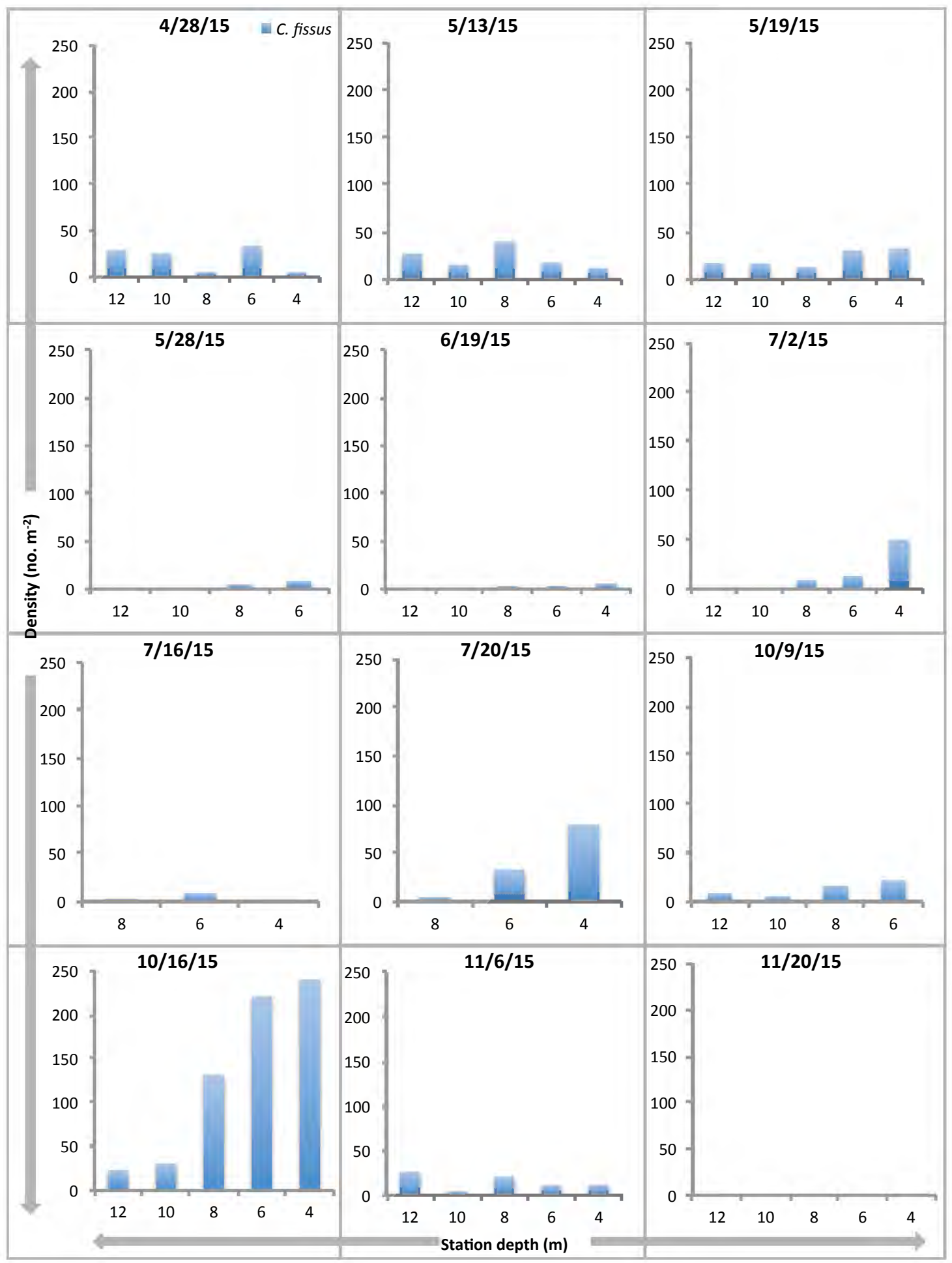


Figure E18. Densities of Balanus glandula cyprids at each station during all cruise dates in 2015 . 


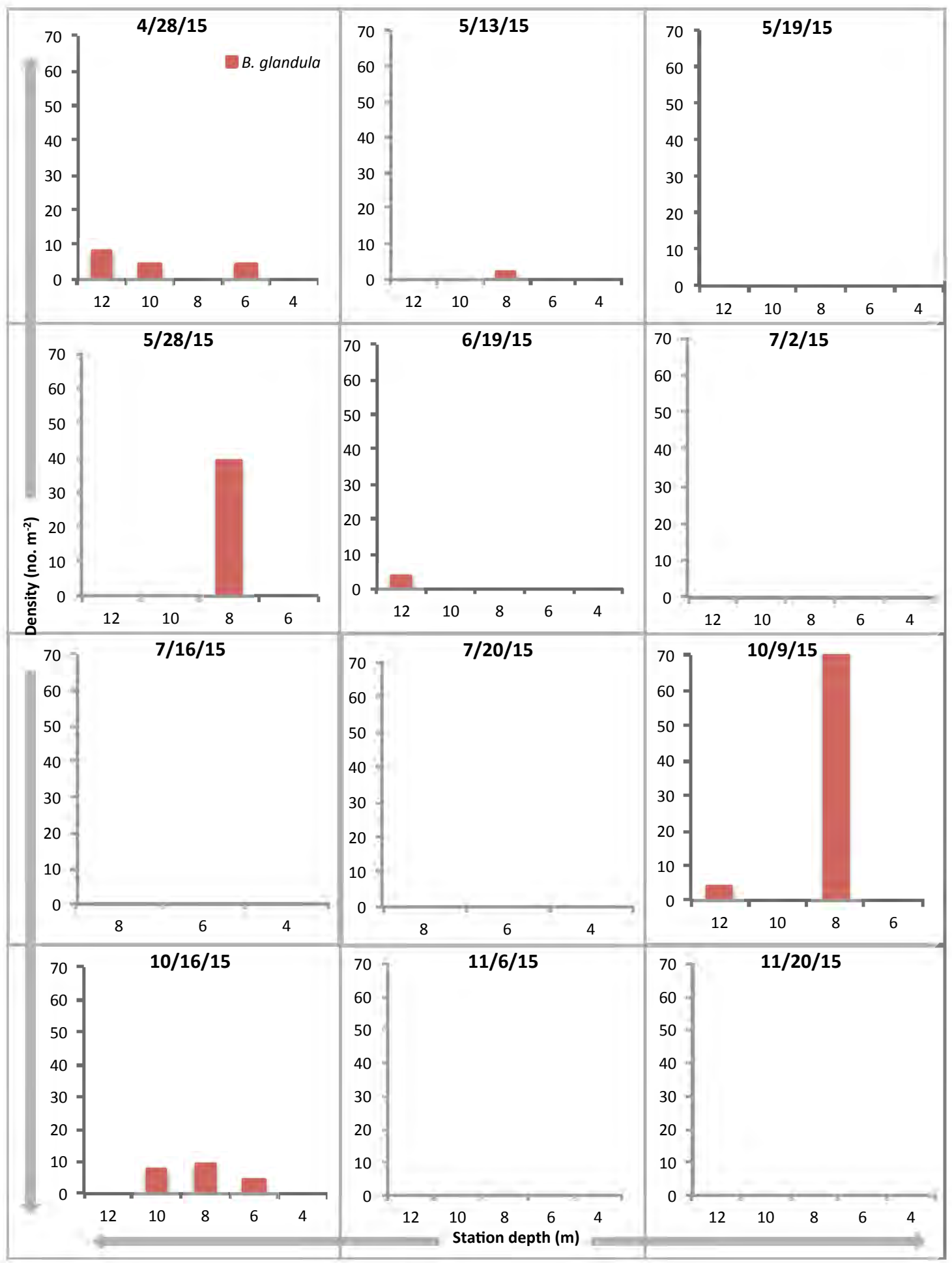


Figure E19. Densities of Pollicipes polymerus cyprids at each station during all cruise dates in 2015 . 


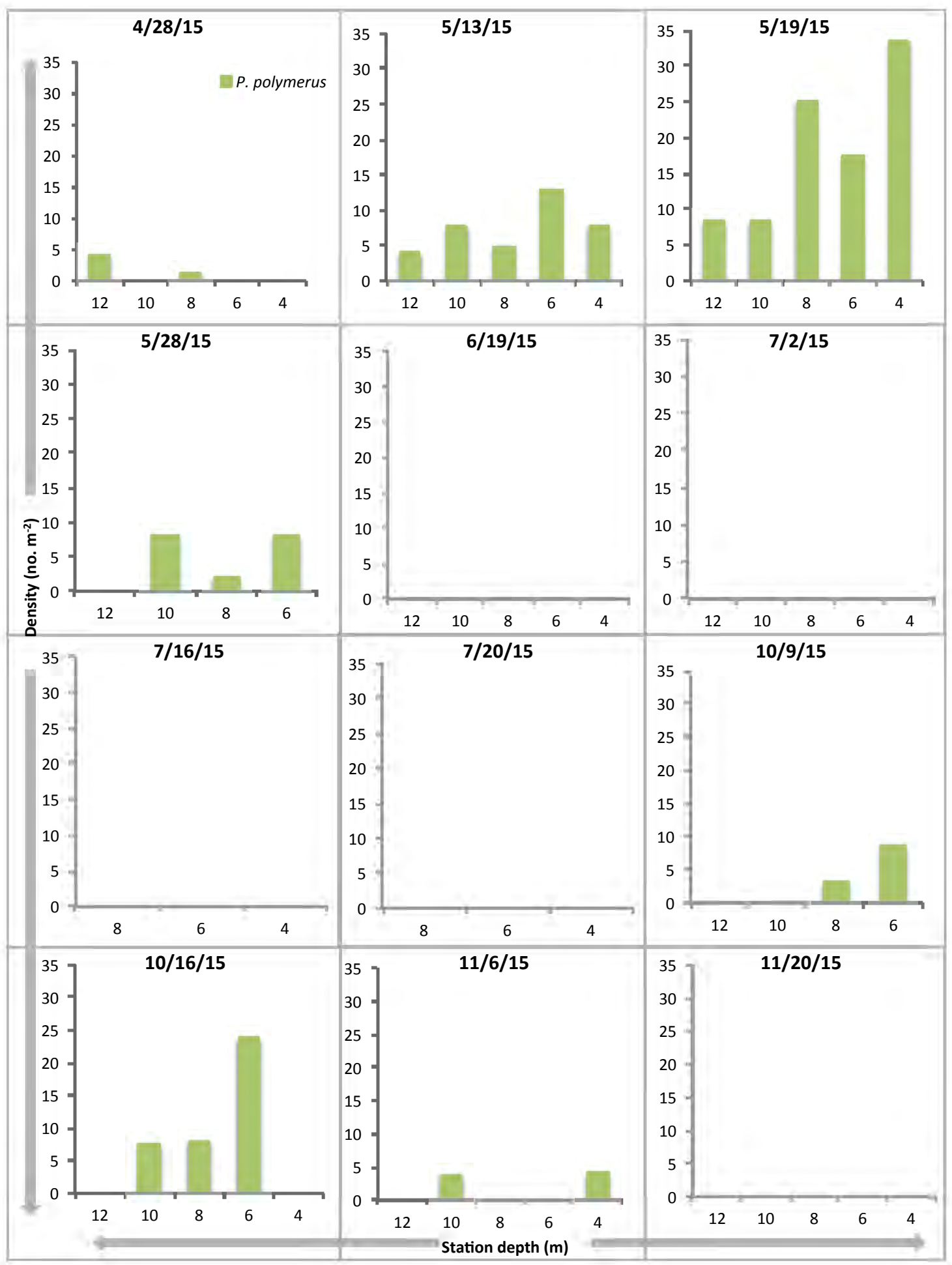


Figure E20. Densities of Tetraclita rubescens cyprids at each station during all cruise dates in 2015 . 


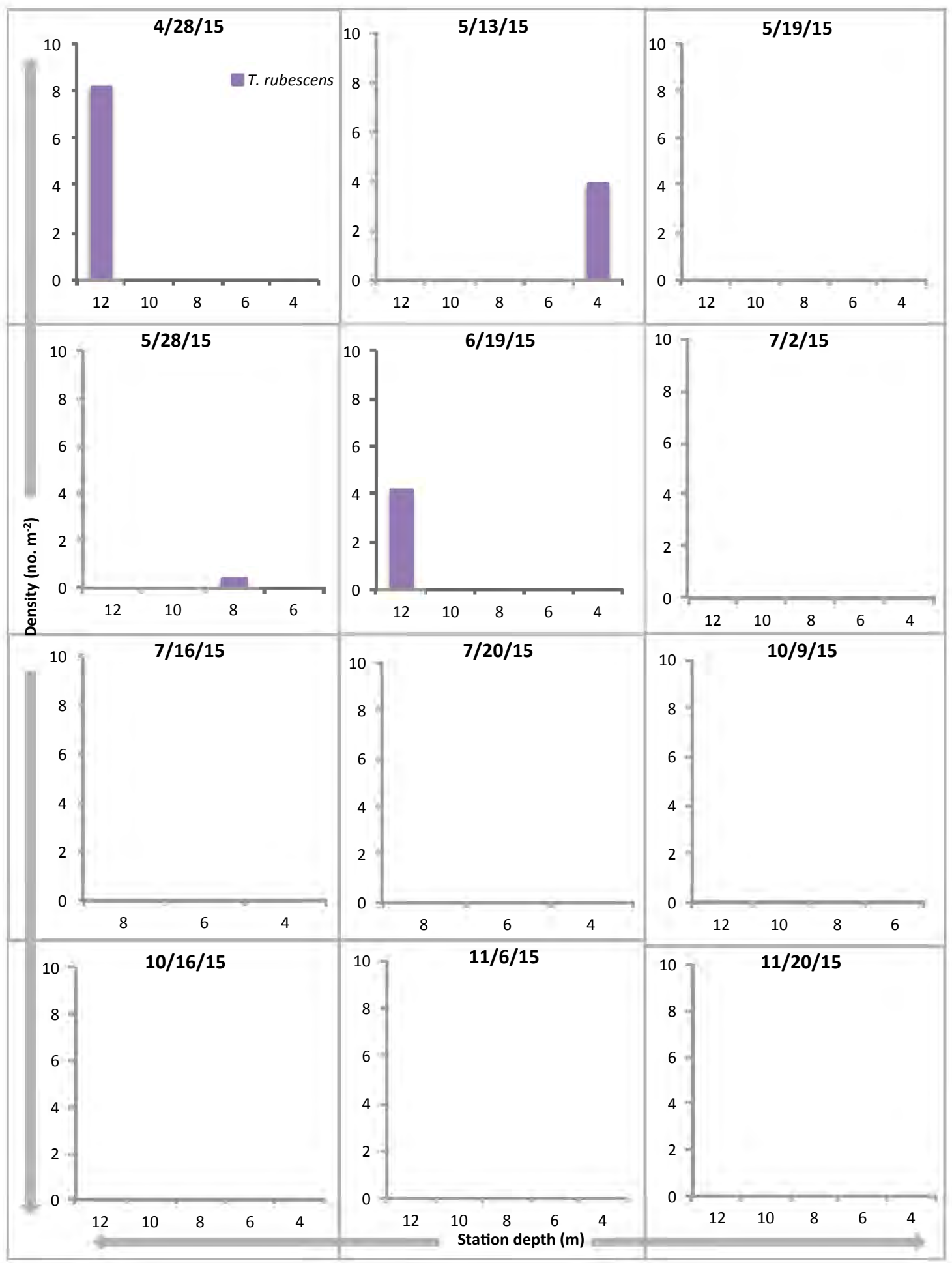


Figure E21. Densities of Megabalanus californicus cyprids at each station during all cruise dates in 2015 . 


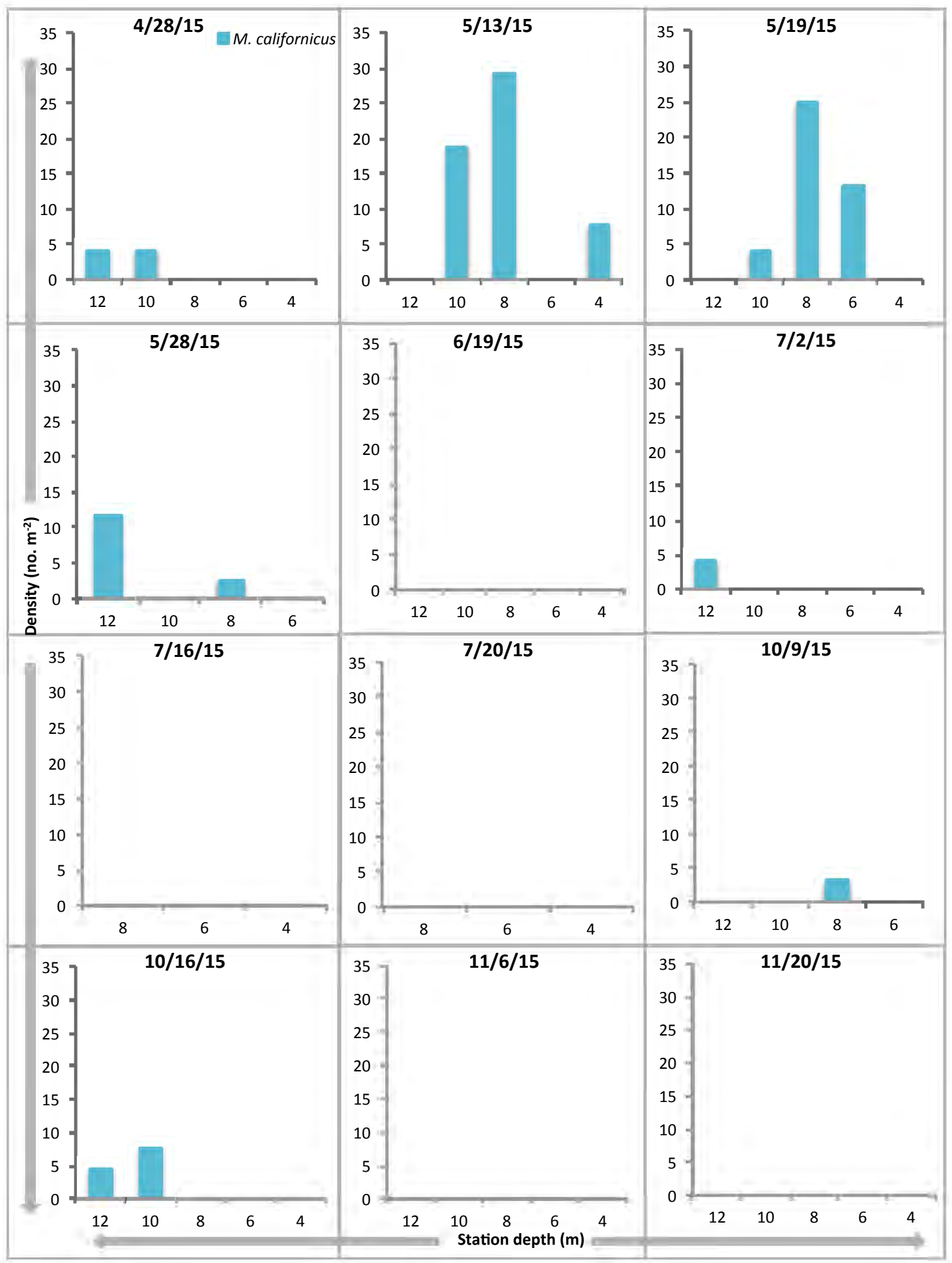


Figure E22. Densities of Balanus trigonus cyprids at each station during all cruise dates in 2015. 


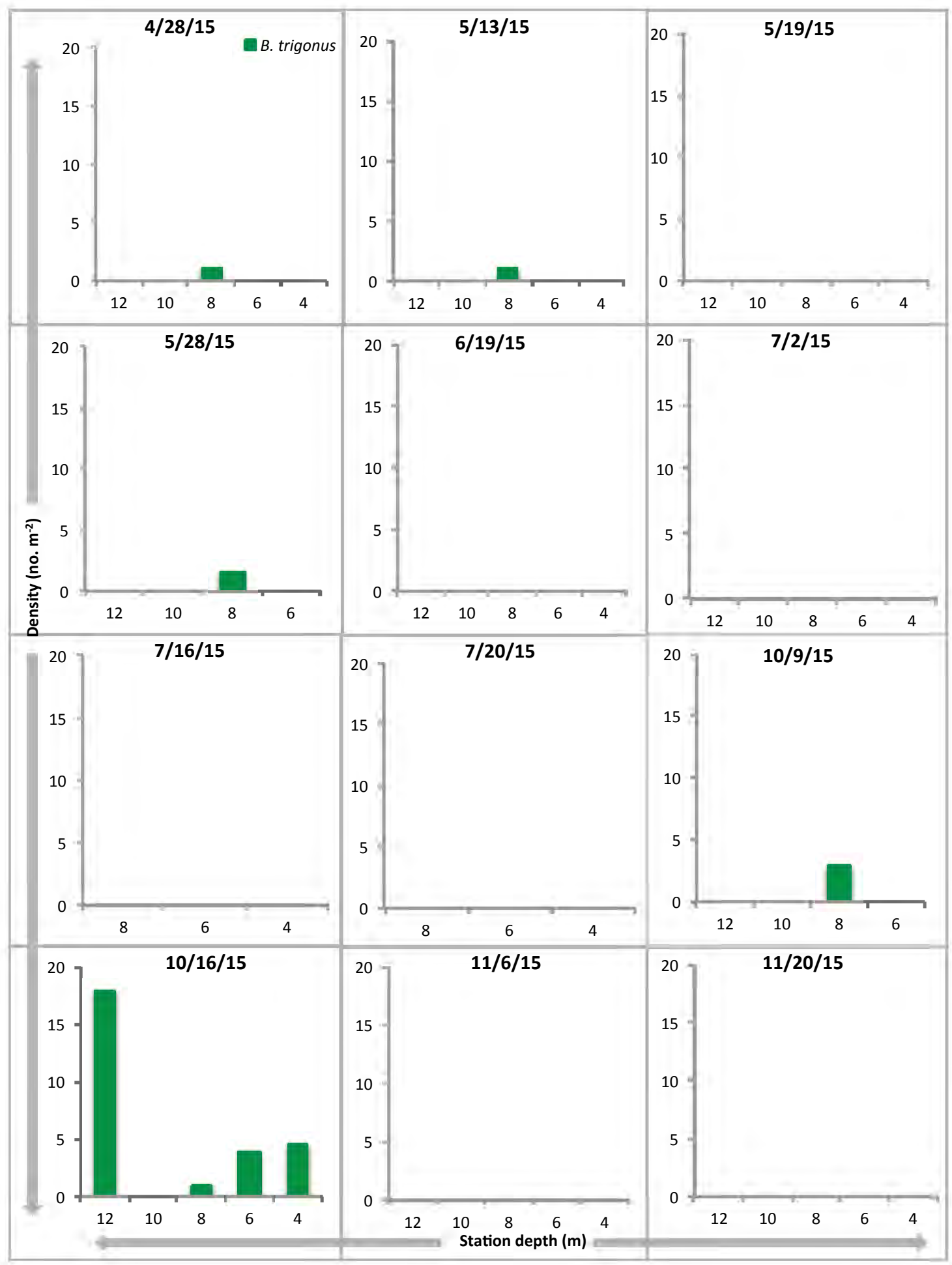


Figure E23. Mean Depth Distributions (MDDs) of Chthamalus fissus cyprids at each station during all cruise dates in 2015 . 


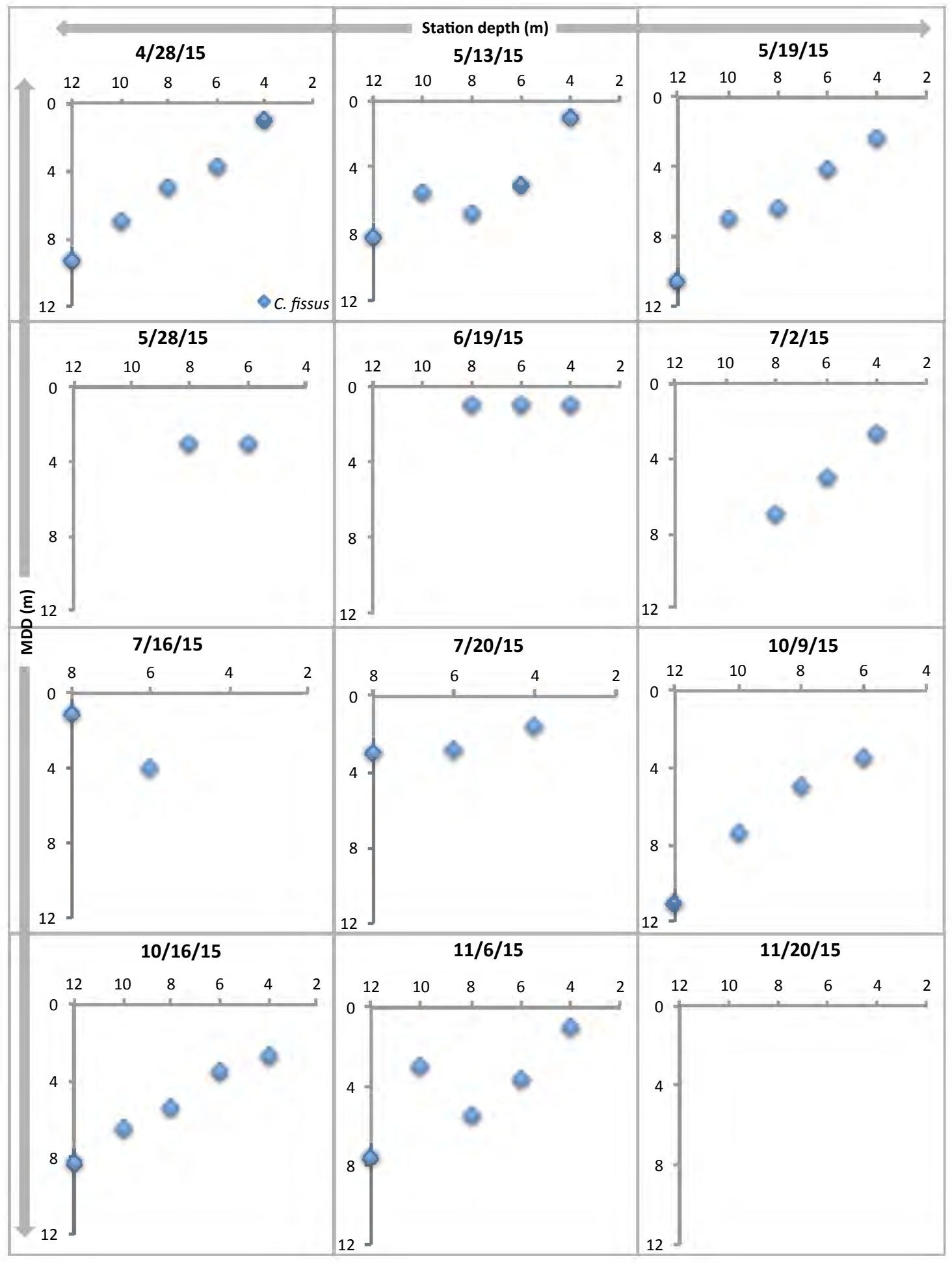


Figure E24. Mean Depth Distributions (MDDs) of Balanus glandula cyprids at each station during all cruise dates in 2015 . 


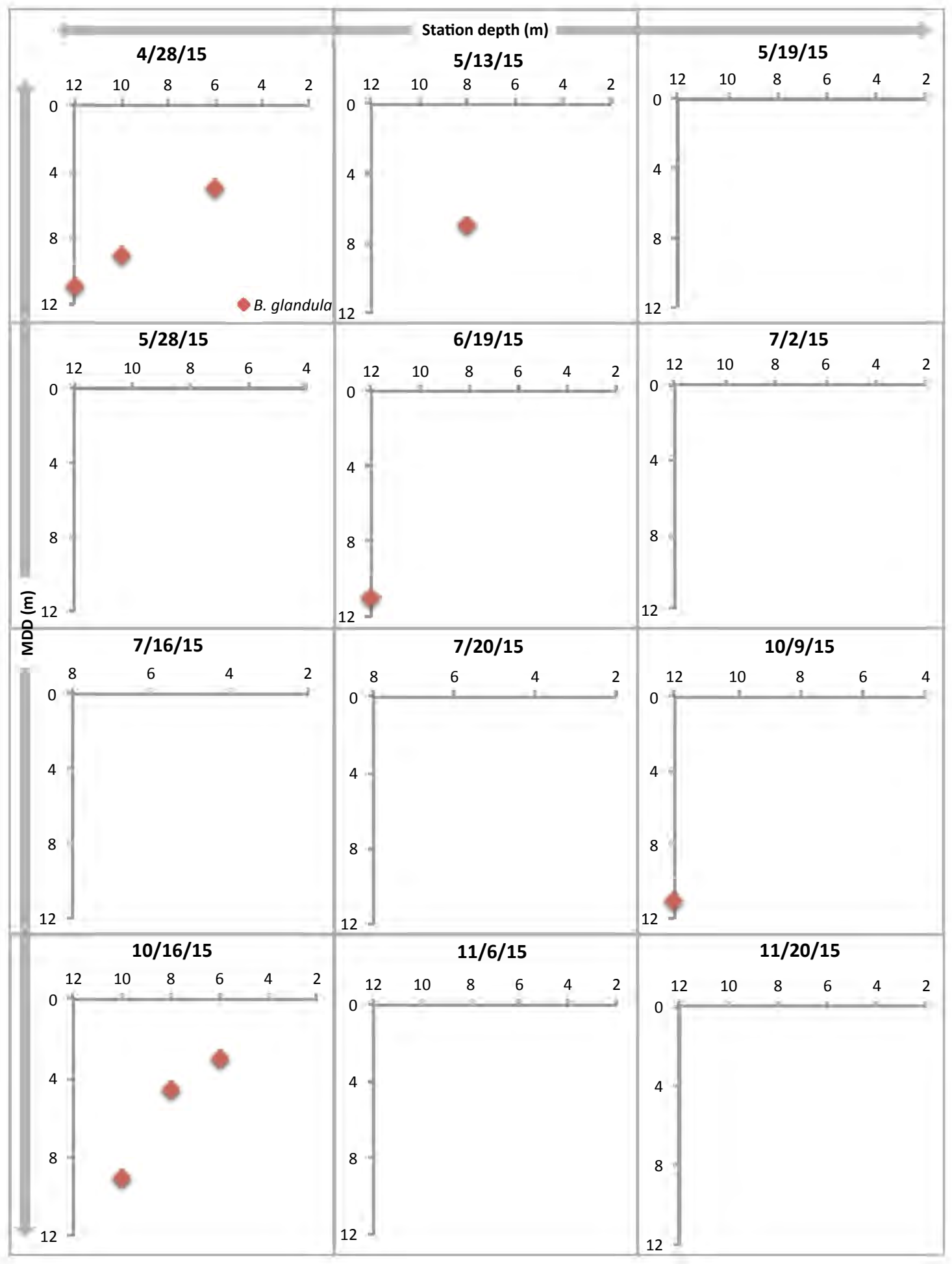


Figure E25. Mean Depth Distributions (MDDs) of Pollicipes polymerus cyprids at each station during all cruise dates in 2015 . 


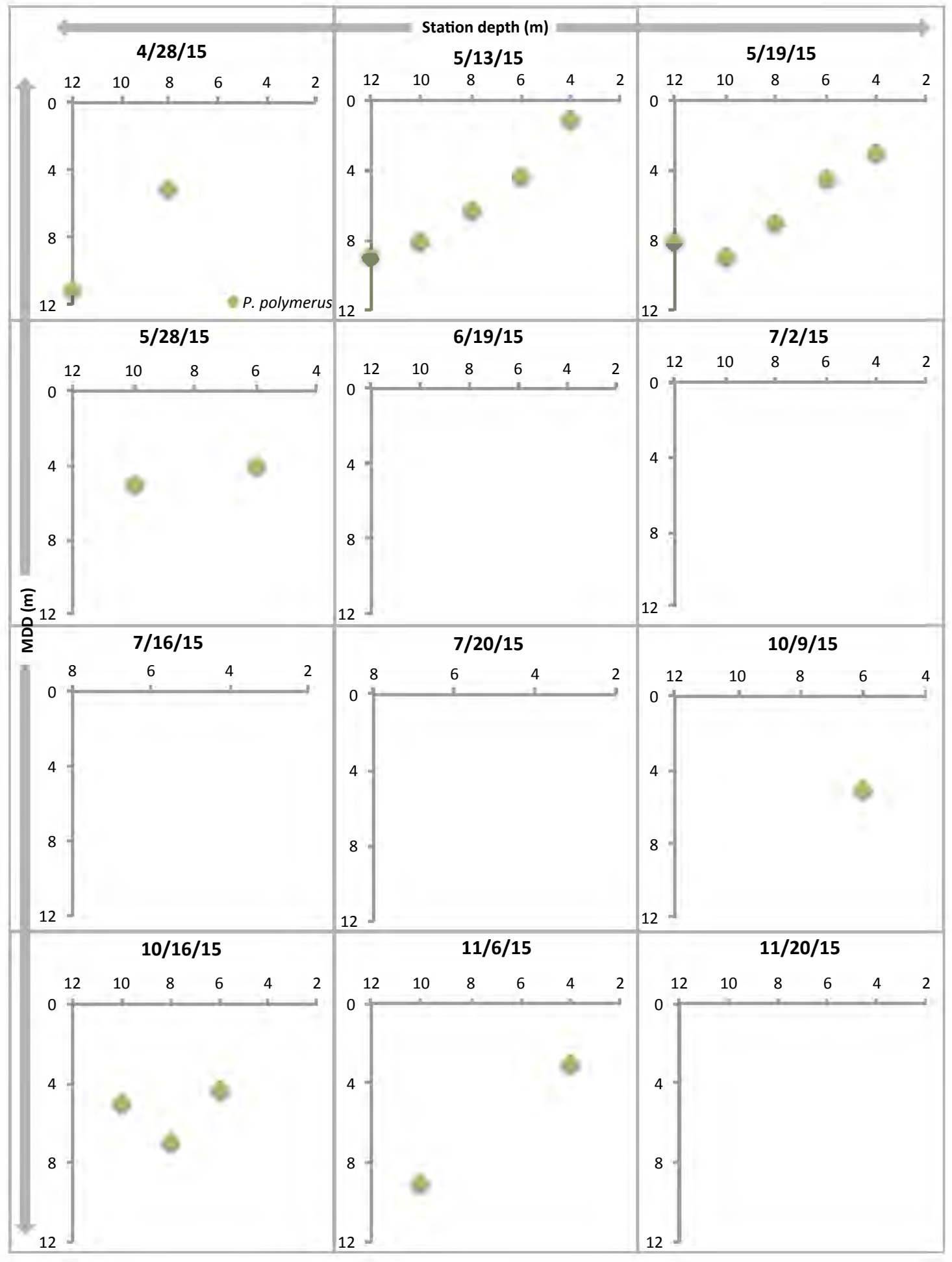


Figure E26. Mean Depth Distributions (MDDs) of Tetraclita rubescens cyprids at each station during all cruise dates in 2015 . 


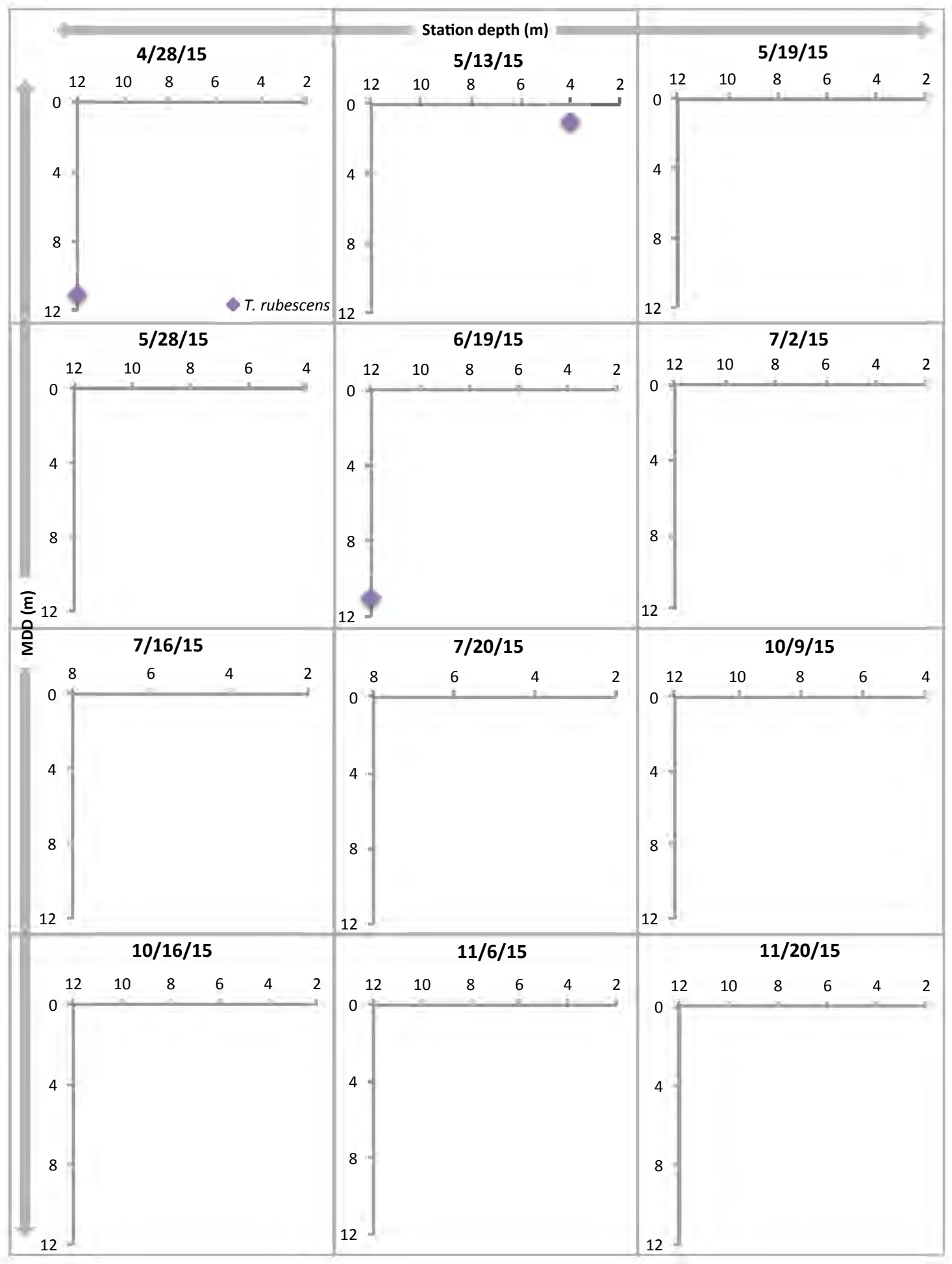


Figure E27. Mean Depth Distributions (MDDs) of Megabalanus californicus cyprids at each station during all cruise dates in 2015. 


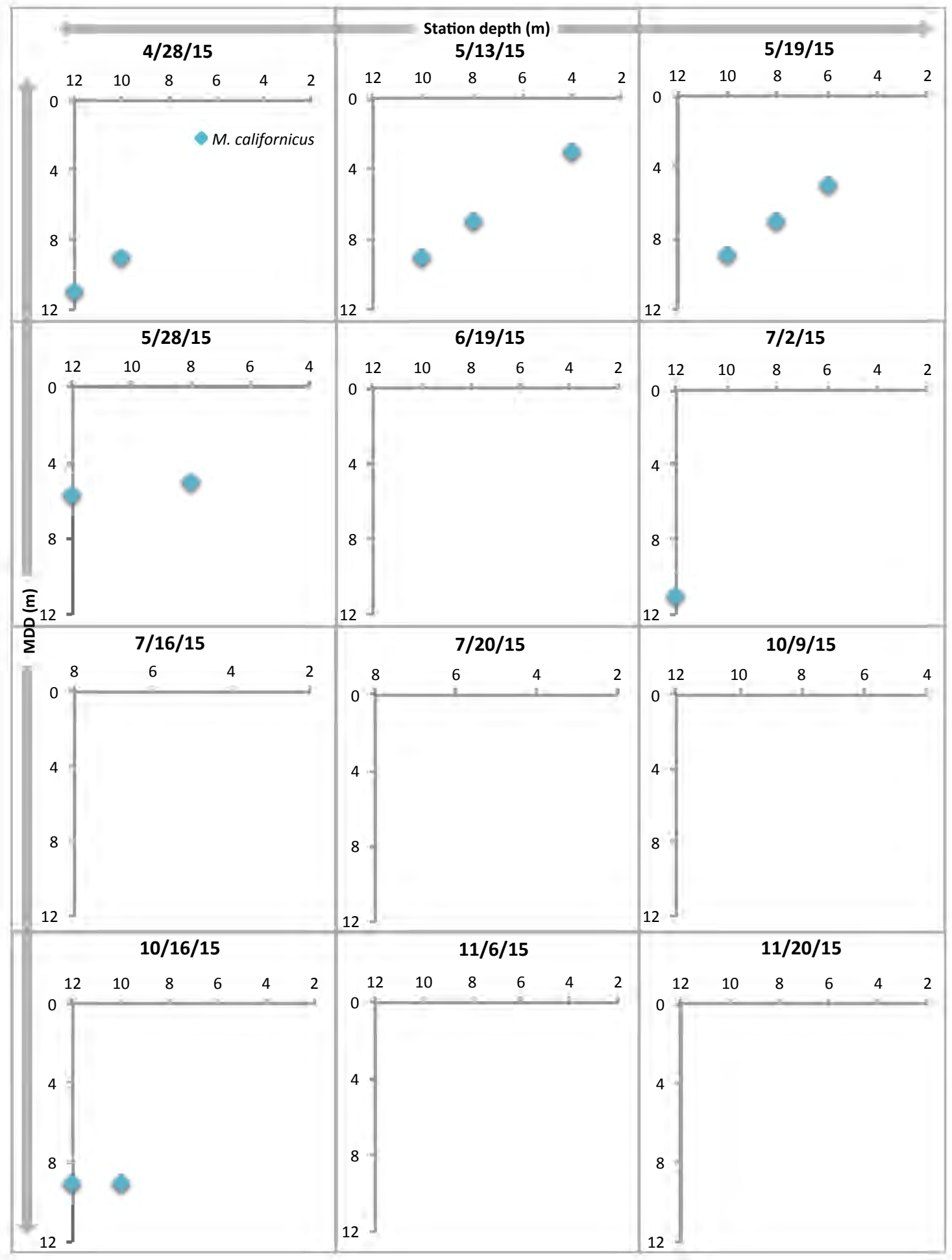


Figure E28. Mean Depth Distributions (MDDs) of Balanus trigonus cyprids at each station during all cruise dates in 2015 . 


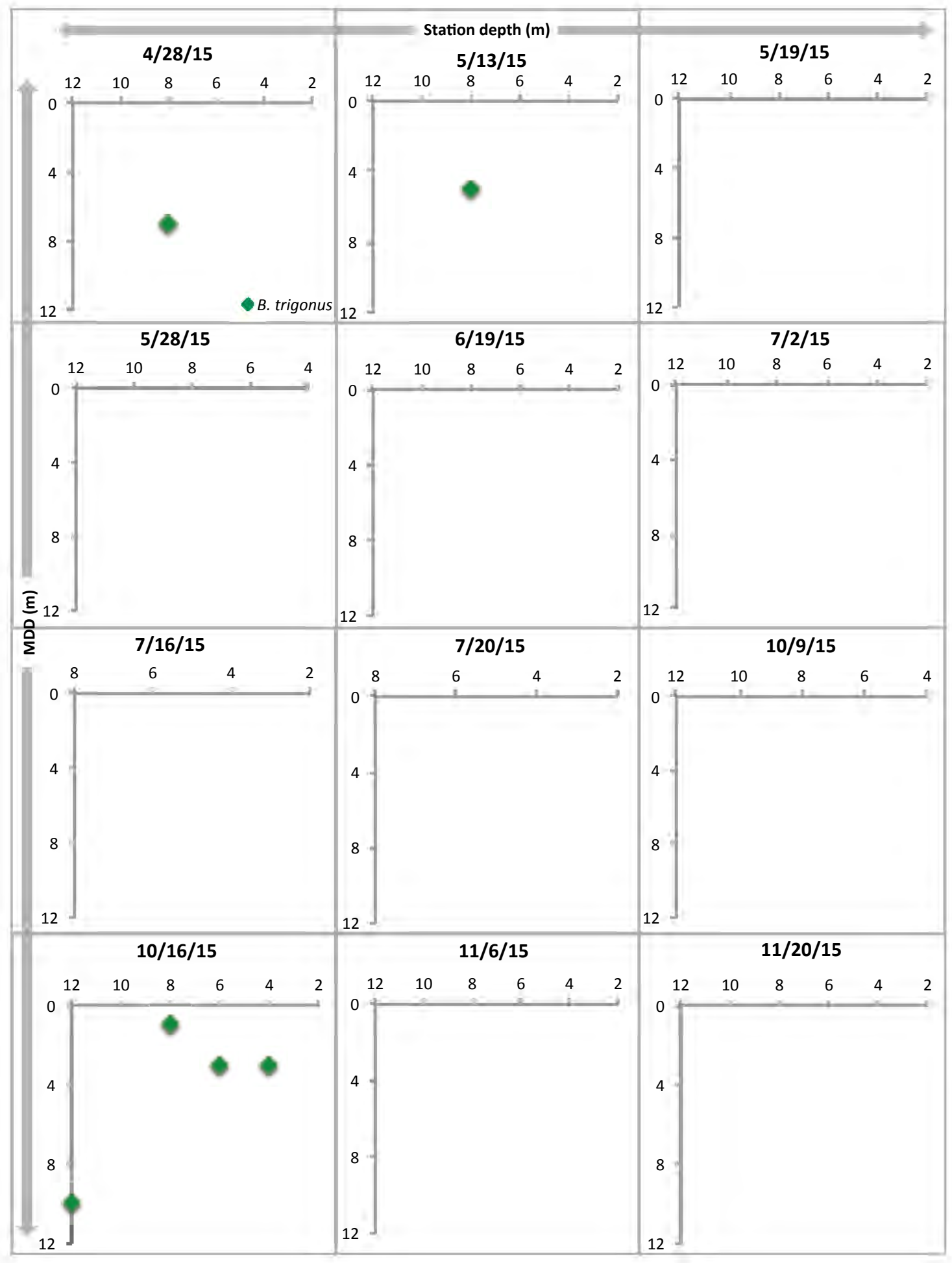


Figure E29. Mean Depth Distributions (MDDs) of early-stage nauplii and Chthamalus fissus cyprids: all measurements shown for all cruises with overall average for each larval stage plotted on top. Black line represents bottom depth. 


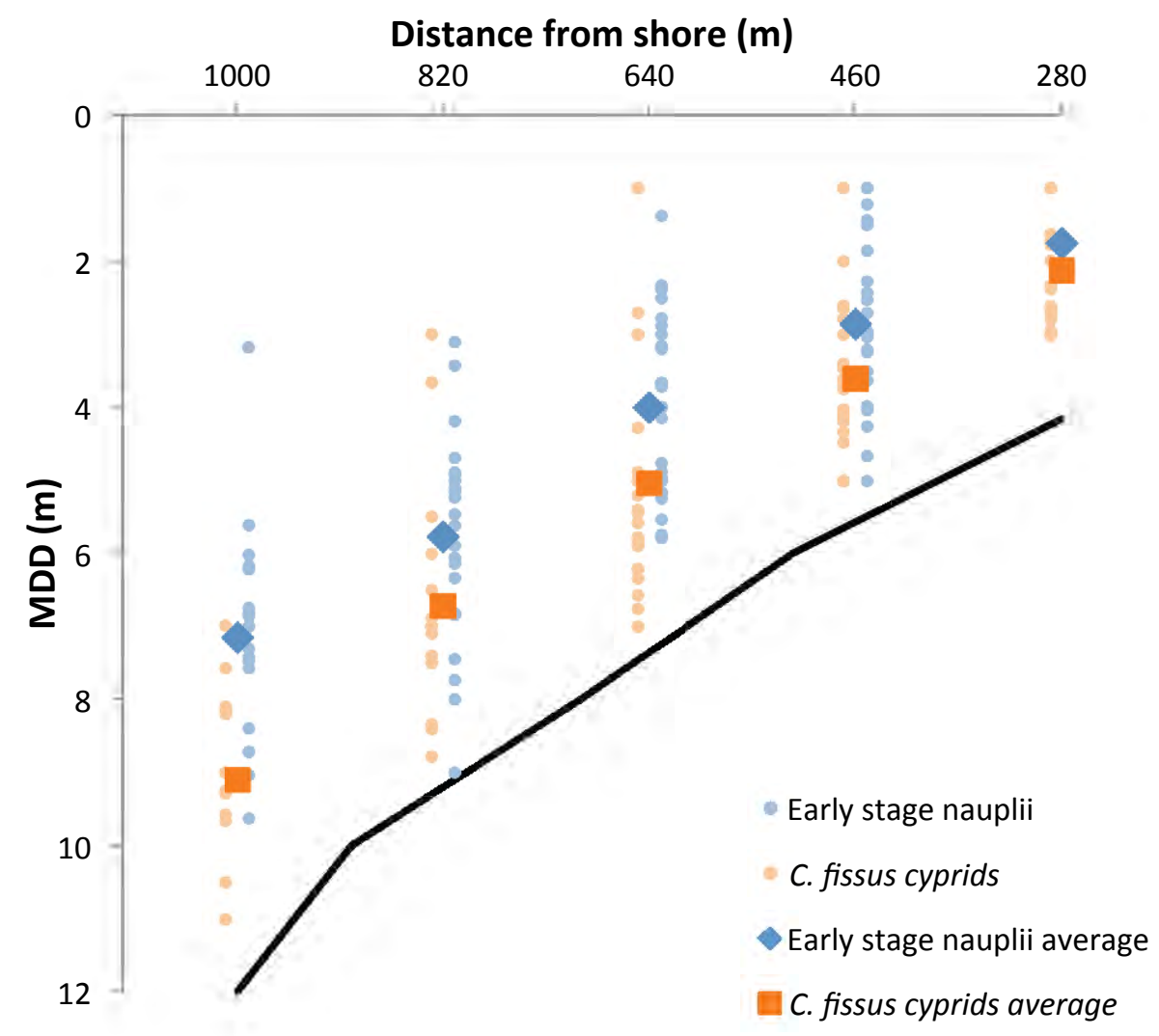


Appendix F: Bubble plots showing concentrations of larvae in each sample during all cruises.

Figure F1. Concentrations of early-stage nauplii in each plankton sample during cruise dates in 2014. Gray circles scale to highest concentration of early-stage nauplii collected in a sample across all cruises during both years: $2104.15 \mathrm{~m}^{-3}$. Sampling stations located 280, 460, 640, 820, and $1000 \mathrm{~m}$ from shore with bottom depths of 4, 6, 8, 10, and $12 \mathrm{~m}$, respectively. Red points represent Mean Depth Distribution (MDD) at each station; black points represent that 0 larvae were collected in that sample. 


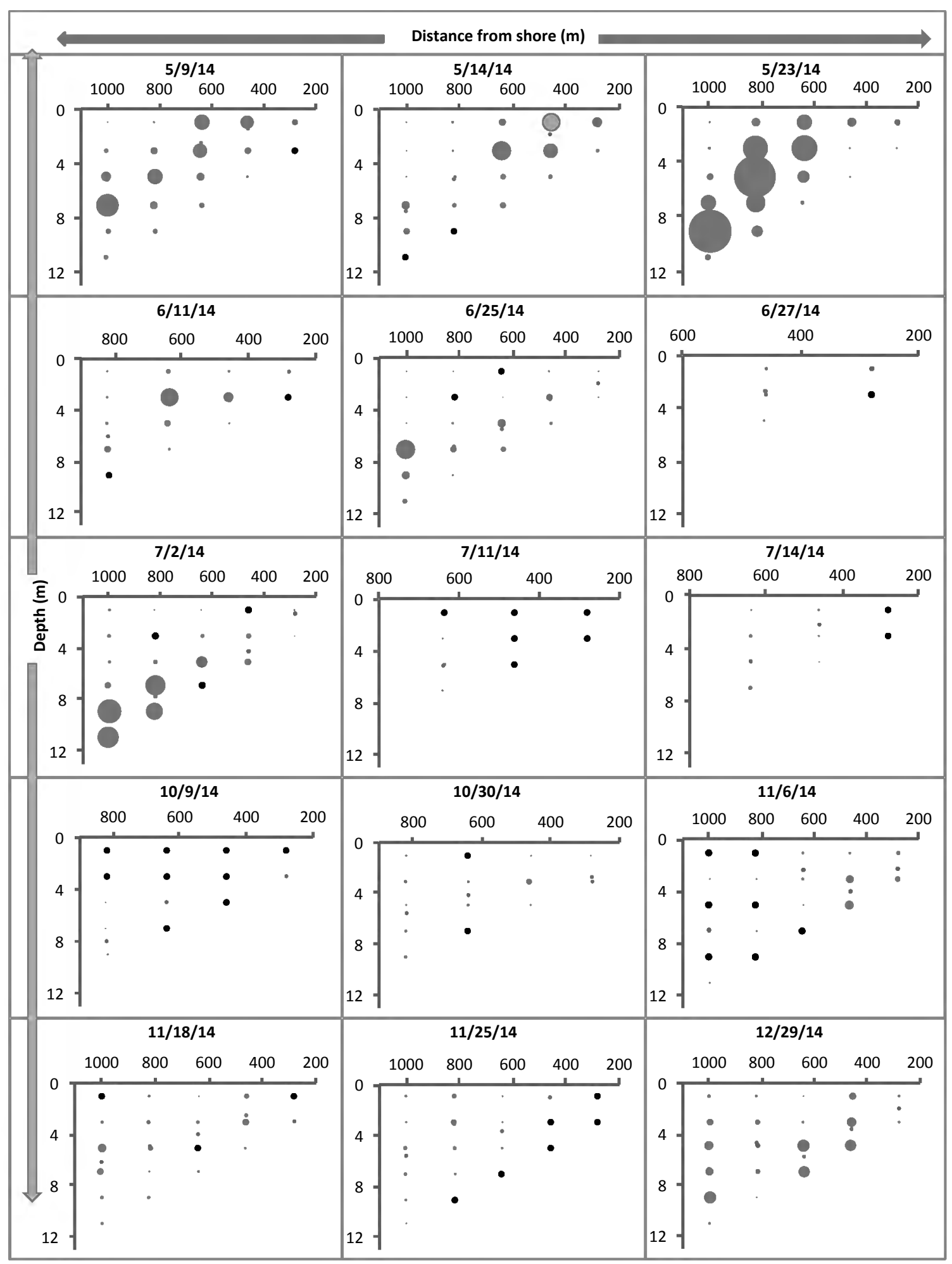


Figure F2. Concentrations of Chthamalus fissus cyprids in each plankton sample during cruise dates in 2014. Black circles scale to highest concentration of $C$. fissus cyprids collected in a sample across all cruises during both years: 216.87 $\mathrm{m}^{-3}$. Sampling stations located $280,460,640,820$, and $1000 \mathrm{~m}$ from shore with bottom depths of $4,6,8,10$, and $12 \mathrm{~m}$, respectively. Red points represent Mean Depth Distribution (MDD) at each station; gray points represent that 0 larvae were collected in that sample. 


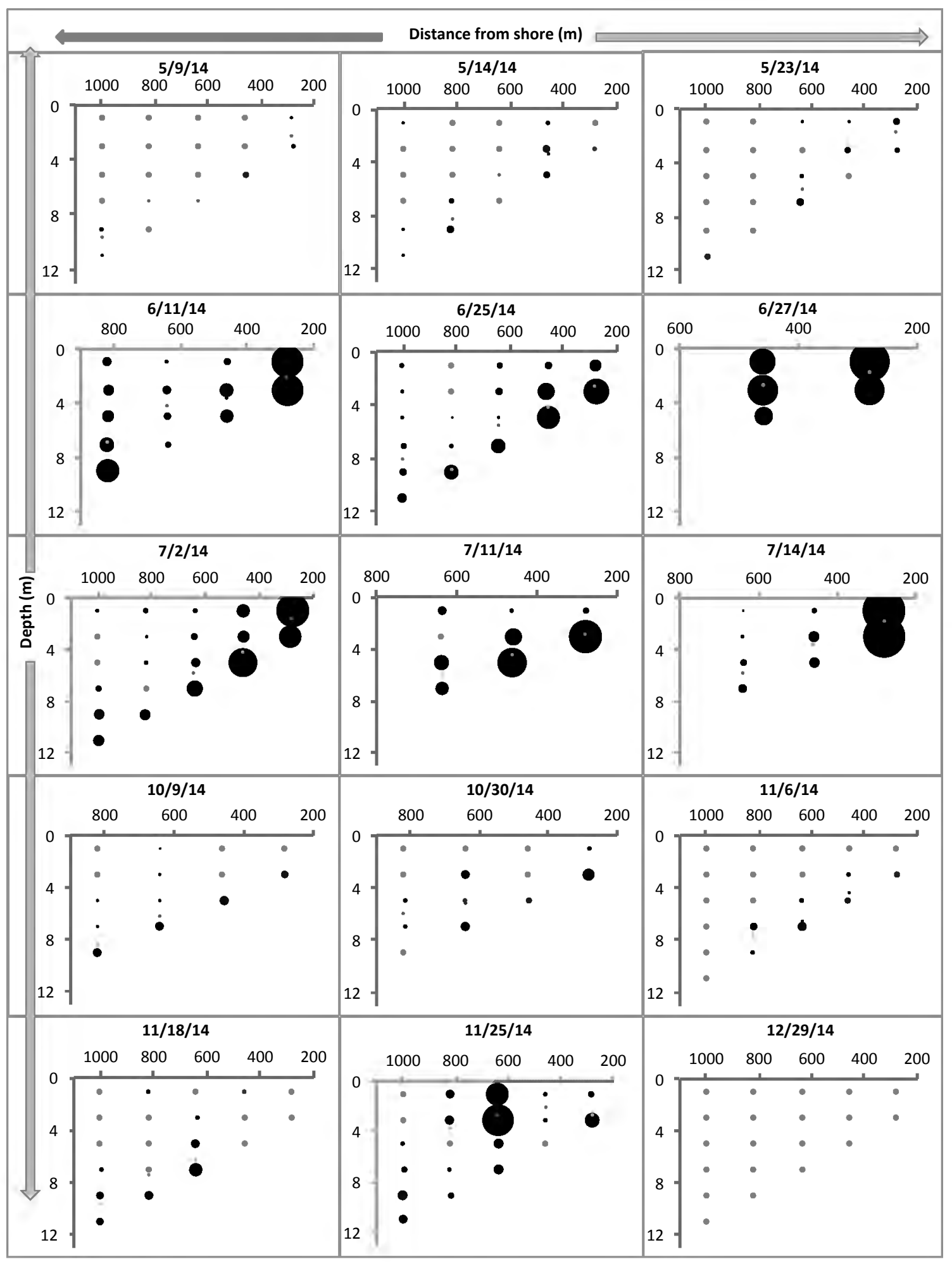


Figure F3. Concentrations of early-stage nauplii in each plankton sample during cruise dates in 2015. Gray circles scale to highest concentration of early-stage nauplii collected in a sample across all cruises during both years: $2104.15 \mathrm{~m}^{-3}$. Sampling stations located 280, 460, 640, 820, and $1000 \mathrm{~m}$ from shore with bottom depths of 4, 6, 8, 10, and $12 \mathrm{~m}$, respectively. Red points represent Mean Depth Distribution (MDD) at each station; black points represent that 0 larvae were collected in that sample. 


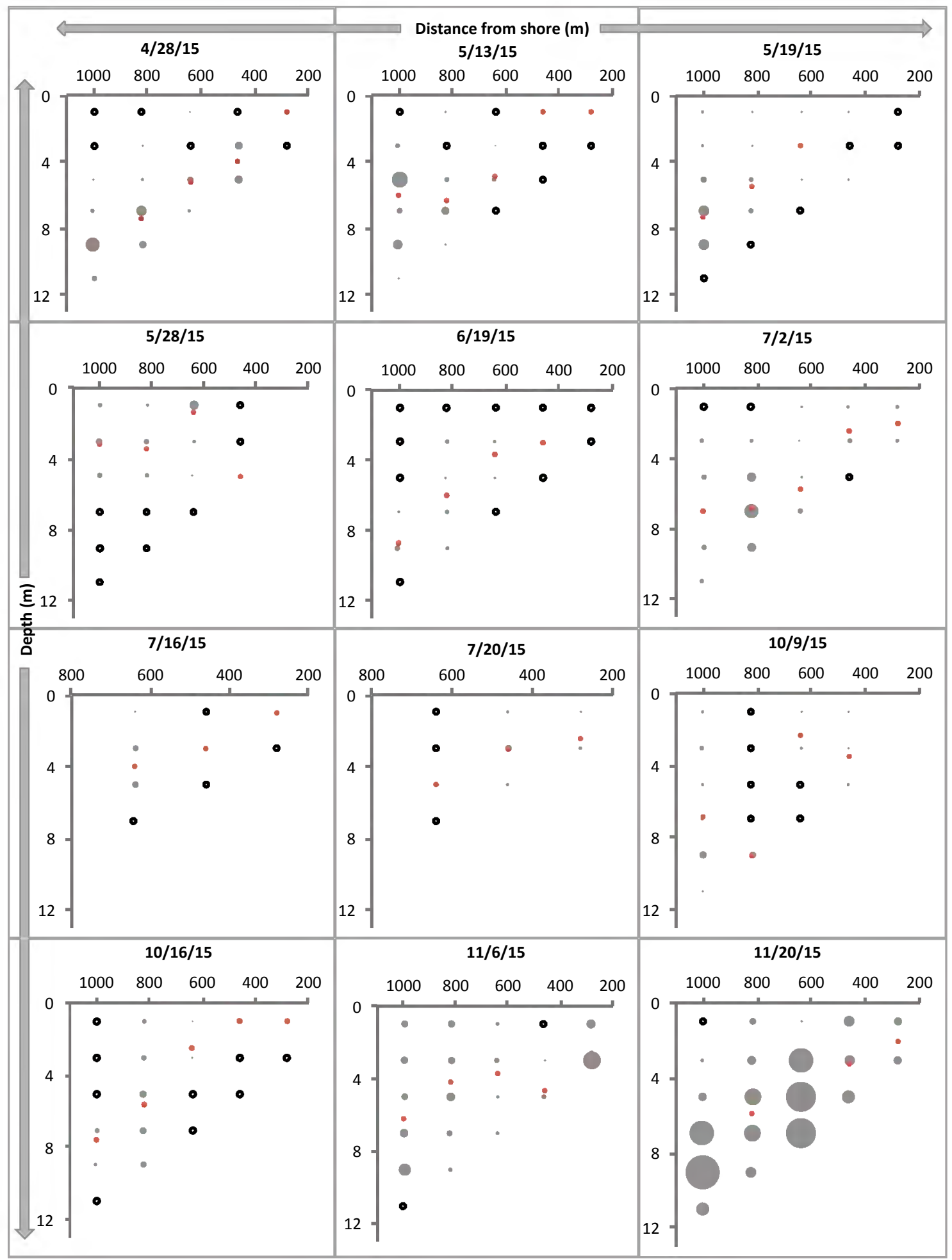


Figure F4. Concentrations of Chthamalus fissus cyprids in each plankton sample during cruise dates in 2015. Black circles scale to highest concentration of $C$. fissus cyprids collected in a sample across all cruises during both years: 216.87 $\mathrm{m}^{-3}$. Sampling stations located $280,460,640,820$, and $1000 \mathrm{~m}$ from shore with bottom depths of 4, 6, 8, 10, and $12 \mathrm{~m}$, respectively. Red points represent Mean Depth Distribution (MDD) at each station; gray points represent that 0 larvae were collected in that sample. 


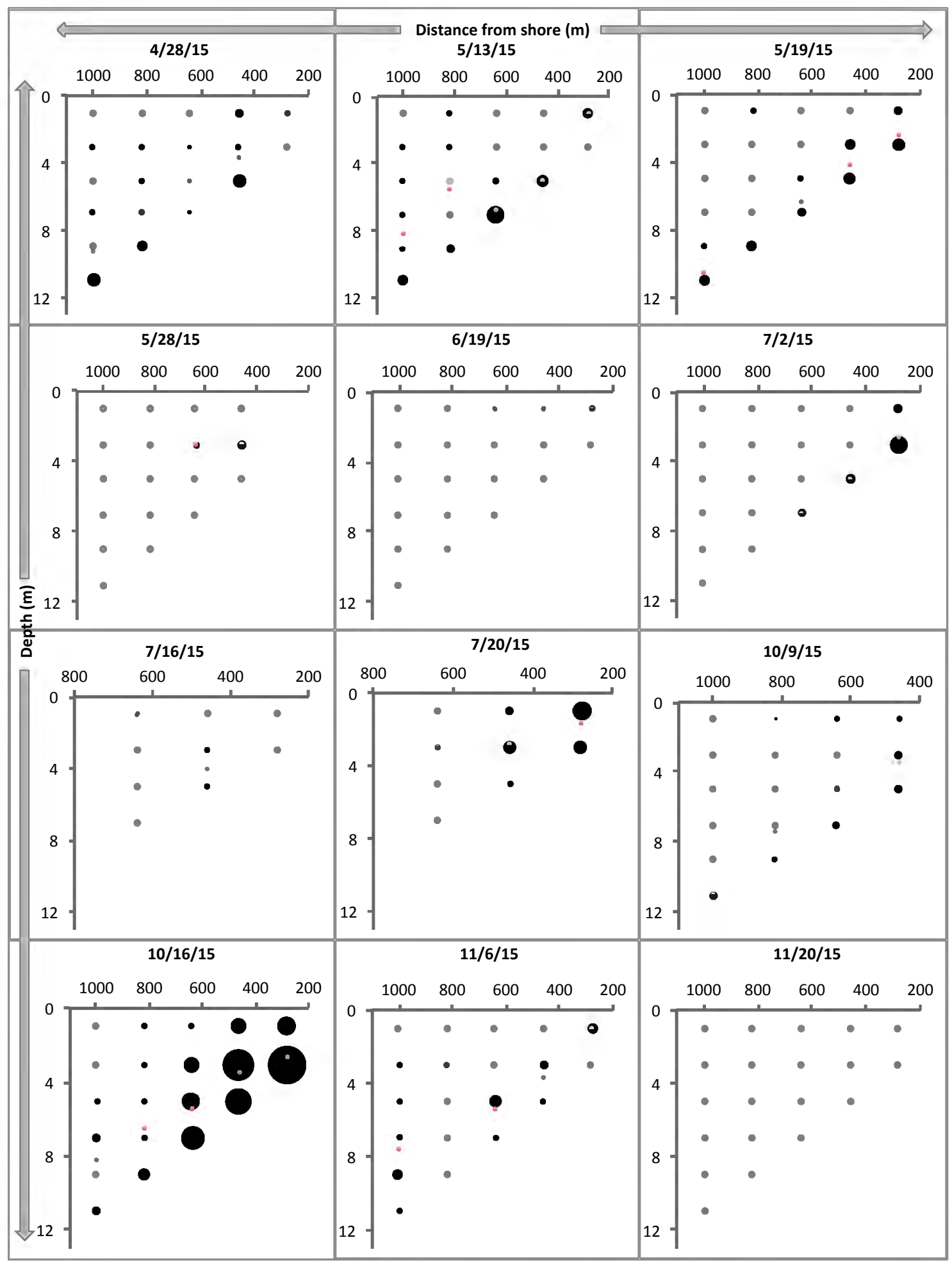


Appendix G: Salinity measurements during sampling periods.

Figure G1. Vertical salinity profiles from 8-m station during all cruise dates for each sampling period: 2014 spring-summer, 2014 fall-winter, 2015 springsummer, 2015 fall-winter. 


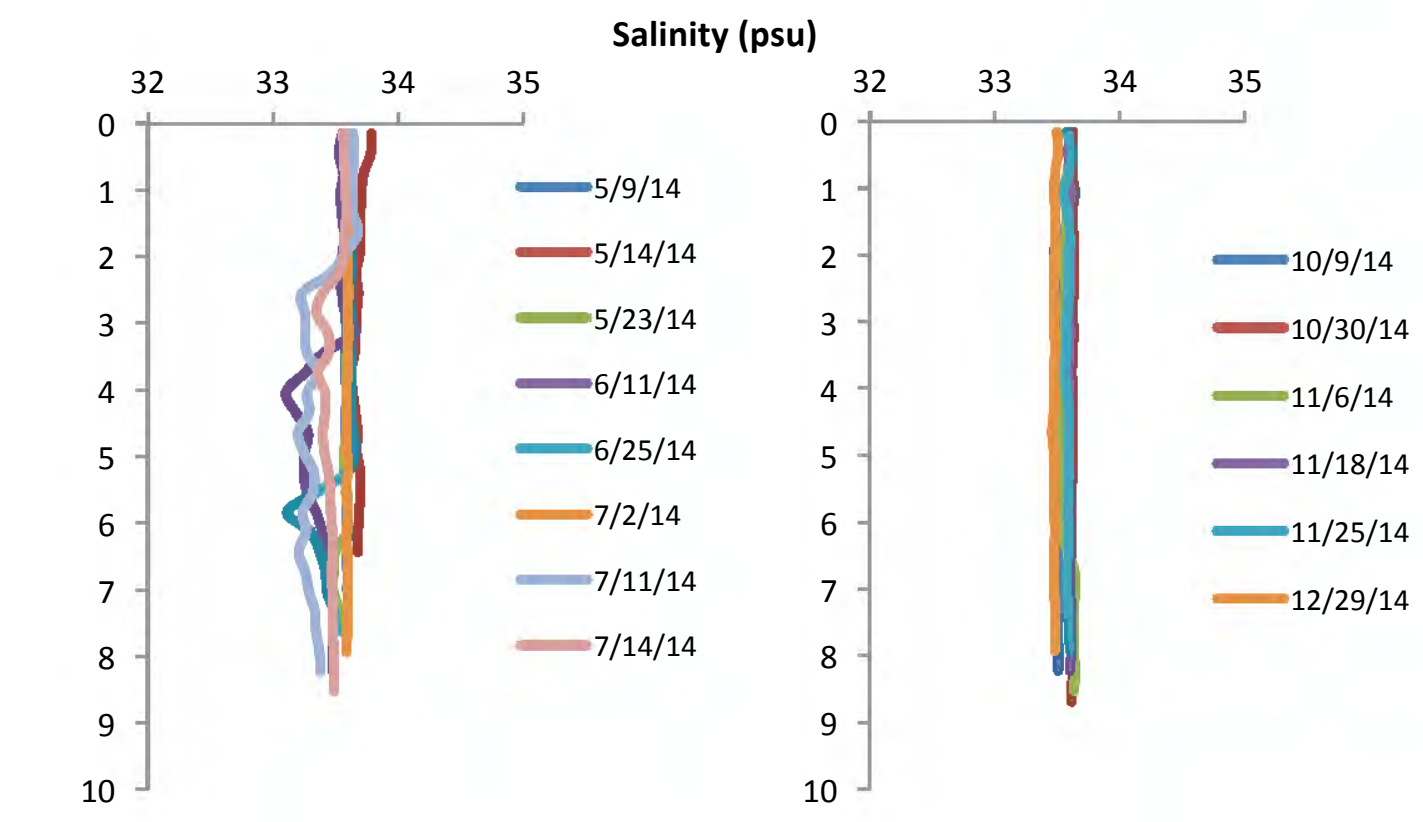

$\bar{\xi}$
$\bar{\xi}$
वे

Spring-Summer 2015

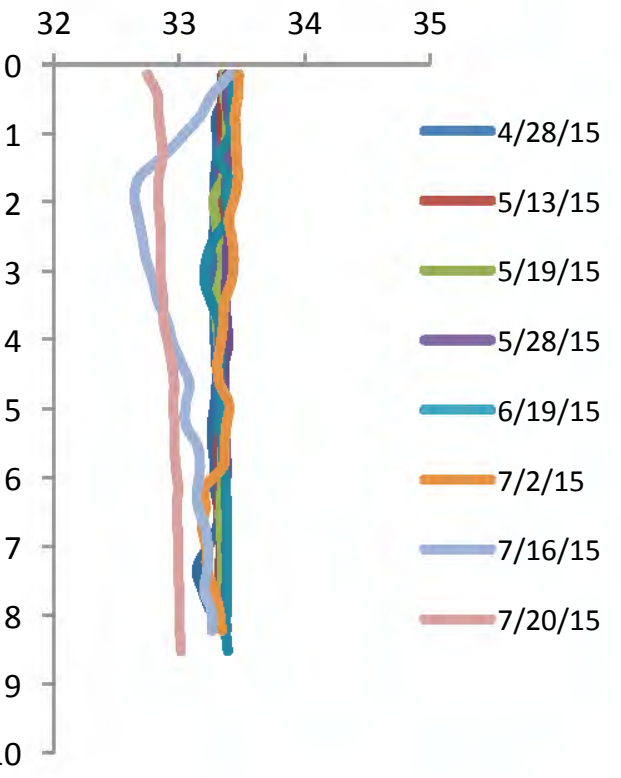

Fall-Winter 2015

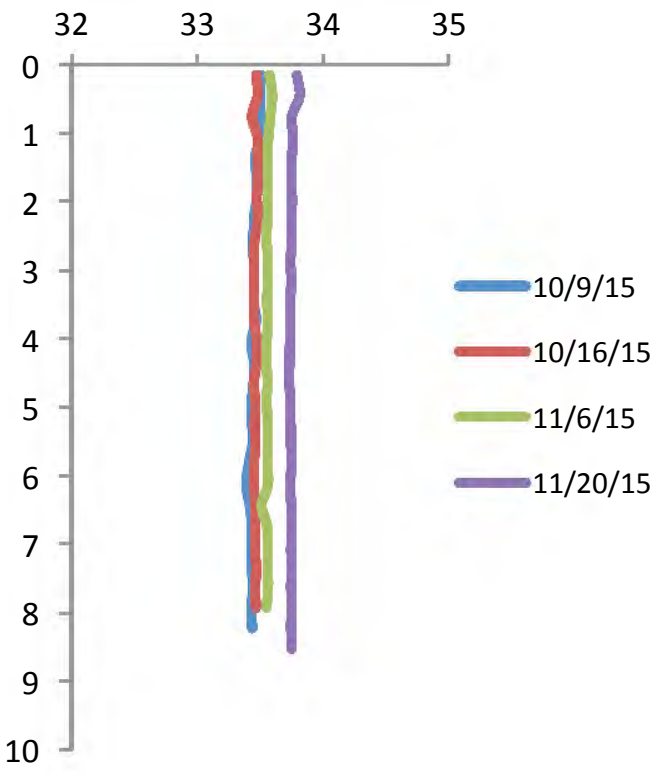

